\section{orml}

OAK RIDGE NATIONAL. LABORATORY
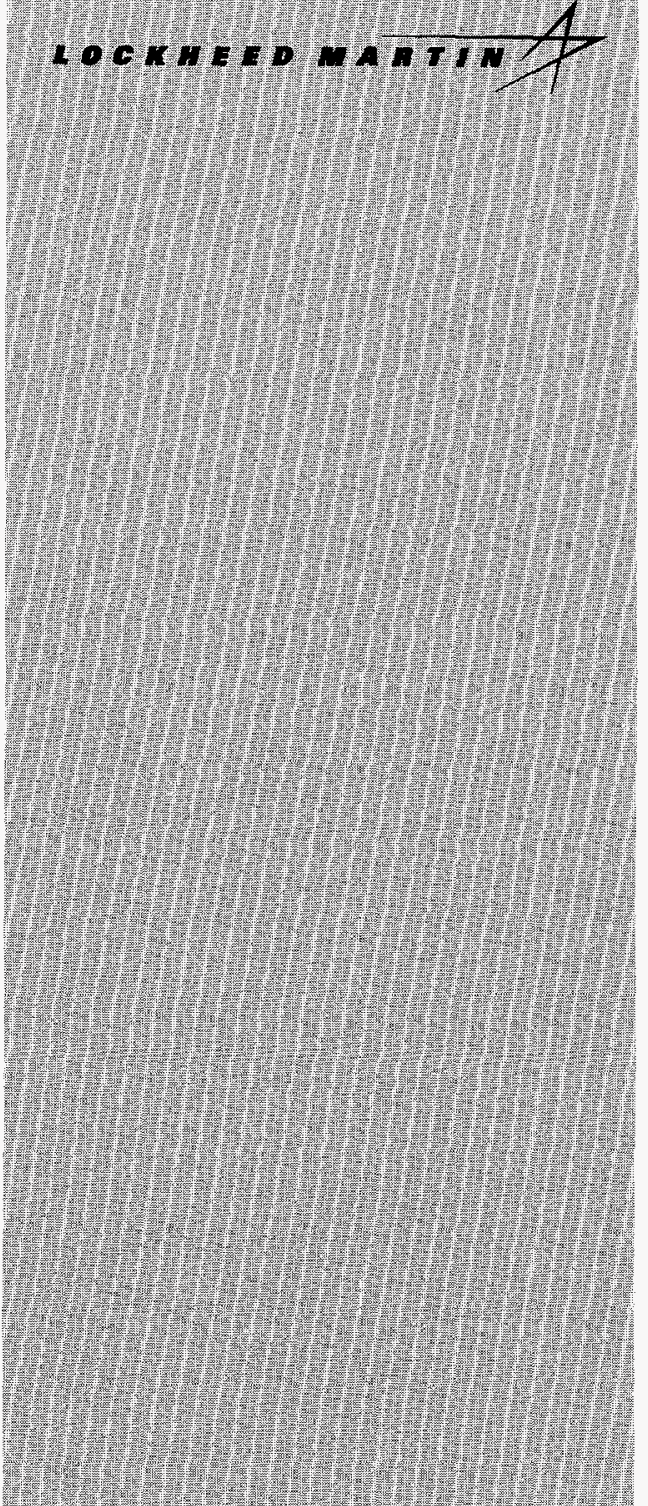

WAMAGEO AND OPERATEO BY LOCKHEED WARMV ENERGY RESEARCH CORPORATION FOR THEUITEO STATES DEPARTNENT OF ENERGY

\section{ORNL/TM-13540, Volume 1}

\section{RECEIVED \\ FFR $\{31998$ \\ 0871}

FEASIBILITY OF DEVELOPING A PORTABLE DRIVER PERFORMANCE DATA ACQUISITION SYSTEM FOR HUMAN FACTORS RESEARCH: TECHNICAL TASKS

Prepared by the

OAK RIDGE NATIONAL LABORATORY

Oak Ridge, Tennessee 37831

managed by

LOCKHEED MARTIN ENERGY RESEARCH CORPORATION for the

DEPARTMENT OF ENERGY

under contract number DE-AC05-960R22464

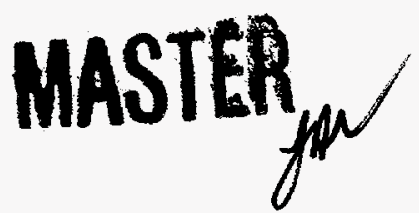

DISTRIBUTION OF THIS DOCUMENT IS INLMMTED 


\section{DISCLAIMER}

This report was prepared as an account of work sponsored by an agency of the United States Government. Neither the United States Government nor any agency thereof, nor any of their employees, makes any warranty, express or implied, or assumes any legal liability or responsibility for the accuracy, completeness, or usefulness of any information, apparatus, product, or process disclosed, or represents that its use would not infringe privately owned rights. Reference herein to any specific commercial product, process, or service by trade name, trademark, manufacturer, or otherwise does not necessarily constitute or imply its endorsement, recommendation, or favoring by the United States Government or any agency thereof. The views and opinions of authors expressed herein do not necessarily state or reflect those of the United States Government or any agency thereof. 


\section{DISCLAIMER}

Portions of this document may be illegible electronic image products. Images are produced from the best available original document. 
ORNL/TM-13540, Volume 1

\title{
FEASIBILITY OF DEVELOPING A PORTABLE DRIVER PERFORMANCE DATA ACQUISITION SYSTEM FOR HUMAN FACTORS RESEARCH: TECHNICAL TASKS
}

\author{
Richard J. Carter, Frank S. Barickman, Philip F. Spelt, \\ Richard L. Schmoyer, and John R. Kirkpatrick \\ Human Systems Research Group \\ Cognitive and Information Sciences Section \\ Computer Science and Mathematics Division
}

Manuscript Completed: March 1997

Date Published: January 1998

Research sponsored by the U.S. Department of Transportation National Highway Traffic Safety Administration Office of Crash Avoidance Research

Heavy Vehicle and Driver Performance Research Division

COTR: Michael J. Goodman under funding document DTNH22-92-X-07453

Prepared by the

OAK RIDGE NATIONAL LABORATORY

Oak Ridge, Tennessee 37831

managed by

LOCKHEED MARTIN ENERGY RESEARCH CORPORATION

for the

DEPARTMENT OF ENERGY

under contract number DE-AC05-960R22464 


\section{TABLE OF CONTENTS}

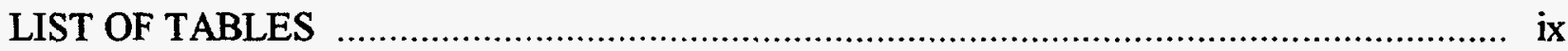

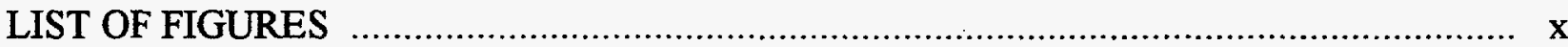

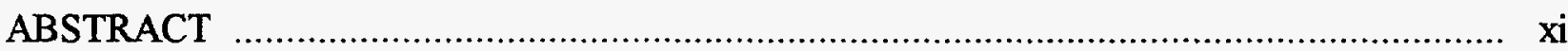

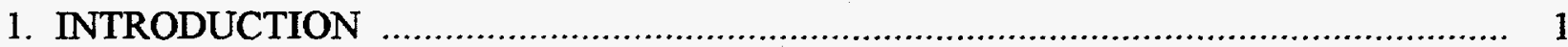

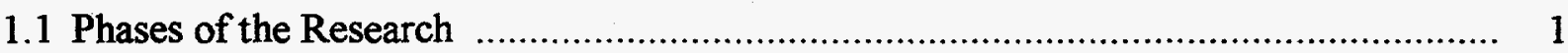

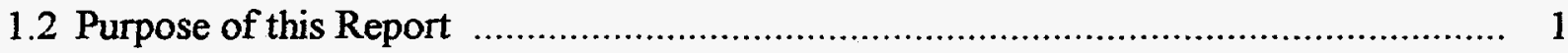

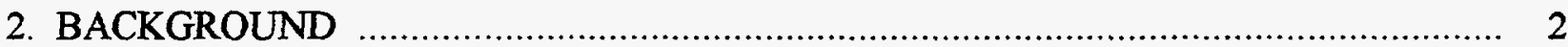

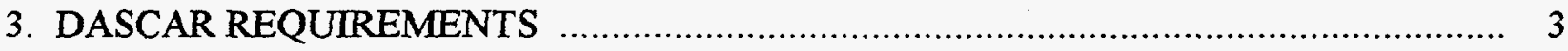

3.1 Parameters and Measures .......................................................................... 3

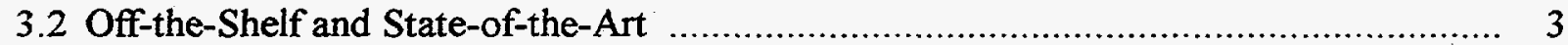

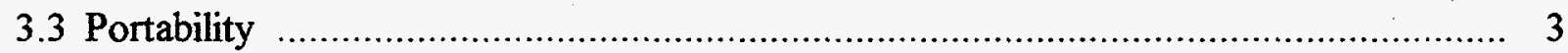

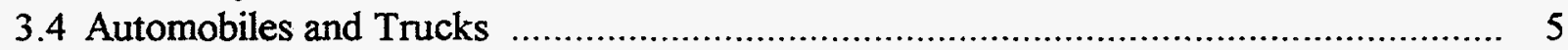

3.5 Unobtrusiveness and Inconspicuousness …………............................................. 5

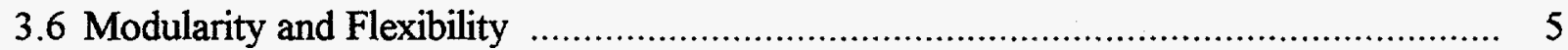

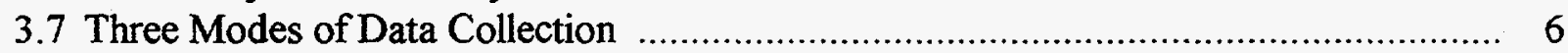

3.8 Extended Periods of Recording Data and Cost ................................................... 6

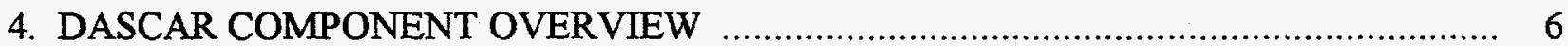

4.1 DAP, Data Storage and Transmission System, Power System, and ESB ................. 6

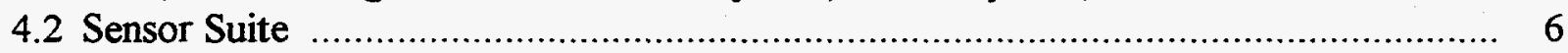

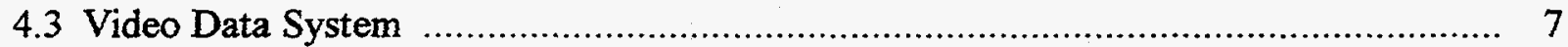

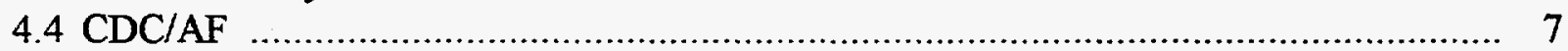

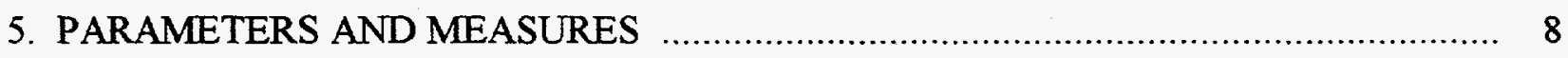

5.1 Identification of Prospective Parameters and Measures …….................................. 8

5.2 Determination of the Sampling Requirements .................................................. 14

5.3 Parameters and Crash Avoidance Research …...................................................... 15

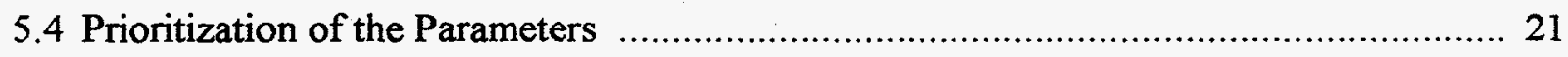

5.5 Definition of a Minimum Set of Parameters ..................................................... 25

6. ANALYSIS TOOLS AND METHODS THAT COULD BE USED TO ASSEMBLE, ANALYZE, AND EVALUATE THE DASCAR DATA ………………………......... 25

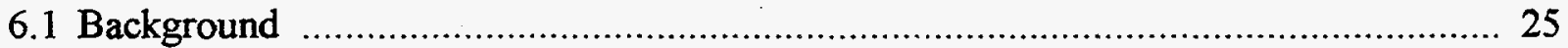

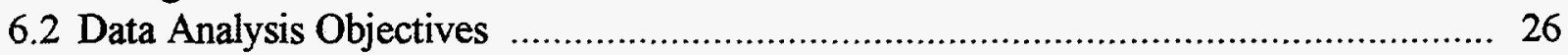

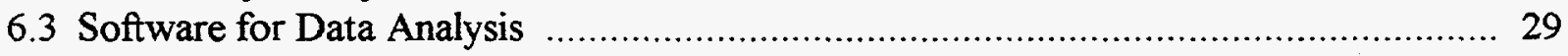


7. MEASUREMENT TECHNIQUES AND HARDWARE TO SUPPORT

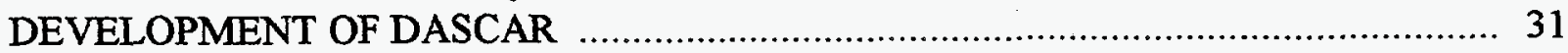

7.1 System Overview ............................................................................................ 31

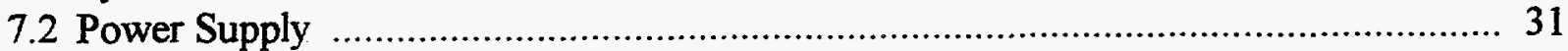

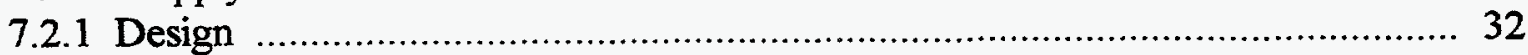

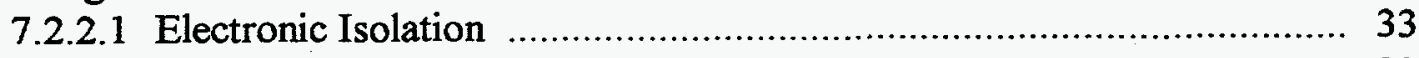

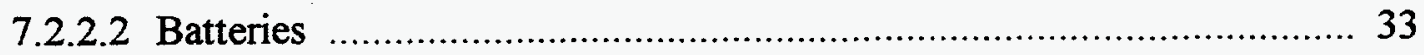

7.2.2.3 Switching Power Supply …………………................................ 33

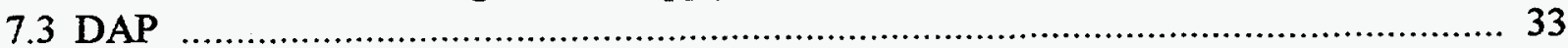

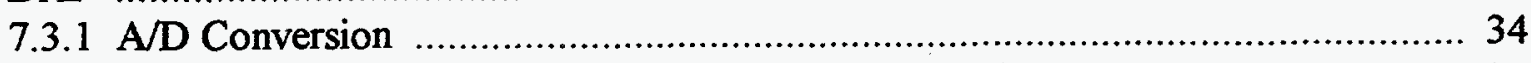

7.3.2 Vendors for the Platform ……….............................................................. 35

7.3.2.1 Dianachart, Incorporated .............................................................. 35

7.3.2.2 OPTIM Electronics ……............................................................ 35

7.3.2.3 Schlumberger Technologies .......................................................... 36

7.3.2.4 Scientific Atlanta, Incorporated …………….................................. 36

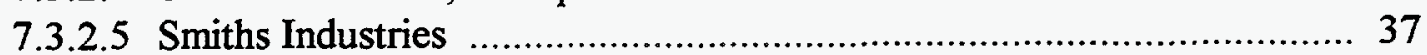

7.4 Data Storage and Communications Link .......................................................... 38

7.4.1 Storage and Communications Requirements ……........................................ 38

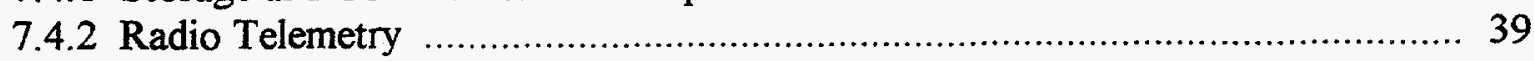

7.4.2.1 Scientific Atlanta ....................................................................... 39

7.4.2.2 Proxim, Incorporated .................................................................... 39

7.4.2.3 Communication Back to the Vehicle .............................................. 40

7.4.3 Satellite Transmission ............................................................................ 40

7.4.3.1 Scientific Atlanta ......................................................................... 40

7.4.3.2 OmniTRACS by QualComm ....................................................... 41

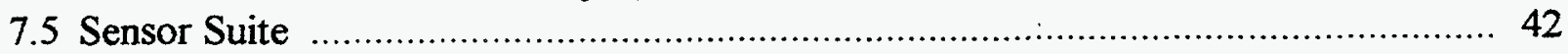

7.5.1 Vehicle Parameters ............................................................................ 42

7.5.1.1 Overall Vehicle Performance .......................................................... 43

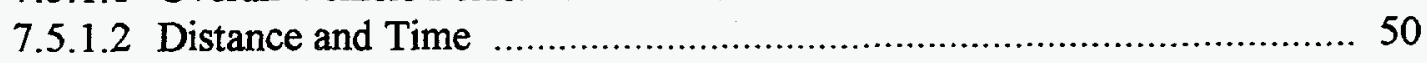

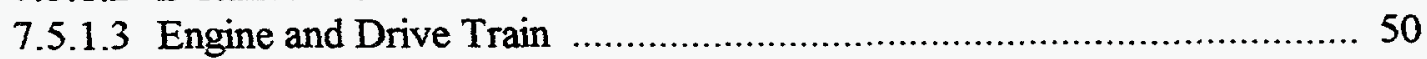

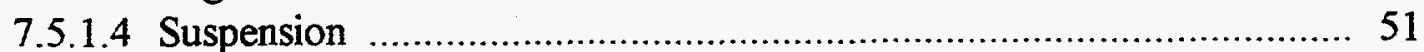

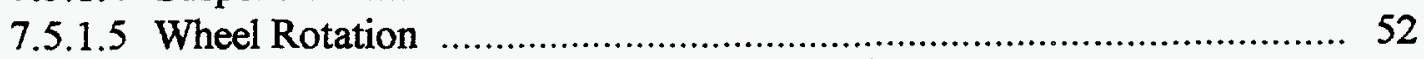

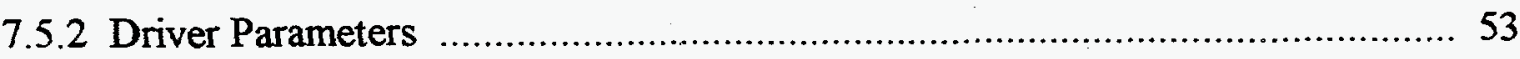

7.5.2.1 Driver Control Actions ............................................................... 53

7.5.2.2 Equipment Status …………....................................................... 54

7.5.2.3 Physiological Measures .............................................................. 55

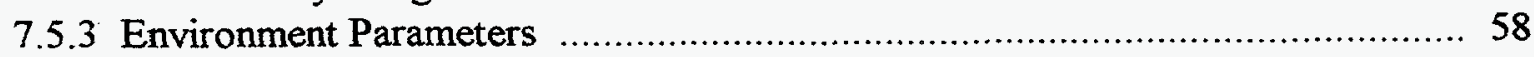

7.5.3.1 Wind Speed and Direction ......................................................... 58

7.5.3.2 Non-Visible Weather Factors .......................................................... 59

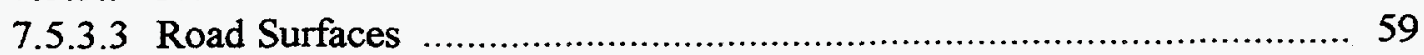

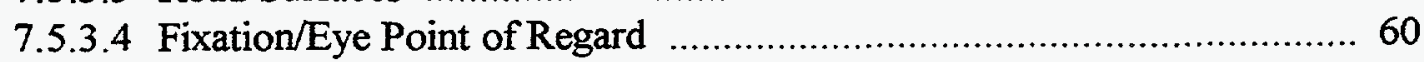

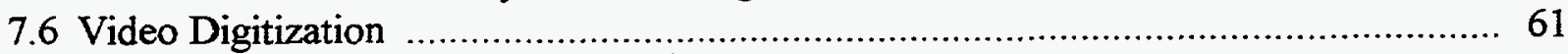

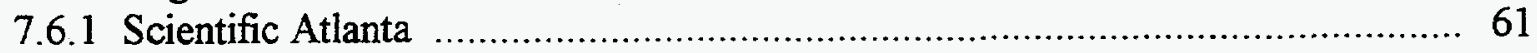




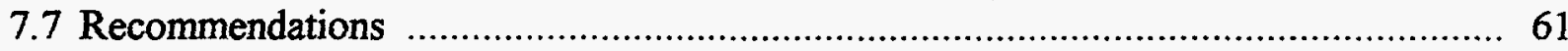

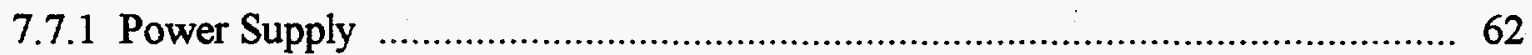

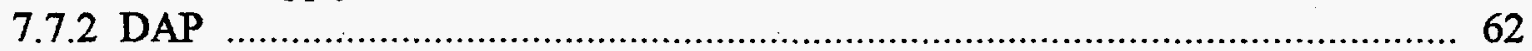

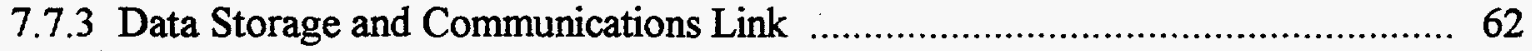

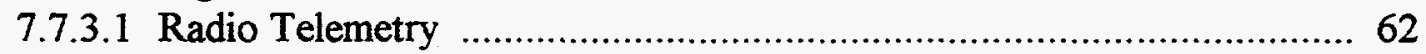

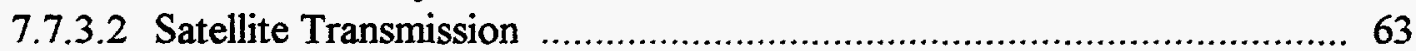

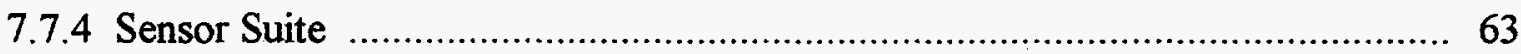

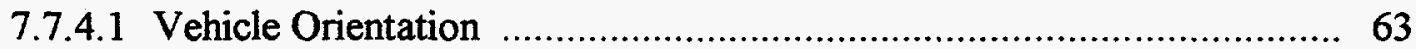

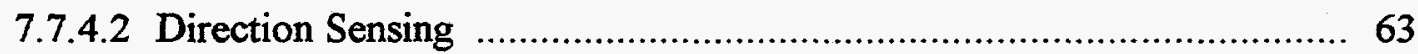

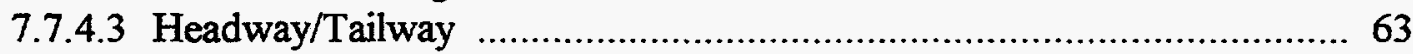

7.7.4.4 Lateral Position Lane Tracking System ........................................... 63

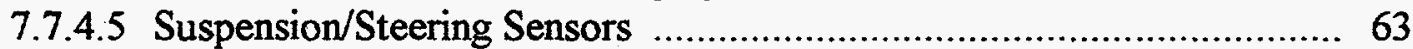

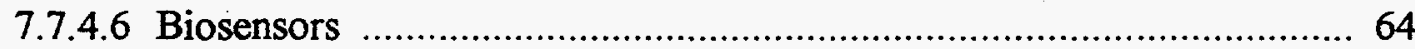

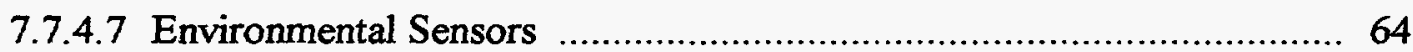

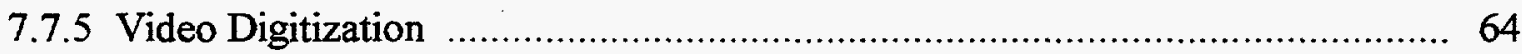

8. DESIGN REQUIREMENTS AND SPECIFICATIONS FOR A PORTABLE DASCAR .. 64

8.1 Alternative Approaches to Meeting the Technical Objectives ……………………..... 64

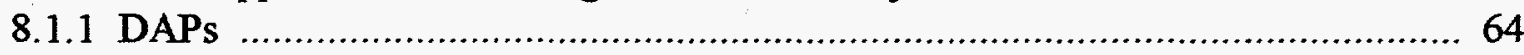

8.1.2 Data Storage and Communications Systems ……......................................... 64

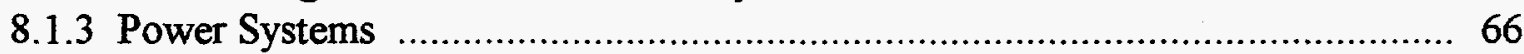

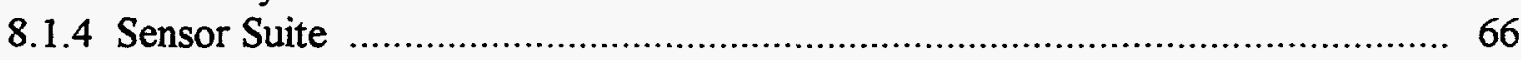

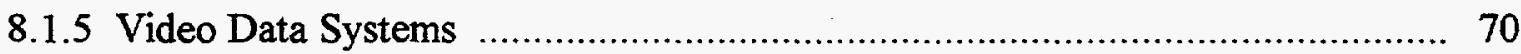

8.2 Design Requirements and Specifications for the Construction of DASCAR ................ 72

9. COST OF ONE OR MORE COPIES OF THE PROPOSED DASCAR ….................... 72

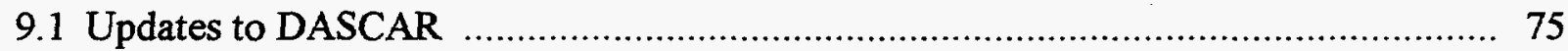

9.2 Hardware and Software Supplied Through CRADA ……................................... 75

9.2.1 DASCAR Prototype ………………….............................................. 75

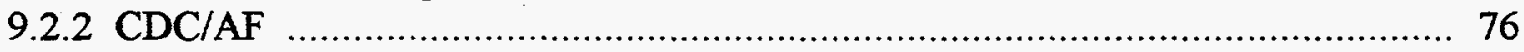

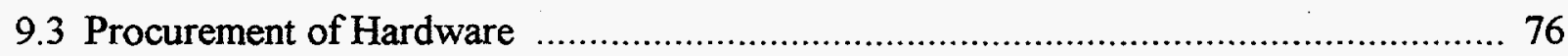

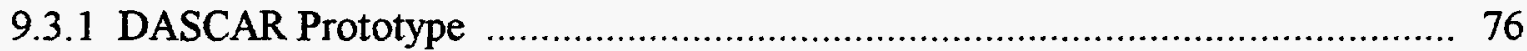

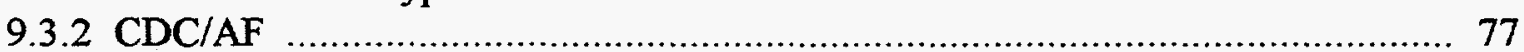

9.4 Development of Hardware for the DASCAR Prototype …….................................... 77

9.5 Prototype Hardware Cost …………......................................................... 77

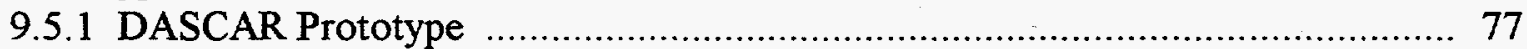

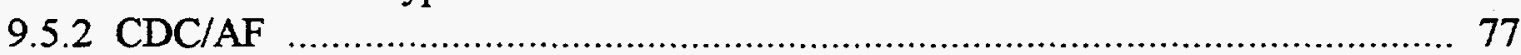

9.5.3 Complete Prototype Hardware Cost ……………...................................... 77

9.6 Procurement of Software for the $\mathrm{CDC} / \mathrm{AF}$.......................................................... 79

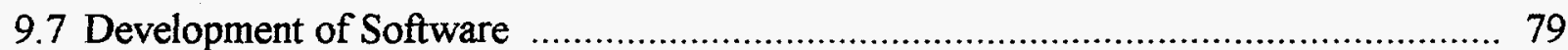

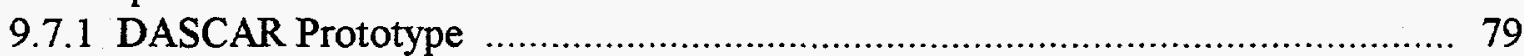

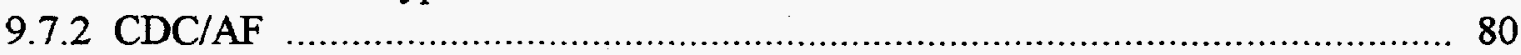

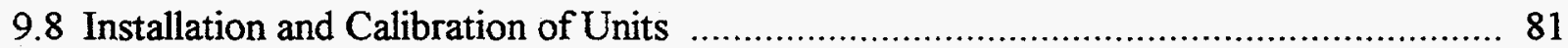




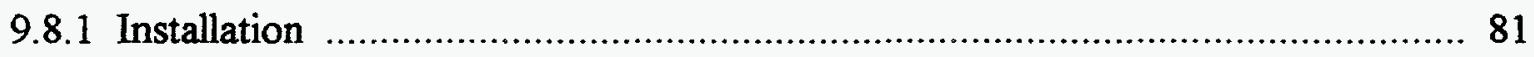

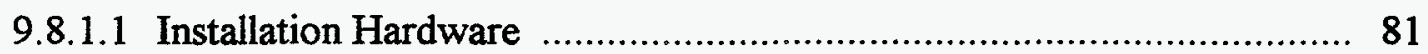

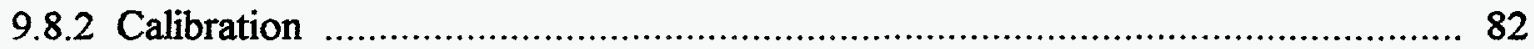

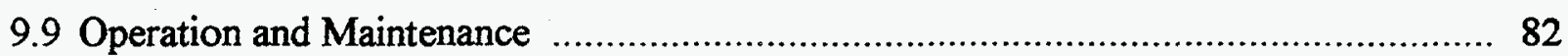

9.9.1 Satellite and Cellular Telephone Transmissions ...................................... 82

9.9.2 General Operation and Maintenance ……….............................................. 85

9.10 Work Breakdown Structure for Phase II ..................................................... 85

9.11 Updated Cost Estimate for the Development and Test of the Data Acquisition

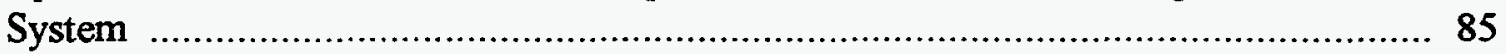

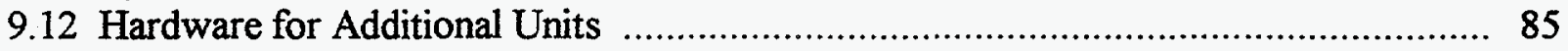

9.13 Hardware and Software for an Additional CDC/AF ……................................. 88

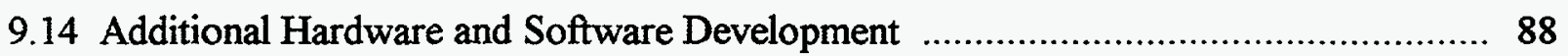

9.14.1 Unobtrusive Physiological Monitoring ................................................... 88

9.14.2 Unobtrusive Visual Scanning ……………........................................... 89

9.14.3 Doppler Range Sensor ………....................................................... 89

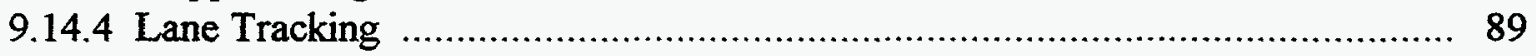

9.14.5 Advanced Communications Technical Satellite ……................................ 89

10. DEVELOPMENT PLAN FOR THE PROTOTYPE DASCAR …........................... 90

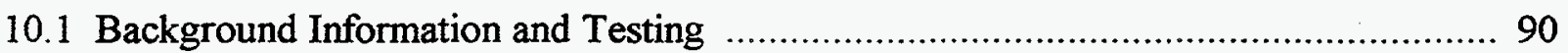

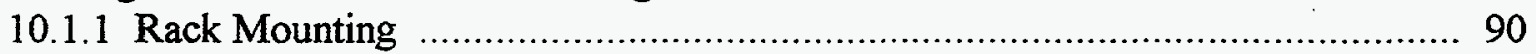

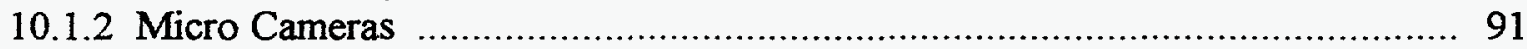

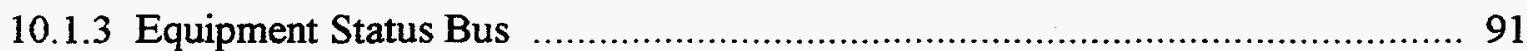

10.2 Acquisition of Hardware and Software for the Prototype DASCAR ………............ 97

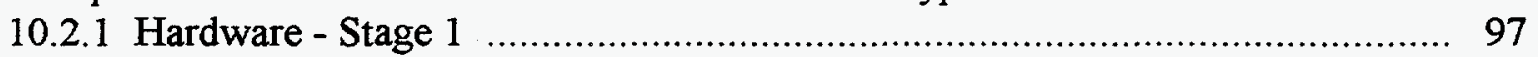

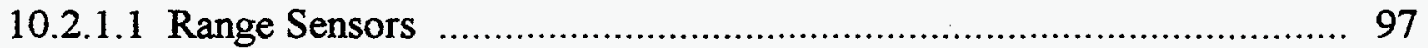

10.2.1.2 Lateral Position Lane Tracking System ...................................... 99

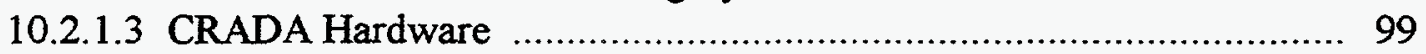

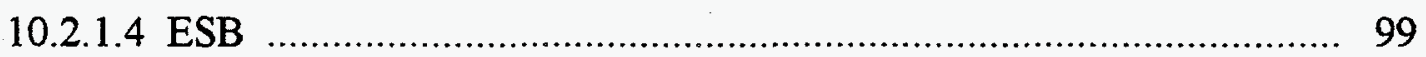

10.2.1.5 Video Data System .................................................................. 99

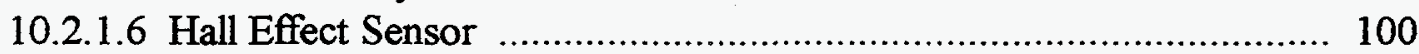

10.2.1.7 Linear Position Transducer ........................................................ 100

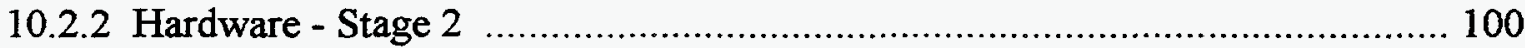

10.2.2.1 Power Supplies and Battery ....................................................... 100

10.2.2.2 Six-DOF Orientation Sensor ................................................... 100

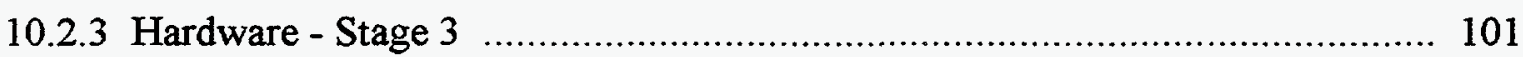

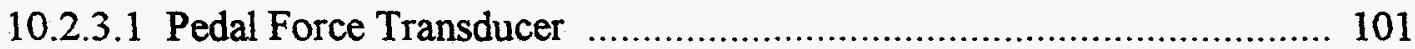

10.2.3.2 Electronic Compass ............................................................... 101

10.2.3.3 Communications Service Plans …............................................... 101

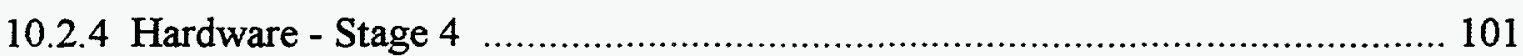

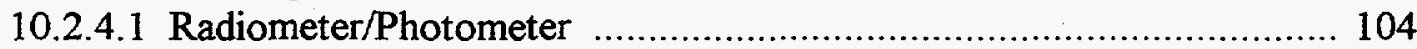

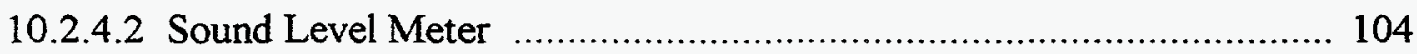

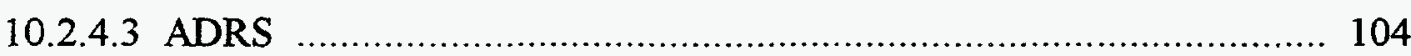




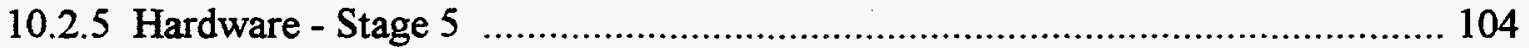

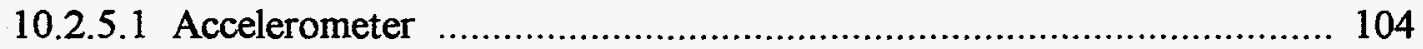

10.2.5.2 Digital Picture Transmission System .............................................. 104

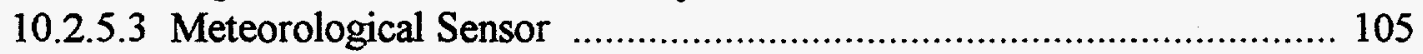

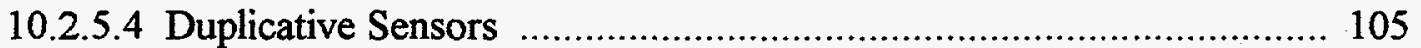

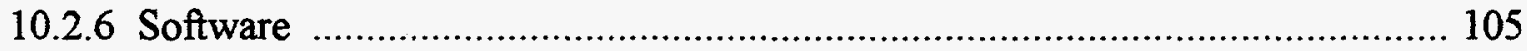

10.3 Acquisition of Hardware and Software for the CDC/AF ..................................... 105

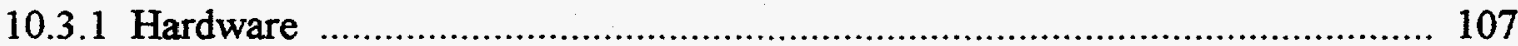

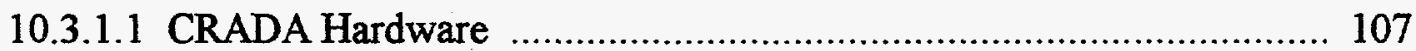

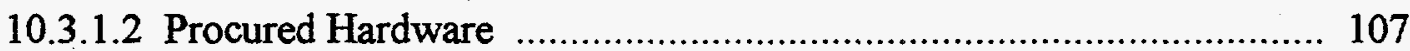

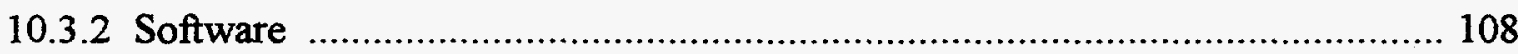

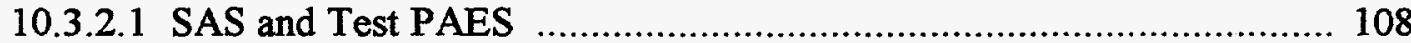

10.3.2.2 Digital Picture Receiver System .................................................. 109

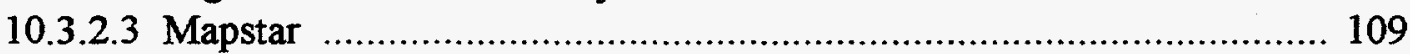

10.3.2.4 ORNL Developed ................................................................... 109

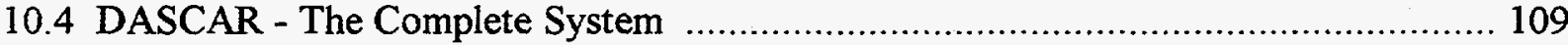

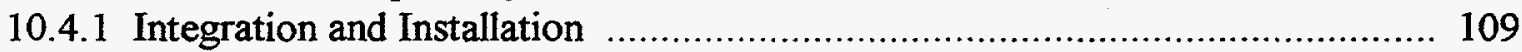

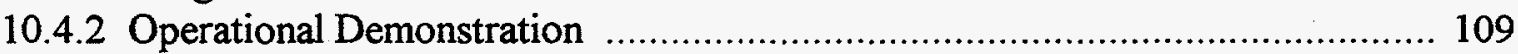

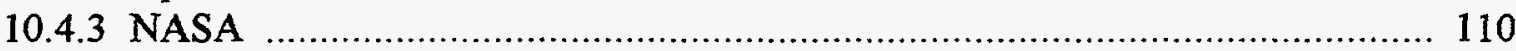

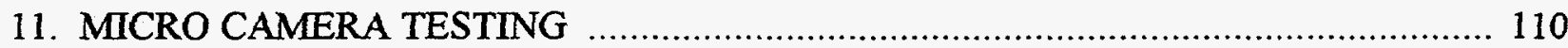

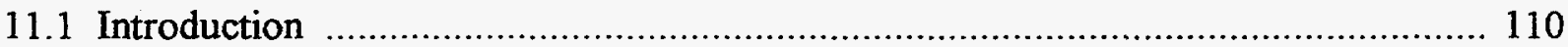

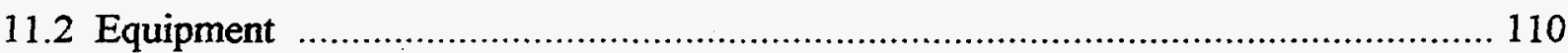

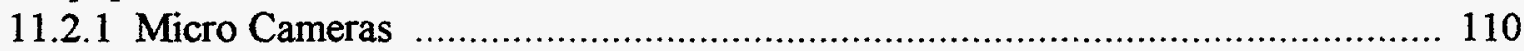

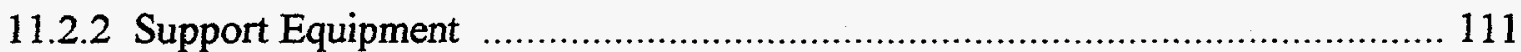

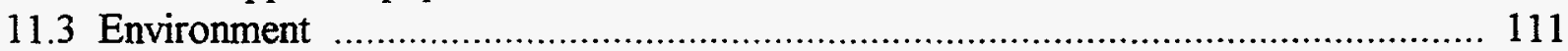

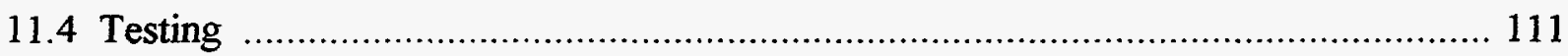

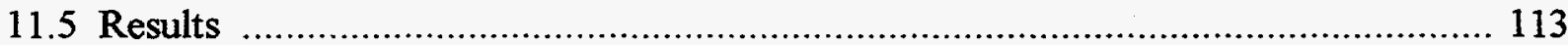

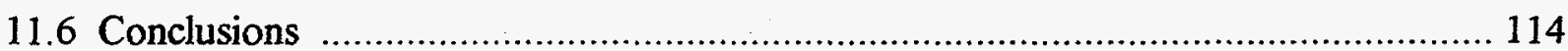

12. HEAT LOAD CALCULATIONS FOR THE INSTRUMENTATION PACKAGE IN

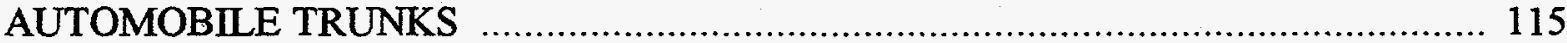

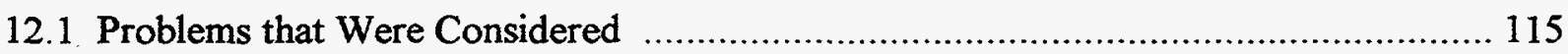

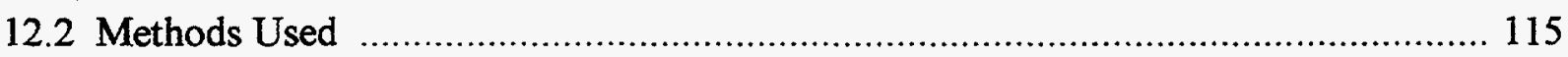

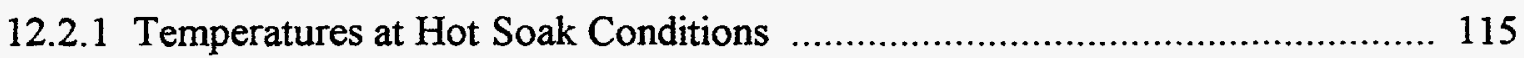

12.2.2 Temperatures with Equipment Running .............................................. 116

12.2.3 Cooling Air Flow Needed to Keep Equipment Below Maximum Operating

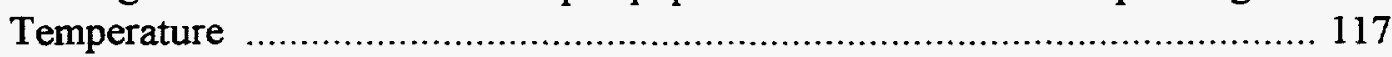

12.2.4 Rate of Rise of Temperature of Equipment Package ................................. 117

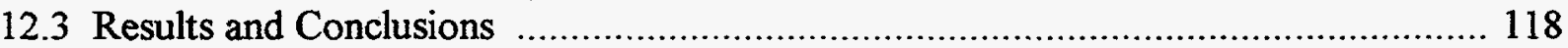

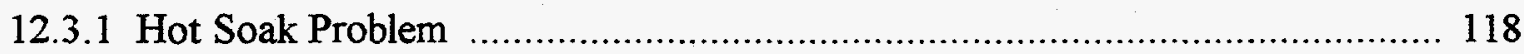

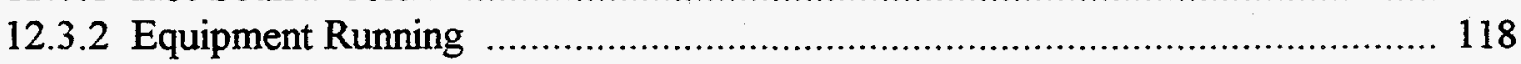

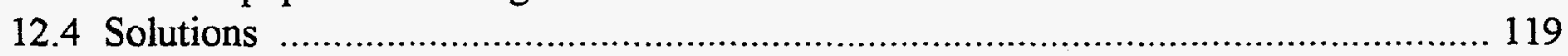




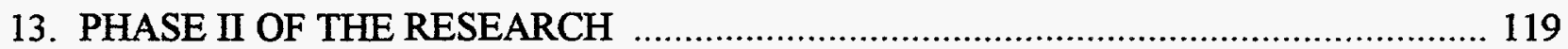

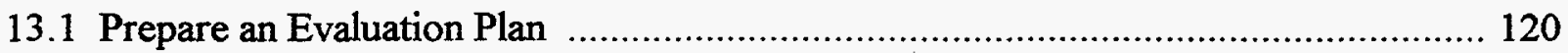

13.1.1 Removal of the System from an Existing Vehicle, and Installation and Calibration in Other Vehicles ................................................................. 120

13.1.2 Reliability of Sensors and Systems .......................................................... 120

13.1.3 Data Collection/Transmission Process ...................................................... 121

13.1.4 Impact on the Driveability of the Vehicle and Obtrusiveness of the System

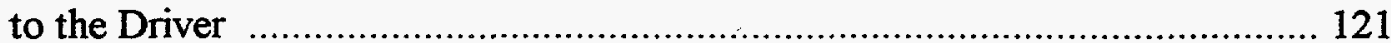

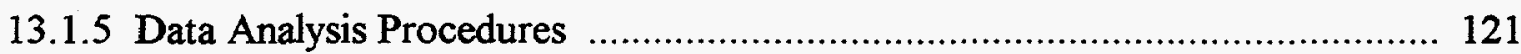

13.1.6 Conspicuousness of the Vehicle to Other Drivers ..................................... 121

13.1.7 DASCAR Installation and Removal Training and Documentation ................... 121

13.2 Conduct the Evaluation, Update the System, and Perform Pilot Research ............... 121

13.3 Demonstrate and Deliver the System, and Train NHTSA Staff ............................ 122

14. DASCAR HARDWARE AND SOFTWARE DELIVERED TO NHTSA ……............ 122

14.1 DAP, Data Storage and Transmission System, Power System, and ESB ……......... 122

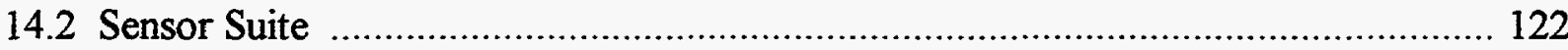

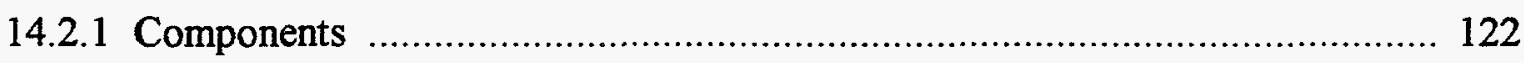

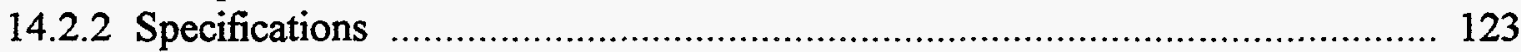

14.2.2.1 Driver Parameters ..................................................................... 123

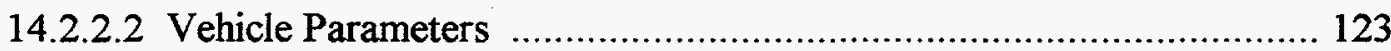

14.2.2.3 Environment Parameters ............................................................ 123

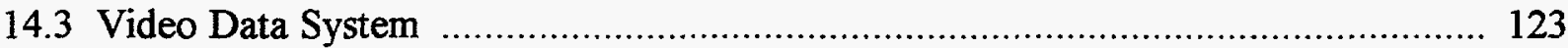

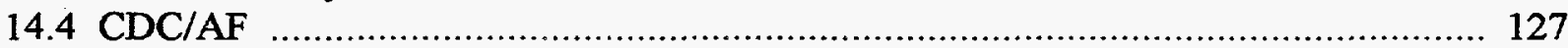

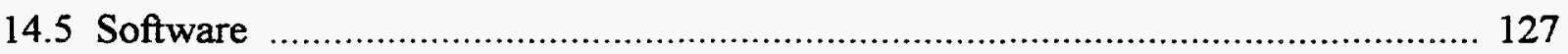

15. CRASH AVOIDANCE PROBLEMS THAT CAN BE ADDRESSED BY DASCAR .... 127

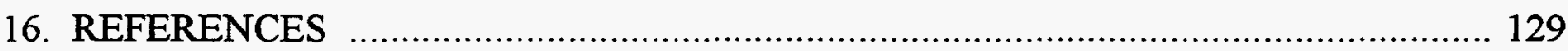

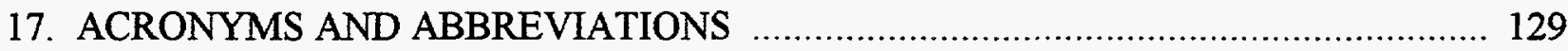




\section{LIST OF TABLES}

Table 1. Parameters Currently Collected by DASCAR …….............................................. 4

Table 2. Parameters, Measures, and Sampling Rates ..................................................... 9

Table 3. Issues, Areas, and Parameters Identified by Consultant \#1 ................................... 16

Table 4. Issues/Problems and Parameters Identified by Consultant \#2 f.............................. 16

Table 5. Problem Areas and Parameters Identified by Consultant \#3 ................................. 18

Table 6. Issues, Areas, and Parameters Identified by ORNL ............................................. 19

Table 7. Priority Rating and Range for Each Parameter .................................................... 22

Table 8. The Minimum Set of Parameters ..................................................................... 25

Table 9. Worst Case Power Consumption ...................................................................... 67

Table 10. Recommended Source for Each Product and Point of Contact and Phone Number of Each Company ...................................................................................... 74

Table 11. DASCAR Prototype Hardware Cost Estimates ………..................................... 78

Table 12. CDC/AF Hardware Cost Estimates ……................................................. 78

Table 13. DASCAR Hardware Total Cost Estimates ........................................................ 79

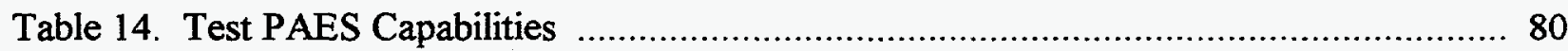

Table 15. Work Breakdown for Software Development ............................................. 81

Table 16. Cost Estimates for Tools, Electrical Components, and Fans ................................ 83

Table 17. Updated Work Breakdown Structure for Phase II .............................................. 86

Table 18. Cost Estimate for Development and Test of DASCAR ….................................. 86

Table 19. Hardware for Additional Vehicle Units …................................................. 87

Table 20. Hardware and Software for an Additional CDC/AF ........................................ 88

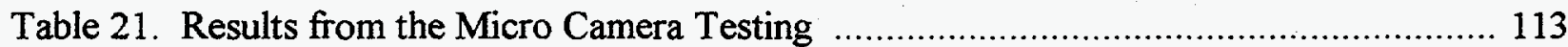

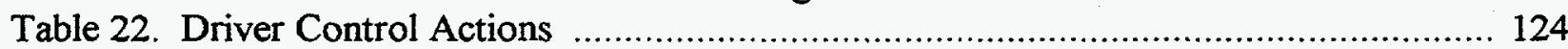

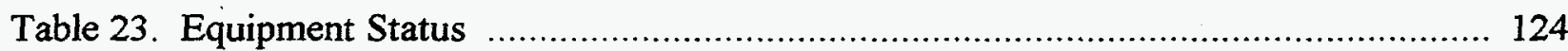

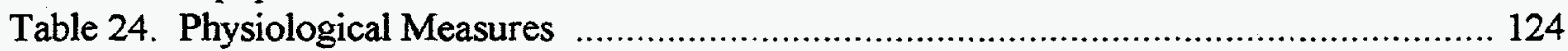

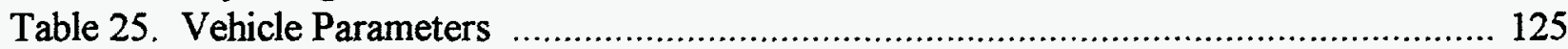

Table 26. Environmental Parameters ....................................................................... 125 


\section{LIST OF FIGURES}

Figure 1. A block diagram of the conceptual design for the proposed modular data acquisition system for the DASCAR project

Figure 2. Power supply for the DASCAR system

Figure 3. An illustration of distributed signal conditioning boards sending digital signals to the DAP

Figure 4. Onboard storage and central (off board) monitoring with Scientific Atlanta components (from Donald Brady)

Figure 5. An illustration of the general layout of components of DASCAR, including sensors and the communications module

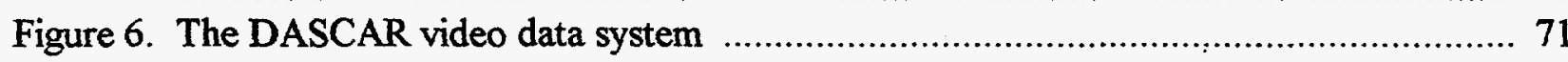

Figure 7. Design and configuration of DASCAR ........................................................ 73

Figure 8. 1994 car models and cargo space (cubic feet) .................................................. 92

Figure 9. A proposed equipment rack in a single enclosure .............................................. 94

Figure 10. An unobtrusive camera placement inside of the rearview mirror ......................... 95

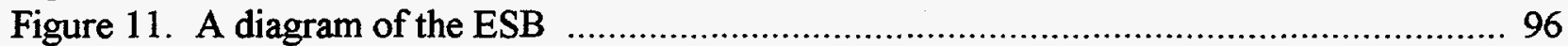

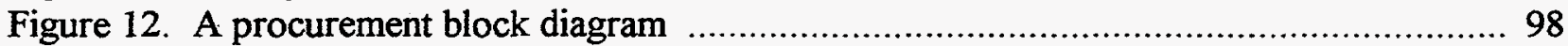

Figure 13. The pedal force transducer mounted on top of the brake pedal and secured by a clamping bracket ................................................................................ 102

Figure 14. The pedal force transducer mounted to the brake pedal without the clamping

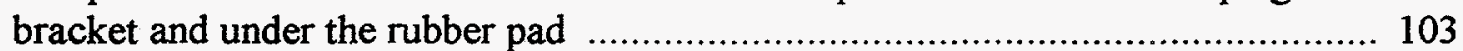

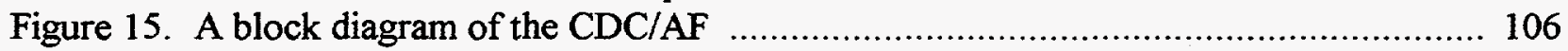

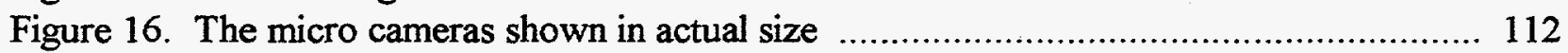

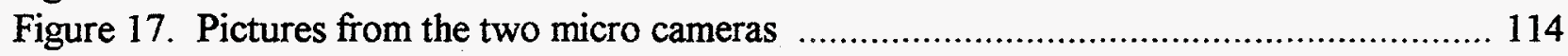

Figure 18. A graphical presentation of the DASCAR video data system ............................ 126

Figure 19. A sample of the Test PAES vehicle data display tools ....................................... 127 


\begin{abstract}
A two-phase, multi-year research program entitled "development of a portable driver performance data acquisition system for human factors research" was recently completed. The primary objective of the project was to develop a portable data acquisition system for crash avoidance research (DASCAR) that will allow driver performance data to be collected using a large variety of vehicle types and that would be capable of being installed on a given vehicle type within a relatively short-time frame. During phase I a feasibility study for designing and fabricating DASCAR was conducted. In phase $I I$ of the research DASCAR was actually developed and validated. This technical memorandum documents the results from the feasibility study. It is subdivided into three volumes. Volume one (this report) addresses the last five items in the phase I research and the first issue in the second phase of the project. Volumes two and three present the related appendices, and the design specifications developed for DASCAR respectively. The six tasks were oriented toward: identifying parameters and measures; identifying analysis tools and methods; identifying measurement techniques and state-of-the art hardware and software; developing design requirements and specifications; determining the cost of one or more copies of the proposed data acquisition system; and designing a development plan and constructing DASCAR. This report also covers: the background to the program; the requirements for the project; micro camera testing; heat load calculations for the DASCAR instrumentation package in automobile trunks; phase II of the research; the DASCAR hardware and software delivered to the National Highway Traffic Safety Administration; and crash avoidance problems that can be addressed by DASCAR. The data acquisition system is a portable, state-of-the art system which can be installed within virtually any passenger vehicle. It is both unobtrusive to the driver and inconspicuous to the outside world. DASCAR is currently capable of collecting and analyzing more than 60 driver-related, vehicular, and environment parameters and measures. DASCAR consists of six-major elements: a data acquisition platform, a data storage and transmission system, a power system, an equipment status bus, a sensor suite, and a video data system. A central data collection/analysis facility was also assembled to manage, support, and analyze data collected by the DASCAR prototype. DASCAR will be employed to collect normative driver performance data, support system performance guideline development, evaluate both conventional and intelligent transportation systems technologies, support simulator validation, and fine tune simulators.
\end{abstract}




\section{INTRODUCTION}

\section{$1.1 \quad$ Phases of the Research}

Oak Ridge National Laboratory (ORNL) recently completed a two phase, multi-year research and development (R\&D) program entitled "development of a portable driver performance data acquisition system for human factors research" for the United States (U.S.) Department of Transportation, National Highway Traffic Safety Administration (NHTSA), Office of Crash Avoidance Research (OCAR). The primary objective of the project was to develop a portable data acquisition system for crash avoidance research (DASCAR) that will allow driver performance data to be collected using a large variety of vehicle models and types and that would be capable of being installed on a given vehicle type within a relatively short-time frame.

During phase I a feasibility study for designing and fabricating DASCAR was conducted. Human factors research needs were evaluated, and existing methods, measures, techniques, hardware, and software for evaluating the driver/vehicle/environment were identified. The tasks consisted of the following:

- Becoming familiar with NHTSA human factors research that would benefit from use of a portable data acquisition system.

- Identifying parameters and measures that could be collected.

- Identifying analysis tools and methods that could be used to assemble, analyze, and evaluate the gathered data in relation to safety issues.

- Identifying measurement techniques and state-of-the-art hardware and software to support development of an in-vehicle data acquisition system.

- Developing design requirements and specifications for a portable driver performance data acquisition system.

- Determining the cost of one or more copies of the proposed data acquisition system.

At the conclusion of phase I, it was determined by NHTSA that the construction of DASCAR was feasible at an acceptable cost. As a result, the second phase of the program was conducted. In phase II of the research, DASCAR was actually developed and validated. The phase consisted of the following steps:

- Designing a development plan and constructing the prototype driver performance data acquisition system.

- Preparing an evaluation plan.

- $\quad$ Conducting the evaluation, updating the system, and performing pilot research.

- Demonstrating and delivering the system, and training NHTSA staff.

\section{$1.2 \quad$ Purpose of this Report}

The primary purpose of this technical memorandum is to document the results from the feasibility 
study. It is subdivided into three volumes. Volume one (this report) addresses the last five items in the phase I research and the first issue in the second phase of the project. It describes and details the results from these six tasks. Volume two presents the related appendices. Volume three displays the design specifications developed for DASCAR.

\section{BACKGROUND}

Given the diverse nature of circumstances leading to motor-vehicle crashes and the associated problem areas and issues, the development of effective collision-avoidance countermeasures can best be realized through a comprehensive knowledge and understanding of both the antecedent events which lead to crashes and the relative contributions of behavioral, vehicular, roadway, and environmental factors. In particular, the development of collision-avoidance countermeasures involving the application of new and innovative technologies represents a promising avenue for using knowledge and understanding to significantly reduce the incidence of crashes.

The evolution of effective advanced-technological countermeasures, however, goes hand-in-hand with the availability of a research tool to investigate the causes of crashes and the influence of vehicle-design characteristics on the relationships among the driver, the vehicle, the roadway, and the environment. This is particularly important where advanced-technology applications may themselves increase the potential for crashes or their severity under a given set of conditions.

The availability of this research tool is vital to fully understand and document the safety benefits and potential liabilities associated with a wide range of countermeasures and technological advancements, and to define the requirements associated with their design and implementation. Such a capability must allow for a flexible, comprehensive, and valid appraisal of countermeasures and advanced-technology applications.

In this regard, recent technological innovations and developments in computers, computer graphics, computational speed and power, miniaturization, communications, and data acquisition and analysis have provided the opportunity to develop DASCAR, a system for addressing the wide range of issues associated with existing problem areas as well as those involving the development and implementation of new advanced-technological systems within the motor vehicle-highway environment. These advances have also greatly enhanced the ability to develop the sophisticated tool needed to carry out a systematic and controlled evaluation of new technologies under operational or high-fidelity conditions.

NHTSA envisions many future situations in which the effectiveness and consequences of new intelligent-transportation systems (ITS) technologies will need to be studied in actual production vehicles. Such studies will enable evaluations in vehicles which are familiar to drivers. These studies would be further enhanced by the availability of a DASCAR that can be easily installed in these vehicles to enable specific vehicle configurations of interest (e.g., pedal placement, head-up displays) to be evaluated, thereby increasing the variety of vehicle options (incorporating 
advanced technology) that are available for study. Ideally, an approach is needed that would allow data collection from a variety of vehicle models and types, and would address the issue of driver familiarity.

Such an approach is embodied in the concept of a DASCAR that can be installed in a wide range of vehicles within a relatively short period of time. As a universally adaptable system, it provides researchers with the ability to record information on driver, vehicle, roadway, and environmental parameters. Furthermore, it enables the measurement of driver performance in the driver's own vehicle, thereby ensuring vehicle familiarity. It is also possible to measure driver performance in relation to any vehicle design characteristic at relatively little expense and effort, and makes it easy to update existing models of driver/vehicle behavior to reflect performance characteristics in vehicles of current manufacture. The availability of such information can lead to improved problem identification in crash-avoidance research, as well as provide NHTSA with the capability to readily answer questions related to vehicle-design characteristics not otherwise available. In addition, such a system has the potential to measure driver performance as it relates to the location of surrounding vehicles. This will allow the study of how drivers interact with other vehicles in their immediate vicinity.

\section{DASCAR REQUIREMENTS}

The development effort for DASCAR was driven by a number of requirements which are briefly described below.

\subsection{Parameters and Measures}

The data acquisition system is capable of collecting and analyzing driver-related, vehicular, and environment parameters and measures. Driver-related variables consist of driver control actions, equipment status, and physiological measures. Parameters that are currently recorded by DASCAR are exhibited in Table 1. A few of the environment parameters are sensor derived; most of them are however video derived. The data acquisition system can collect other variables if a researcher so desires. All that would have to be done would be to add additional sensors.

\subsection{Off-the-Shelf and State-of-the-Art}

DASCAR consists of both off-the-shelf hardware and software, and state-of-the-art technology. ORNL procured most of the system required equipment. The hardware was subsequently modified as appropriate for DASCAR application. A portion of the hardware and some of the software had to be designed and developed from scratch.

\section{$3.3 \quad$ Portability}

The data acquisition system is portable. It can be installed in a particular vehicle quickly and can 
Table 1. Parameters Currently Collected by DASCAR

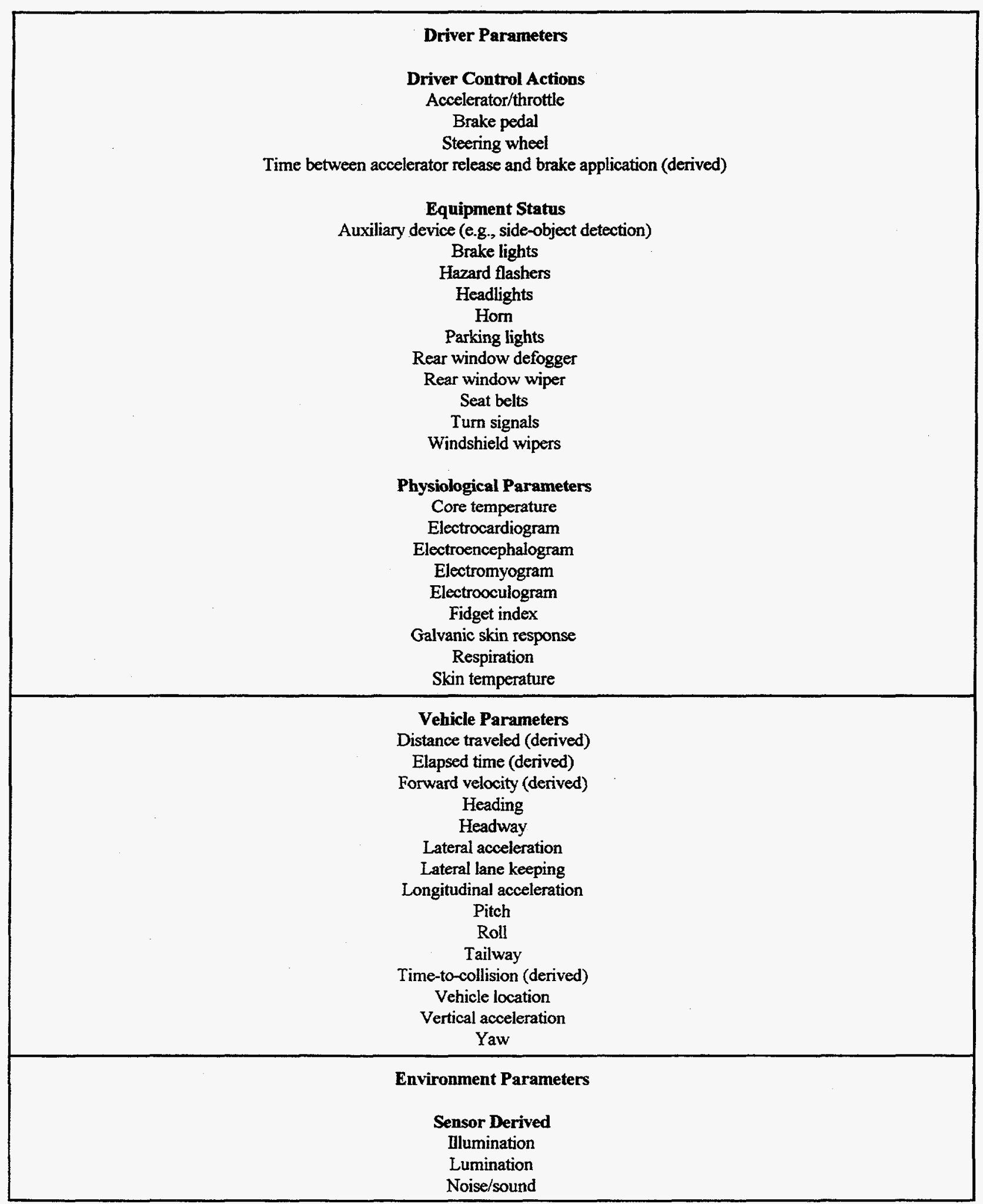


Time of day

Video Derived

Car lights

Distracting lights, obstacles, and signs

Exits

Hand positions

Haze/dust

Head movements

Intersections

Lane vehicle is in

One- or two-way traffic

Parked vehicles

Pedestrians

Posted speed limits

Precipitation

Road lighting

Road surfaces

Road types

Roadway delineation

Surrounding field of view

Traffic conditions

Traffic events

Traffic lights

Turns/hills

rapidly be removed and placed within another vehicle. It takes between one and two weeks to install the complete DASCAR within a new automobile or truck, depending on the vehicle type and configuration.

\subsection{Automobiles and Trucks}

DASCAR was designed so that it can be positioned within virtually any passenger vehicle. It can be installed within a wide range of vehicle models and types (compact, intermediate, and large automobiles, minivans, and small, mid-size, and large trucks) built by the three U.S. domestic vendors (General Motors (GM), Ford, and Chrysler).

\subsection{Unobtrusiveness and Inconspicuousness}

The data acquisition system is both unobtrusive to the driver and inconspicuous to the outside world. Placement of hardware within a vehicle does not obstruct the driver's primary task of driving. Instrumentation, cables, and wires connecting different pieces of the system are hidden, well out of the view of the driver. Antennas, sensors, and cameras are situated on the exterior of the vehicle so that they cannot be seen by other drivers. As far as possible, the vehicle looks and drives like any other vehicle on the road.

\subsection{Modularity and Flexibility}

DASCAR was modularly designed; that is to say, the system permits installation of only those 
data collection capabilities required for a particular study. An individual does not have to instrument the vehicle with the entire system in order to collect or record a subset of parameters. The data acquisition system was designed so that it has the flexibility to accommodate new data acquisition and sensor technologies as the state-of-the-art changes.

\subsection{Three Modes of Data Collection}

DASCAR has three modes of data collection. The first consists of recording parameter data onboard the vehicle via a laptop computer. This mode provides a backup capability in the case of radio-link failure or signal corruption during data transmission. The second mode comprises radio telemetry. The radio telemetry link is used to transmit data from the vehicle to a base station during use at a test track. The third includes cellular telephone equipment. This technology is employed to transmit data from a vehicle in an open-road situation, anywhere in the U.S. which supports cellular phone communications, to a base station that may be located a few, to many hundreds of, kilometers away.

\subsection{Extended Periods of Recording Data and Cost}

DASCAR collects parameter data over two extremes of time - from as little as 20 minutes to as much as six months. The data acquisition system was designed with cost as a main consideration. Technical capabilities - cost tradeoff analyses were performed for each part of DASCAR.

\section{DASCAR COMPONENT OVERVIEW}

The DASCAR which was delivered to NHTSA consists of seven major elements: a data acquisition platform (DAP), a data storage and transmission system, a power system, an equipment-status bus (ESB), a sensor suite, a video data system, and a central data collection/analysis facility (CDC/AF).

\subsection{DAP, Data Storage and Transmission System, Power System, and ESB}

The DAP contains data acquisition boards. The data storage and transmission system is composed of several components: cellular telephone equipment, radio telemetry, a laptop computer, a docking station, and a small computer system interface (SCSI)-two hard drive. The DAP and the data storage and transmission system capture, process, and transmit signals from the various sensors installed within and around the vehicle. The power system includes three items, a sealed lead-acid storage battery, switching-precision power supplies, and a dual-battery isolator. The ESB was designed to monitor the use of the driver equipment-status parameters.

\section{$4.2 \quad$ Sensor Suite}

The DASCAR sensor suite comprises transducers, systems, devices, sensors, and meters that 
gather parameter data from the driver, vehicle, and environment. The sensor suite includes: a linear position transducer, pedal force transducers, an ambulatory data recording system (ADRS), an accelerometer, a six degrees-of-freedom (DOF) orientation sensor, Hall-effect sensors, an electronic compass, range sensors, a global positioning system (GPS) receiver, a lateral-position lane tracking system, radiometers/photometers, and a sound level meter.

The linear position transducer is employed to collect steering wheel data from the vehicle. The pedal force transducers are utilized to record brake pedal application force. The ADRS is used to collect core temperature, electrocardiogram, electroencephalogram, electromyogram, electrooculogram, galvanic skin response, respiration, and skin temperature from the driver. The accelerometer is employed to record fidget index (i.e., the driver moving in his/her seat). The six DOF orientation sensor is utilized to collect acceleration (lateral, longitudinal, and vertical), pitch, roll, and yaw data from the vehicle. The Hall-effect sensors are used to record distance traveled and velocity data. The electronic compass is employed to collect heading data from the vehicle. The range sensors are utilized to record headway, tailway, target velocity, and headway time data from the vehicle. The GPS receiver is used to collect vehicle location and route traveled. The lateral-position lane tracking system is employed to measure lateral lane keeping behavior of the driver. The radiometers/photometers are utilized to record illumination and lumination data from the environment outside the vehicle. The sound level meter is employed to collect steady state and impulse noise and sound as heard by the driver inside the vehicle.

\subsection{Video Data System}

The DASCAR video data system comprises both black-and-white and color video micro cameras, a vertical interval time code (VITC) generator, a digital quad picture processor, a super-VHS recorder, a compressed video digital storage and retrieval system (CVDSRS) encoder, and a digital picture transmission system. The micro cameras are utilized to record video data inside the vehicle (hand positions and head movements of the driver) and in the outside environment (forward and aft). The VITC generator is used to time code the video output from the micro cameras and to provide video data synchronization with the collected sensor data. The digital quad picture processor is employed to multiplex four video images into one full screen picture. The super-VHS recorder is utilized to store video from the quad picture processor. The CVDSRS encoder is used record digital video, instead of analog, on VHS tape. The digital picture transmission system is employed to send high quality color pictures to the CDC/AF from the vehicle in near real time (approximately one frame every two seconds) over cellular telephone.

\section{$4.4 \quad \underline{\mathrm{CDC} / \mathrm{AF}}$}

The CDC/AF consists of components that manage, support, and analyze the parameter data recorded by DASCAR. Hardware support systems include: a digital quad picture processor, a super-VHS recorder, a super-VHS monitor, a CVDSRS decoder, radio telemetry hardware, and a digital picture receiver system. Analysis of the acquired parameter data is facilitated by a personal computer (PC) platform and special supporting software. The software consists of: the 
Statistical Analysis System (SAS), and the Test Planning, Analysis, and Evaluation System (PAES). Collection of the DASCAR sensor data at the CDC/AF is handled via removable SCSI hard drive. Video data is transferred via analog tape(s). The CDC/AF also contains data storage devices compatible with the DASCAR devices. They are utilized for archiving information and directly downloading parameter data from DASCAR

\section{PARAMETERS AND MEASURES}

The "identify parameters and measures that could be collected" task had five objectives. They include: to identify appropriate parameters and measures that could be incorporated into DASCAR; to determine the sampling requirements for each parameter and/or measure; to map the parameters to specific issues and problem areas of crash-avoidance research; to prioritize the parameters with regard to their incorporation within the data acquisition system; and to define a minimum set of parameters that would be necessary in DASCAR.

\subsection{Identification of Prospective Parameters and Measures}

For this project, parameters were defined as the generic, dependent, and concomitant variables that can be used in field studies involving instrumented vehicles and that serve to improve our understanding of driver behavior and/or performance. Measures specify the data that can be collected and used to infer the state of a parameter. In simpler terms, a parameter represents the function or the "what" to be recorded (e.g., acceleration, steering, and braking). A measure is defined as the "how"; for example, meters/second and number of speed changes (for speed) and pedal position and system line pressure (for braking).

ORNL derived the parameters and measures that could be collected via a review of relevant human-performance research and previous NHTSA data acquisition efforts and programs. Appendix A lists the documentation which was reviewed. The parameter and measure identification process also consisted of discussions with the NHTSA staff and input from three highway-safety consultants who served as an advisory panel and in a review capacity throughout the DASCAR system development, construction, and evaluation. There was no consensus among the consultants; each identified a different subset of parameters and measures (see section 5.3). Parameters and measures derived by the NHTSA staff and the highway-safety consultants were folded into the final set of parameters and measures. No field or laboratory research was carried out as part of the effort.

The parameters which were identified are shown in Table 2. They are subdivided into three categories: driver-related variables, vehicle parameters, and environment considerations. The driver factors are further partitioned into driver control actions, equipment status, and physiological parameters. The derived measure(s) for each parameter is exhibited next to the parameter. Definitions of a number of the parameters and measures are provided in Appendix B. 
Also presented in Table 2 is the sampling rate for each parameter and/or measure (see section 5.2). $\mathrm{Hz}$ is the symbol for hertz.

Table 2. Parameters, Measures, and Sampling Rates

\begin{tabular}{|c|c|c|}
\hline Parameters & Measures & - Sampling Rates \\
\hline \multicolumn{3}{|l|}{ Driver Parameters } \\
\hline \multicolumn{3}{|l|}{ Driver Control Actions } \\
\hline Accelerator/throttle & $\begin{array}{l}\text { - Control (centimeters) } \\
\text { - Number of reversals of direction } \\
\text { o Pedal position/displacement/travel } \\
\text { (centimeters; percentage of full travel) }\end{array}$ & $\begin{array}{ll}0 & 20 \mathrm{~Hz} \\
0 & 20 \mathrm{~Hz} \\
0 & 20 \mathrm{~Hz}\end{array}$ \\
\hline Brake pedal & $\begin{array}{l}\text { - Duration (seconds) } \\
\text { o Number of reversals of direction } \\
\text { - Pedal position/displacement/travel } \\
\text { (centimeters; percentage of full travel) } \\
\text { - System line pressure } \\
\text { (kilograms/centimeter squared) } \\
\text { - System line pressure modulation }\end{array}$ & $\begin{array}{l}\text { ० } 20 \mathrm{~Hz} \\
\text { o } 20 \mathrm{~Hz} \\
\text { ० } 20 \mathrm{~Hz} \\
\text { ० } 20 \mathrm{~Hz} \\
\text { o } 2 \mathrm{~Hz}\end{array}$ \\
\hline Steering (road following) & $\begin{array}{l}\text { - Control (meters) } \\
\text { - Disturbance }\end{array}$ & $\begin{array}{l}\text { o } 2 \mathrm{~Hz} \\
\text { o } 2 \mathrm{~Hz}\end{array}$ \\
\hline $\begin{array}{l}\text { Steering wheel } \\
\text { - Course steering/lane changing } \\
\text { Fine steering }\end{array}$ & $\begin{array}{l}\text { - Angle (degrees) } \\
\text { - Deflection/variance from a } \\
\text { predetermined position (degrees) } \\
\text { - Position/displacement (revolutions) } \\
\text { - Rate/velocity (revolutions/second; } \\
\text { degrees/second) } \\
\text { - Torque (kilograms/meter) } \\
\text { - Number of reversals } \\
\text { - Number of reversals }\end{array}$ & $\begin{array}{l}\text { 0 } 20 \mathrm{~Hz} \\
\text { o } 20 \mathrm{~Hz} \\
\text { o } 20 \mathrm{~Hz} \\
\text { - } 20 \mathrm{~Hz} \\
\text { - } 20 \mathrm{~Hz} \\
\text { o } 20 \mathrm{~Hz} \\
\text { 0 } 20 \mathrm{~Hz}\end{array}$ \\
\hline $\begin{array}{l}\text { Time between accelerator release and } \\
\text { brake application }\end{array}$ & - Seconds & ○ $20 \mathrm{~Hz}$ \\
\hline \multicolumn{3}{|l|}{ Equipment Status } \\
\hline Air vents & - Open/closed & $\circ 1 \mathrm{~Hz}$ \\
\hline Ash tray & $\begin{array}{l}\text { O Open/closed } \\
\text { Osed/not used }\end{array}$ & $\begin{array}{l}01 \mathrm{~Hz} \\
02 \mathrm{~Hz}\end{array}$ \\
\hline Auxiliary device & ○ On/off & - $1 \mathrm{~Hz}$ \\
\hline Brake lights & o On/off & . $2 \mathrm{~Hz}$ \\
\hline Cellular telephone & O On/off & $01 \mathrm{~Hz}$ \\
\hline Cigarette lighter & On/off & $01 \mathrm{~Hz}$ \\
\hline Clutch pedal & - In/out & $02 \mathrm{~Hz}$ \\
\hline
\end{tabular}




\begin{tabular}{|c|c|c|}
\hline Cruise control & - On/off & o $2 \mathrm{~Hz}$ \\
\hline Driver in & o Seat pressure & - $1 \mathrm{~Hz}$ \\
\hline Emergency brake & o On/off & $01 \mathrm{~Hz}$ \\
\hline Engine & o On/off & $\circ 1 \mathrm{~Hz}$ \\
\hline Hazard flashers & o On/off & - $2 \mathrm{~Hz}$ \\
\hline Headlight dimmer switch & . On/off & $02 \mathrm{~Hz}$ \\
\hline Headlights & $\circ$ On/off & - $1 \mathrm{~Hz}$ \\
\hline Heater/air conditioner & ○ On/off & - $1 \mathrm{~Hz}$ \\
\hline Horn & - On'off & o $2 \mathrm{~Hz}$ \\
\hline Parking lights & o On/off & o $1 \mathrm{~Hz}$ \\
\hline Radio/tape player/compact disk player & $\begin{array}{l}\text { - On/off } \\
\text { o Station change }\end{array}$ & $\begin{array}{l}\text { o } 1 \mathrm{~Hz} \\
\text { o } 2 \mathrm{~Hz}\end{array}$ \\
\hline Rearview mirror & o Adjustments & o $1 \mathrm{~Hz}$ \\
\hline Rear window defogger & o On/off & o $1 \mathrm{~Hz}$ \\
\hline Rear window wiper & - On/off & o $1 \mathrm{~Hz}$ \\
\hline Seat belts & - Latched/unlatched & o $1 \mathrm{~Hz}$ \\
\hline Turn signals & o On/off & o $2 \mathrm{~Hz}$ \\
\hline Transmission selector & o Control position & $02 \mathrm{~Hz}$ \\
\hline Windows & - Open/closed & $01 \mathrm{~Hz}$ \\
\hline Windshield washer & 0 On/off & $02 \mathrm{~Hz}$ \\
\hline Windshield wipers & $\circ$ On/off & $\circ 2 \mathrm{~Hz}$ \\
\hline \multicolumn{3}{|l|}{ Physiological Parameters } \\
\hline Acceleration at the driver's head & - Meters/second squared; gravity & - $20 \mathrm{~Hz}$ \\
\hline Blood pressure & $\begin{array}{l}\text { - Diastolic pressure } \\
\text { - Systolic pressure }\end{array}$ & $\begin{array}{l}\circ 2 \mathrm{~Hz} \\
\circ 2 \mathrm{~Hz}\end{array}$ \\
\hline Core temperature & - Degrees & $\circ 2 \mathrm{~Hz}$ \\
\hline Electrocardiogram & $\begin{array}{l}\text { - Rate (beats/minute) } \\
\text { o Rate rise } \\
\text { o Rate variability }\end{array}$ & $\begin{array}{l}\text { 0 } 5 \mathrm{~Hz} \\
\text { o } 5 \mathrm{~Hz} \\
\text { o } 20 \mathrm{~Hz}\end{array}$ \\
\hline Electroencephalogram & $\begin{array}{l}\text { - Alpha waves (millivolts) } \\
\text { - Beta waves (millivolts) } \\
\text { - Delta waves (millivolts) } \\
\text { o Theta waves (millivolts) } \\
\end{array}$ & $\begin{array}{l}\circ 5 \mathrm{~Hz} \\
\circ 5 \mathrm{~Hz} \\
05 \mathrm{~Hz} \\
05 \mathrm{~Hz} \\
\end{array}$ \\
\hline Electromyogram & $\begin{array}{l}\text { o Average tension levels (millivolts) } \\
\text { o Differential muscle activity }\end{array}$ & $\begin{array}{l}\text { o } 5 \mathrm{~Hz} \\
\text { o } 5 \mathrm{~Hz}\end{array}$ \\
\hline
\end{tabular}




\begin{tabular}{|c|c|c|}
\hline Electrooculogram & - Rate (blinks/minute) & o $30 \mathrm{~Hz}$ \\
\hline Fidget index & o Movement in seat & $05 \mathrm{~Hz}$ \\
\hline Galvanic skin response & o Rate (ohms) & - $5 \mathrm{~Hz}$ \\
\hline Gross body activity & o Number of gross postural changes & - $30 \mathrm{~Hz}$ \\
\hline Respiration & $\begin{array}{l}\text { - Rate (breaths/minute) } \\
\text { o Volume }\end{array}$ & $\begin{array}{l}\text { o } 5 \mathrm{~Hz} \\
\text { o } 5 \mathrm{~Hz}\end{array}$ \\
\hline Skin temperature & o Degrees & o $2 \mathrm{~Hz}$ \\
\hline \multicolumn{3}{|c|}{ Vehicle Parameters } \\
\hline $\begin{array}{l}\text { Acceleration } \\
\text { - Lateral } \\
\text { - Longitudinal } \\
\text { - Vertical }\end{array}$ & $\begin{array}{l}\text { - Meters/second squared; gravity } \\
\text { o Meters/second squared; gravity } \\
\text { - Meters/second squared; gravity }\end{array}$ & $\begin{array}{l}\text { o } 20 \mathrm{~Hz} \\
\text { o } 20 \mathrm{~Hz} \\
\text { o } 20 \mathrm{~Hz}\end{array}$ \\
\hline Braking & $\begin{array}{l}\text { - Stopping accuracy (meters) } \\
\text { - Stopping distance (meters) }\end{array}$ & $\begin{array}{l}02 \mathrm{~Hz} \\
05 \mathrm{~Hz}\end{array}$ \\
\hline Distance traveled & o Meters & o $1 \mathrm{~Hz}$ \\
\hline Elapsed time & o Seconds & $02 \mathrm{~Hz}$ \\
\hline Engine torque & $\begin{array}{l}\text { - Percent } \\
\text { o Kilograms-meter }\end{array}$ & $\begin{array}{l}\circ 20 \mathrm{~Hz} \\
\circ 20 \mathrm{~Hz}\end{array}$ \\
\hline Heading & $\begin{array}{l}\text { - Angle/direction (degrees) } \\
\text { - Angle position/placement (degrees) } \\
\text { - Error (degrees; meters) } \\
\text { o Rate (degrees/second) }\end{array}$ & $\begin{array}{l}\text { - } 20 \mathrm{~Hz} \\
020 \mathrm{~Hz} \\
020 \mathrm{~Hz} \\
020 \mathrm{~Hz}\end{array}$ \\
\hline Headway & $\begin{array}{l}\text { o Distance from the vehicle ahead } \\
\text { (meters) } \\
\text { o Relative velocity (meters/second) }\end{array}$ & $\begin{array}{l}020 \mathrm{~Hz} \\
020 \mathrm{~Hz}\end{array}$ \\
\hline $\begin{array}{l}\text { Lane keeping } \\
\text { o Lateral } \\
\text { o Longitudinal }\end{array}$ & $\begin{array}{l}\text { o Exceedance ratio } \\
\text { o Position variability (centimeters) } \\
\text { o Time-to-line crossing (seconds) } \\
\text { o Control (meters) } \\
\text { - Control (meters) }\end{array}$ & $\begin{array}{l}\text { o } 20 \mathrm{~Hz} \\
\text { o } 20 \mathrm{~Hz} \\
\text { o } 20 \mathrm{~Hz} \\
\text { o } 20 \mathrm{~Hz} \\
\text { o } 20 \mathrm{~Hz}\end{array}$ \\
\hline Path & $\begin{array}{l}\text { - Angle (degrees) } \\
\text { - Angle position/displacement (degrees) } \\
\text { - Angle rate (degrees/second) } \\
\text { - Error (centimeters) } \\
\text { o Error rate (centimeters/second) } \\
\text { - Lateral deviation (centimeters) } \\
\text { - Trajectory }\end{array}$ & $\begin{array}{l}\text { 0 } 20 \mathrm{~Hz} \\
\text { 0 } 20 \mathrm{~Hz} \\
\text { 0 } 20 \mathrm{~Hz} \\
\text { 0 } 20 \mathrm{~Hz} \\
\text { 0 } 20 \mathrm{~Hz} \\
\text { o } 20 \mathrm{~Hz} \\
\text { 0 } 20 \mathrm{~Hz}\end{array}$ \\
\hline Pitch & $\begin{array}{l}\text { - Angle (degrees) } \\
\text { - Angle position/displacement (degrees) } \\
\text { - Angle rate (degrees/second) } \\
\text { o Velocity (centimeters/second) }\end{array}$ & $\begin{array}{l}020 \mathrm{~Hz} \\
020 \mathrm{~Hz} \\
020 \mathrm{~Hz} \\
020 \mathrm{~Hz}\end{array}$ \\
\hline Pitman arm & $\begin{array}{l}\text { o Angle (degrees) } \\
\text { o Force (kilograms) }\end{array}$ & $\begin{array}{l}\text { - } 20 \mathrm{~Hz} \\
\text { o } 2 \mathrm{~Hz}\end{array}$ \\
\hline
\end{tabular}




\begin{tabular}{|c|c|c|}
\hline Roll & $\begin{array}{l}\text { - Angle (degrees) } \\
\text { - Angle position/displacement (angle) } \\
\text { o Angle rate (degrees/second) } \\
\text { o Velocity (centimeters/second) }\end{array}$ & $\begin{array}{l}\circ 20 \mathrm{~Hz} \\
020 \mathrm{~Hz} \\
020 \mathrm{~Hz} \\
020 \mathrm{~Hz}\end{array}$ \\
\hline Sideslip & o Angle (degrees) & $020 \mathrm{~Hz}$ \\
\hline Steering & 0 Angle at front wheels (degrees) & ○ $20 \mathrm{~Hz}$ \\
\hline Suspension & o Deflections (centimeters) & o $2 \mathrm{~Hz}$ \\
\hline Tailway & $\begin{array}{l}\text { - Distance from the vehicle behind } \\
\text { (meters) } \\
\text { o Rate (meters/second) }\end{array}$ & $\begin{array}{l}\text { - } 20 \mathrm{~Hz} \\
020 \mathrm{~Hz}\end{array}$ \\
\hline Throttle & o Percent open & $020 \mathrm{~Hz}$ \\
\hline Time-to-collision & o Seconds & o $2 \mathrm{~Hz}$ \\
\hline Vehicle location & o Degrees & o $1 \mathrm{~Hz}$ \\
\hline $\begin{array}{l}\text { Velocity } \\
\text { o Forward (speed) } \\
\text { o Lateral }\end{array}$ & $\begin{array}{l}\text { o Meters/second } \\
\text { o Number of speed changes } \\
\text { o Meters/second }\end{array}$ & $\begin{array}{l}\text { o } 10 \mathrm{~Hz} \\
\text { o } 20 \mathrm{~Hz} \\
\text { o } 20 \mathrm{~Hz}\end{array}$ \\
\hline Wheel rotation (front and rear wheels) & $\begin{array}{l}\text { o Velocity (revolutions/second; } \\
\text { meters/second) }\end{array}$ & - $20 \mathrm{~Hz}$ \\
\hline Yaw & $\begin{array}{l}\text { - Angle position/displacement (degrees) } \\
\text { o Rate/velocity (degrees/second) } \\
\end{array}$ & $\begin{array}{l}\circ 20 \mathrm{~Hz} \\
020 \mathrm{~Hz} \\
\end{array}$ \\
\hline \multicolumn{3}{|l|}{ Environment Parameters } \\
\hline Barometric pressure & 0 Centimeters of mercury & $02 \mathrm{~Hz}$ \\
\hline Car lights & $\begin{array}{l}\text { - How far away (meters) } \\
\text { o Yesino }\end{array}$ & $\begin{array}{l}02 \mathrm{~Hz} \\
02 \mathrm{~Hz} \\
\end{array}$ \\
\hline Distracting lights, obstacles, and signs & $\begin{array}{l}\text { - How far away (meters) } \\
\text { - Yes/no }\end{array}$ & $\begin{array}{l}\circ 2 \mathrm{~Hz} \\
02 \mathrm{~Hz}\end{array}$ \\
\hline Exits & $\begin{array}{l}\text { o How many } \\
\text { o Spacing }\end{array}$ & $\begin{array}{l}02 \mathrm{~Hz} \\
02 \mathrm{~Hz}\end{array}$ \\
\hline $\begin{array}{l}\text { Hand positions } \\
\text { o Right hand } \\
\text { o Left hand }\end{array}$ & & $\begin{array}{l}\circ 2 \mathrm{~Hz} \\
02 \mathrm{~Hz}\end{array}$ \\
\hline Haze/dust & o Yes/no & o $2 \mathrm{~Hz}$ \\
\hline Humidity & o Percent & $\circ 2 \mathrm{~Hz}$ \\
\hline Intersections & $\begin{array}{l}\text { o How many } \\
\text { o Spacing }\end{array}$ & $\begin{array}{l}\circ 2 \mathrm{~Hz} \\
\circ 2 \mathrm{~Hz}\end{array}$ \\
\hline Lane vehicle is in & o Left, middle, right & $02 \mathrm{~Hz}$ \\
\hline Noise & o Decibels & o $2 \mathrm{~Hz}$ \\
\hline One- or two-way traffic & & $\circ 2 \mathrm{~Hz}$ \\
\hline
\end{tabular}




\begin{tabular}{|c|c|c|}
\hline Parked vehicles & $\begin{array}{l}\text { o How many } \\
\text { o Spacing }\end{array}$ & $\begin{array}{ll}0 & 2 \mathrm{~Hz} \\
0 & 2 \mathrm{~Hz}\end{array}$ \\
\hline Pedestrians & $\begin{array}{l}\text { o How many } \\
\text { o Spacing }\end{array}$ & $\begin{array}{lll}0 & 2 \mathrm{~Hz} \\
0 & 2 \mathrm{~Hz}\end{array}$ \\
\hline Posted speed limits & ○ Kilometers/hour & $02 \mathrm{~Hz}$ \\
\hline Precipitation & $\begin{array}{l}\text { o Centimeters/hour } \\
\text { o Yes/no }\end{array}$ & $\begin{array}{lll}0 & 2 \mathrm{~Hz} \\
0 & 2 \mathrm{~Hz}\end{array}$ \\
\hline $\begin{array}{l}\text { Road } \\
\text { o Conditions } \\
\text { - Gradient } \\
\text { - Lighting } \\
\text { o Surfaces } \\
\text { - Types }\end{array}$ & $\begin{array}{l}\text { - Friction coefficient (grams/grams) } \\
\text { o Radius of curvature (centimeters) } \\
\text { o Inclination angle (degrees) } \\
\text { o Percent } \\
\text { o Yes/no } \\
\text { o Crown } \\
\text { o Superelevation } \\
\text { o Paved, unpaved } \\
\text { o Divided, undivided } \\
\text { - Rural, urban }\end{array}$ & $\begin{array}{lll}0 & 5 \mathrm{~Hz} \\
0 & 2 \mathrm{~Hz} \\
0 & 2 \mathrm{~Hz} \\
0 & 2 \mathrm{~Hz} \\
0 & 2 \mathrm{~Hz} \\
0 & 2 \mathrm{~Hz} \\
0 & 2 \mathrm{~Hz} \\
0 & 1 \mathrm{~Hz} \\
0 & 1 \mathrm{~Hz} \\
0 & 1 \mathrm{~Hz}\end{array}$ \\
\hline Roadway delineation & o Curved, straight & $02 \mathrm{~Hz}$ \\
\hline Sound & - Decibels & o $2 \mathrm{~Hz}$ \\
\hline $\begin{array}{l}\text { Surrounding field of view } \\
\text { o Inside the vehicle } \\
\text { O Outside the vehicle (ahead and } \\
\text { behind) }\end{array}$ & & $\begin{array}{l}02 \mathrm{~Hz} \\
02 \mathrm{~Hz}\end{array}$ \\
\hline Temperature & - Degrees & $01 \mathrm{~Hz}$ \\
\hline Time of day & - Hour and minutes & $01 \mathrm{~Hz}$ \\
\hline $\begin{array}{l}\text { Traffic } \\
\text { o Conditions } \\
\text { - Congestion } \\
\text { - Mix } \\
\text { - Proximity } \\
\text { o Events } \\
\text { - Disturbances } \\
\text { - Situations } \\
\text { o Lights }\end{array}$ & $\begin{array}{l}\text { - Density } \\
\text { Speed of other traffic/relative velocity } \\
\text { (meters/second) } \\
\text { o Volume (vehicles/kilometer) } \\
\text { o Percentage of trucks and cars } \\
\text { o Closeness of other vehicles to the } \\
\text { driven vehicle } \\
\text { o How many } \\
\text { o Spacing }\end{array}$ & $\begin{array}{l}\text { - } 2 \mathrm{~Hz} \\
020 \mathrm{~Hz} \\
\text { o } 2 \mathrm{~Hz} \\
\text { o } 2 \mathrm{~Hz} \\
\text { o } 2 \mathrm{~Hz} \\
\\
\text { o } 2 \mathrm{~Hz} \\
\text { o } 2 \mathrm{~Hz} \\
\text { o } 2 \mathrm{~Hz} \\
\text { o } 2 \mathrm{~Hz}\end{array}$ \\
\hline Turns/hills & $\begin{array}{l}\text { - Where } \\
\text { o Yes/no }\end{array}$ & $\begin{array}{l}\text { o } 2 \mathrm{~Hz} \\
\text { o } 2 \mathrm{~Hz}\end{array}$ \\
\hline $\begin{array}{l}\text { Visibility/sight distance } \\
\text { o Contrast } \\
\text { o Ilumination } \\
\text { o Lumination } \\
\text { o Reflectance }\end{array}$ & $\begin{array}{l}\text { - Percentage } \\
\text { o Lux } \\
\text { o Candelas/square meter } \\
\text { o Percentage }\end{array}$ & $\begin{array}{l}\text { - } 2 \mathrm{~Hz} \\
\text { o } 2 \mathrm{~Hz} \\
\text { o } 2 \mathrm{~Hz} \\
\text { o } 2 \mathrm{~Hz}\end{array}$ \\
\hline
\end{tabular}




\begin{tabular}{|c|c|c|}
\hline $\begin{array}{l}\text { Visual scanning } \\
\text { o Eye movements } \\
\text { o Head movements }\end{array}$ & $\begin{array}{l}\text { o Dwell time (seconds) } \\
\text { o Fixation/eye point of regard } \\
\text { o Frequency of horizontal movements } \\
\text { o Frequency of movements }(\mathrm{Hz}) \\
\text { o Frequency of vertical movements } \\
\text { o Look frequency (Hz) } \\
\text { - Angle of horizontal deflection } \\
\text { (degrees) } \\
\text { - Angle of vertical deflection (degrees) } \\
\text { - Frequency of horizontal movements } \\
\text { - Frequency of movements }(\mathrm{Hz}) \\
\text { - Frequency of vertical movements } \\
\text { - Turning reversal frequency }\end{array}$ & $\begin{array}{l}\text { o } 20 \mathrm{~Hz} \\
\text { o } 20 \mathrm{~Hz} \\
\text { o } 20 \mathrm{~Hz} \\
\text { o } 20 \mathrm{~Hz} \\
\text { o } 20 \mathrm{~Hz} \\
\text { o } 20 \mathrm{~Hz} \\
\text { o } 5 \mathrm{~Hz} \\
\text { o } 5 \mathrm{~Hz} \\
\text { o } 20 \mathrm{~Hz} \\
\text { o } 20 \mathrm{~Hz} \\
\text { o } 20 \mathrm{~Hz} \\
\text { o } 30 \mathrm{~Hz}\end{array}$ \\
\hline $\begin{array}{l}\text { Wind } \\
\text { o Direction } \\
\text { o Speed } \\
\text { - Gusts } \\
\text { - Steady }\end{array}$ & $\begin{array}{l}\text { - North, south, east, west } \\
\text { o Meters/second } \\
\text { o Meters/second }\end{array}$ & $\begin{array}{l}\circ 2 \mathrm{~Hz} \\
\text { ० } 2 \mathrm{~Hz} \\
\circ 2 \mathrm{~Hz}\end{array}$ \\
\hline
\end{tabular}

These lists of parameters and measures should be considered as comprehensive and all encompassing. NHTSA, with input and assistance from ORNL, weeded them down to a workable and manageable set in a systematic manner (see section 3.1). ORNL could have also built up from a baseline set of parameters (see section 5.5). This is the old controversy of a topdown versus bottom-up approach.

\subsection{Determination of the Sampling Requirements}

The sampling requirements (i.e., how often the parameters and/or measures should be collected) for the parameters and measures can be influenced by several factors. First, the sampling rate depends on the important information content of the variable. Second, the sampling rate hinges on the nature of the sensor function. For example, the inherent information from an optical encoder is dependent upon its resolution and how fast the basic variable changes. Third, some parameters and measures have high inherent frequency content that could be reduced by on-line processing. Finally, parameter and measure frequency content can also be a function of the type of sensor selected; for instance, optical encoders versus potentiometers or rate gyros that are based on differential accelerometers, and thus have a higher frequency content than electromechanical gyros.

ORNL determined the sampling requirements through the review of the human performance research and previous NHTSA data acquisition programs. Input was received from the three highway-safety consultants and was also used during the effort. There was much more agreement among the consultants in regards to the sampling requirements than there was on the subset of parameters and measures.

How frequently the variables should be measured ranges between one and 30 times per second. Most of the driver-control actions and vehicle parameters should be collected 20 times per 
second. The majority of the driver-equipment status variables and environment considerations should be recorded twice a second. How often the driver's physiological factors should be measured is about equally divided between five and 20 times a second. Table 2 displays the specific sampling requirements for each of the identified parameters and/or measures.

\subsection{Parameters and Crash Avoidance Research}

The three highway-safety consultants and ORNL each identified a different set of specific issues and problem areas of crash-avoidance research. The first consultant's list consists of the following:

1. Vehicle lateral/directional control

2. Driver state/impairment monitoring

3. Steering activity

4. Driver actions not measurable by position changes

5. Vehicle longitudinal/headway control

6. Emergency maneuvering

7. Driver safety, judgement, and decision making

8. Vehicle handling

9. Risk taking and aggressiveness

10. Ride quality

11. Braking

12. Driver fatigue, arousal, and attention

13. Visibility

14. Situational awareness

15. Traffic interaction

16. Workload and stress

The mapping of these issues and areas to the parameters which the highway-safety consultant identified are displayed in Table 3 . Specific issues are listed by number.

The second consultant put NHTSA's research applications into four categories (driver performance modeling (1), avoidance response (2), strategic behaviors (3), and workload (4)). He defines driver-performance modeling as the effect on driving of stressors such as substances, fatigue, vehicle handling, and other characteristics, and organismic variables such as age. Avoidance response is defined as human response and performance limitations. Strategic behaviors are the mechanisms underlying task sharing and supervisory control under normal conditions of traffic, etc. Workload consists of mental workload including performance tradeoffs and multitask interference under conditions of high-anxiety task demands. The relationship of these four issues/problems to the parameters which the highway-safety consultant derived is exhibited in Table 4. 
Table 3. Issues, Areas, and Parameters Identified by Consultant \#1

\begin{tabular}{|c|c|}
\hline Parameters & Specific Issues \\
\hline $\begin{array}{l}\text { Driver Control Actions } \\
\text { - Steering wheel position } \\
\text { o Steering wheel rate } \\
\text { - Steering wheel torque } \\
\text { - Throttle position } \\
\text { - Throttle rate } \\
\text { - Brake pedal force } \\
\text { o Discrete controls }\end{array}$ & $\begin{array}{l}\circ 1,2 \\
01,2,3 \\
04 \\
02,5 \\
02 \\
05,6 \\
07\end{array}$ \\
\hline $\begin{array}{l}\text { Vehicle Body Axis Motions } \\
\text { o Angular rates (pitch, roll, and yaw) } \\
\text { o Lateral, fore/aft acceleration } \\
\text { o Vertical acceleration } \\
\text { o Forward velocity } \\
\text { o Wheel velocities }\end{array}$ & 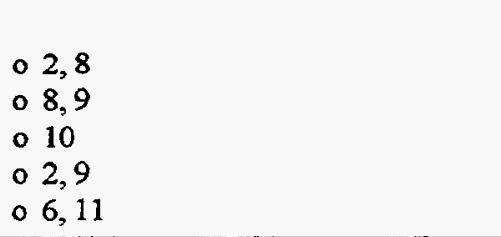 \\
\hline $\begin{array}{l}\text { Vehicle/Road/Environment } \\
\text { o Distance traveled } \\
\text { o Lateral lane position } \\
\text { o Lead vehicle headway } \\
\text { o Front and rear field of view }\end{array}$ & $\begin{array}{l}\text { - } 12 \\
\text { o } 2,8,13 \\
\text { o } 2,5,9 \\
\text { o } 9,14,15\end{array}$ \\
\hline $\begin{array}{l}\text { Psychophysiological Measures } \\
\text { o Heart rate } \\
\text { o Eye movements and eye point of regard } \\
\text { o Electromyogram } \\
\text { o Electroencephalogram } \\
\text { o Basal skin temperature }\end{array}$ & $\begin{array}{l}\text { o } 2,9,16 \\
\text { o } 12 \\
\text { o } 1,8,16 \\
\text { o } 12,16 \\
\text { o } 12,16\end{array}$ \\
\hline
\end{tabular}

Table 4. Issues/Problems and Parameters Identified by Consultant \#2

\begin{tabular}{|l|l|}
\hline \multicolumn{1}{|c|}{ Parameters } & \multicolumn{1}{c|}{ Specific Issues } \\
\hline Driver Actions & \\
o Braking & 01,2 \\
o Steering & $01,2,4$ \\
o Accelerating & $01,2,3$ \\
o Eye movements & 03,4 \\
\hline Vehicle Response & \\
o Distance & \\
o Location & \\
o Speed & $01,2,3,4$ \\
o Lateral tracking & $01,2,3,4$ \\
o Acceleration & $01,2,3$ \\
o Headway & $01,2,3,4$ \\
o Obstacle avoidance & 02,4 \\
\hline
\end{tabular}




\begin{tabular}{|c|c|}
\hline $\begin{array}{l}\text { Environmental Variables } \\
\text { - Traffic condition } \\
\text { o Road inclination } \\
\text { - Road curvature } \\
\text { - Wind } \\
\text { o Video record } \\
\text { o llumination } \\
\text { o Road friction }\end{array}$ & $\begin{array}{l}03,4 \\
01,3 \\
01,3 \\
01 \\
01 \\
01,2,3,4 \\
01,2,4\end{array}$ \\
\hline $\begin{array}{l}\text { Organismic Variables } \\
\text { o Physiological status } \\
\text { o Workload }\end{array}$ & $\begin{array}{l}\circ 3,4 \\
\circ 4\end{array}$ \\
\hline
\end{tabular}

The third highway-safety consultant identified 12 problem areas. They are:

1. Alcohol and drugs

2. As needed

3. Attention

4. Elderly

5. Epidemiological exposure studies

6. Fatigue

7. ITS

8. Learning

9. Roadway and traffic control device studies

10. Response time studies

11. Weather

12. Visual allocation

The links between the problem areas and the parameters derived by the consultant are shown in Table 5 .

ORNL extracted specific issues and problem areas of crash-avoidance research via a review of relevant human-performance research and previous NHTSA data-acquisition efforts and programs. The derived issues and areas are as follows:

1. Arousal and attention

2. Fatigue

3. Task-induced and environmental stress

4. Internally induced stress

5. Psychophysiological response

6. Traffic capacity and flow

7. Day-night comparisons

8. Three-beam headlight/wide-angle headlight/steady burn lights evaluation

9. Roadway delineation

10. Visibility 
Table 5. Problem Areas and Parameters Identified by Consultant \#3

\begin{tabular}{|c|c|}
\hline Parameters & Specific Areas \\
\hline $\begin{array}{l}\text { Time } \\
\text { Speed } \\
\text { Distance } \\
\text { Longitudinal acceleration } \\
\text { Vehicle jerk } \\
\text { Lane position } \\
\text { Lateral speed } \\
\text { Lateral acceleration } \\
\text { Steering wheel position } \\
\text { Steering wheel velocity } \\
\text { Headway } \\
\text { Relative velocity } \\
\text { Yaw } \\
\text { Yaw rate } \\
\text { Roll rate } \\
\text { Break pressure } \\
\text { Brake pedal status } \\
\text { Accelerator pedal status } \\
\text { Clutch pedal status } \\
\text { Turn signal status } \\
\text { Seat belt use } \\
\text { Parking lights use } \\
\text { Low beam/high beam lights use } \\
\text { Radio use } \\
\text { Heater/air conditioner use } \\
\text { Seat position adjustment } \\
\text { Coefficient of friction } \\
\text { Near object detection } \\
\text { Driver glance location } \\
\text { Driver glance duration } \\
\text { Driver glance frequency } \\
\text { Driver hand location } \\
\text { Driver's hands activity time } \\
\text { Electrocardiogram } \\
\text { Electroencephalogram } \\
\text { Head turning reversal frequency } \\
\text { Blink rate } \\
\text { Head nod } \\
\text { Gross body activity }\end{array}$ & 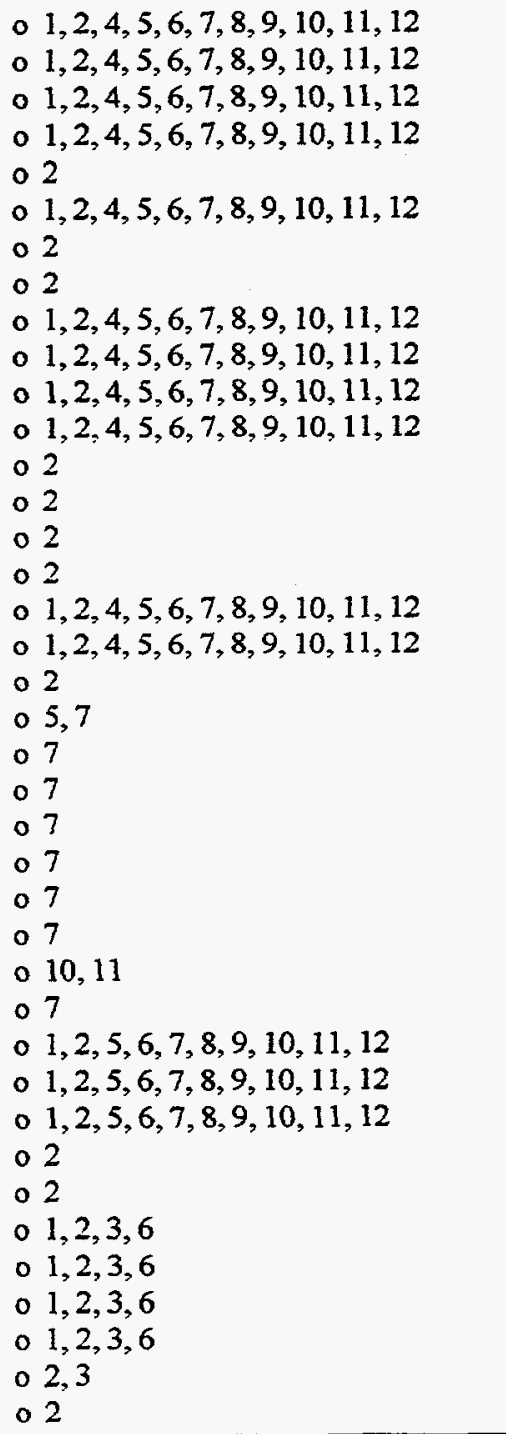 \\
\hline
\end{tabular}

11. Fuel economy

12. Head restraints and seating systems

13. Conspicuity enhancement

14. Antilock brake systems (ABS)

15. Alcohol and drugs

16. Automatic headway control

17. Overtaking and passing

18. Lane changing

19. Crosswind disturbance 
20. Mental load

21. Mobile telephoning

22. Kilometers/liter meters

23. Intelligent automobile displays

The mapping of these specific issues and problems areas to the parameters identified by ORNL is depicted in Table 6. Parameters not linked to any specific issues were not used or cited in the open literature which was reviewed.

Table 6. Issues, Areas, and Parameters Identified by ORNL

\begin{tabular}{|c|c|}
\hline Parameters & Specific Issues \\
\hline $\begin{array}{l}\text { Driver Parameters } \\
\text { Driver Control Actions } \\
\text { Accelerator/throttle } \\
\text { Brake pedal } \\
\text { Steering } \\
\text { Steering wheel } \\
\text { o Coarse steering/lane changing } \\
\text { o Fine steering } \\
\text { Time between accelerator release and brake application } \\
\text { Equipment Status } \\
\text { Air vents } \\
\text { Ash tray } \\
\text { Auxiliary device } \\
\text { Brake lights } \\
\text { Cellular telephone } \\
\text { Cigarette lighter } \\
\text { Clutch pedal } \\
\text { Cruise control } \\
\text { Driver in } \\
\text { Emergency brake } \\
\text { Engine } \\
\text { Hazard flashers } \\
\text { Headlight dimmer switch } \\
\text { Headlights } \\
\text { Heater/air conditioner } \\
\text { Horn } \\
\text { Parking lights } \\
\text { Radio/tape player/compact disk player } \\
\text { Rearview mirror } \\
\text { Rear window defogger } \\
\text { Rear window wiper } \\
\text { Seat belts } \\
\text { Turn signals } \\
\text { Transmission selector } \\
\text { Windows } \\
\text { Windshield washer } \\
\text { Windshield wipers } \\
\text { W }\end{array}$ & $\begin{array}{l}\text { 2,3,7,15,16,17 } \\
2,3,8,9,10,14,15,16,17 \\
09,10,18 \\
2,3,7,8,14,15,17,18,19,21 \\
15 \\
15\end{array}$ \\
\hline
\end{tabular}




\section{Physiological Parameters}

Acceleration at the driver's head position

Blood pressure

Core temperature

Electrocardiogram

Electroencephalogram

Electromyogram

Electrooculogram

Fidget index

Galvanic skin response

Gross body activity

Respiration

Skin temperature

Vehicle Parameters

Acceleration

o Lateral

o Longitudinal

o Vertical

Braking

Distance traveled

Elapsed time

Engine torque

Heading

Headway

Lane keeping

o Lateral

o Longitudinal

Path

Pitch

Pitman arm

Roll

Sideslip

Steering

Suspension

Tailway

Throttle

Time-to-collision

Vehicle location

Velocity

- Forward

- Lateral

Wheel rotation

Yaw

\section{Environmental Parameters}

Barometric pressure

Car lights

Distracting lights, obstacles, and signs

Exits

Hand positions

o Right hand

- Left hand

Haze/dust

Humidity

Intersections

Lane vehicle is in

Noise o $1,2,3,4,5,7,9,10,15,20,21$

o $1,2,3,4,5,9,10,15$

- $1,2,3,4,5$

o $1,2,3,4,5,7,8,15$

03

o $3,9,10,12,14,15,17,18,19$

o $8,14,17$

o $2,3,8,9,10,14,15,16,17$

- $1,2,8,14,15,17$

- $2,8,11,15$

- 11

- $15,17,18,19$

o $3,8,13,16,17,21,23$

- 23

- $8,9,10,15,17,18,21$

- 15,17

o $9,10,17$

○ 3,17

o $1,2,3,6,8,9,10,11,12,14,15,16,17,19,21,22,23$

014 


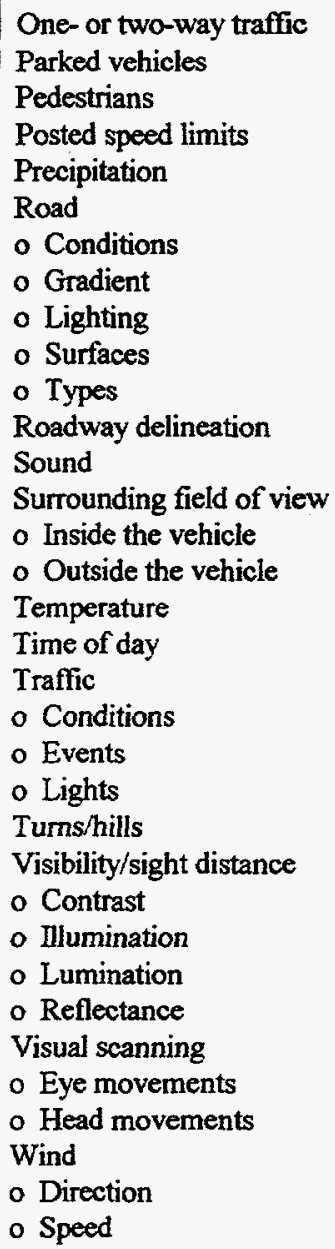

- $1,2,3,7,15,23$

o 3

\subsection{Prioritization of the Parameters}

The derived parameters were evaluated and analyzed with regard to their need for being incorporated within the data acquisition system. One of three priority ratings/rankings was assigned to each parameter dependent upon the requirement to have sensors and instrumentation to collect the parameter. A "1" was given a parameter if it has high priority (i.e., it is critical) for being recorded by DASCAR. The parameter was allocated the value of " 2 " if it was determined that the variable has a medium priority (i.e., important but not critical). A " 3 " was allotted to a parameter if it was assessed to have a low priority (i.e., less important than the variables given the other two ratings) for being gathered by the DASCAR equipment.

Prioritization of the parameters was accomplished via the review of the human-performance research and previous NHTSA data-acquisition programs. Input received from one of the highway-safety consultants was also used during the effort. The rating given to each parameter was highly dependent upon its use in prior NHTSA research and its utilization in investigating specific issues and problem areas of crash-avoidance research. 
All of the driver control actions, except time between accelerator release and brake application, received a priority rating of 1 . The majority of the driver-equipment status variables and driver physiological factors were ranked a 3 . The ratings provided to the vehicle parameters were about equally divided between 1 and 2 . Most of the environment considerations were rated a 2 . The median priority rating and range for each parameter are displayed in Table 7.

Table 7. Priority Rating and Range for Each Parameter

\begin{tabular}{|c|c|c|}
\hline Parameters & Median & Range \\
\hline \multicolumn{3}{|l|}{ Driver Parameters } \\
\hline Driver Control Actions & & \\
\hline Accelerator/throttle & 1 & 0 \\
\hline Brake pedal & 1 & 1 \\
\hline Steering & 1 & 2 \\
\hline Steering wheel & 1 & 0 \\
\hline - Coarse steering/lane changing & 1 & 0 \\
\hline o Fine steering & 1 & 0 \\
\hline Time between accelerator release and brake application & 2 & 2 \\
\hline \multicolumn{3}{|l|}{ Equipment Status } \\
\hline Air vents & 3 & 0 \\
\hline Ash tray & 3 & 0 \\
\hline Auxiliary device & 1 & 2 \\
\hline Brake lights & 1 & 2 \\
\hline Cellular telephone & 1 & 2 \\
\hline Cigarette lighter & 3 & 0 \\
\hline Clutch pedal & 3 & 2 \\
\hline Cruise control & 2 & 2 \\
\hline Driver in & 3 & 2 \\
\hline Emergency brake & 3 & 1 \\
\hline Engine & 3 & 2 \\
\hline Hazard flashers & 3 & 0 \\
\hline Headlight dimmer switch & 2 & 1 \\
\hline Headlights & 2 & 2 \\
\hline Heater/air conditioner & 3 & 1 \\
\hline Hom & 2 & 2 \\
\hline Parking lights & 3 & 1 \\
\hline Radio/tape player/compact disk player & 2 & 1 \\
\hline Rearview mirror & 2 & 2 \\
\hline Rear window defogger & 3 & 1 \\
\hline Rear window wiper & 3 & 1 \\
\hline Seat belts & 3 & 0 \\
\hline Tum signals & 1 & 2 \\
\hline Transmission selector & 3 & 1 \\
\hline Windows & 3 & 0 \\
\hline Windshield washer & 2 & 2 \\
\hline Windshield wipers & 2 & 2 \\
\hline \multicolumn{3}{|l|}{ Physiological Parameters } \\
\hline Acceleration at the driver's head & 3 & 0 \\
\hline Blood pressure & 3 & 2 \\
\hline Core temperature & 3 & 2 \\
\hline
\end{tabular}




\begin{tabular}{|c|c|c|}
\hline $\begin{array}{l}\text { Electrocardiogram } \\
\text { Electroencephalogram } \\
\text { Electromyogram } \\
\text { Electrooculogram } \\
\text { Fidget index } \\
\text { Galvanic skin response } \\
\text { Gross body activity } \\
\text { Respiration } \\
\text { Skin temperature }\end{array}$ & $\begin{array}{c}2 \\
2.5 \\
3 \\
2 \\
2 \\
3 \\
3 \\
2.5 \\
3\end{array}$ & $\begin{array}{l}2 \\
1 \\
1 \\
2 \\
2 \\
1 \\
1 \\
2 \\
0\end{array}$ \\
\hline $\begin{array}{l}\text { Vehicle Parameters } \\
\text { Acceleration } \\
\text { o Lateral } \\
\text { o Longitudinal } \\
\text { o Vertical } \\
\text { Braking } \\
\text { Distance traveled } \\
\text { Elapsed time } \\
\text { Engine torque } \\
\text { Heading } \\
\text { Headway } \\
\text { Lane keeping } \\
\text { o Lateral } \\
\text { o Longitudinal } \\
\text { Path } \\
\text { Pitch } \\
\text { Pitman arm } \\
\text { Roll } \\
\text { Sideslip } \\
\text { Steering } \\
\text { Suspension } \\
\text { Tailway } \\
\text { Throttle } \\
\text { Time-to-collision } \\
\text { Vehicle location } \\
\text { Velocity } \\
\text { o Forward } \\
\text { o Lateral } \\
\text { Wheel rotation } \\
\text { Yaw }\end{array}$ & $\begin{array}{c}1 \\
1 \\
2 \\
1 \\
1 \\
1 \\
3 \\
2 \\
1 \\
1 \\
1 \\
2 \\
2.5 \\
2 \\
2 \\
2 \\
3 \\
1 \\
2 \\
2 \\
2 \\
2.5 \\
1 \\
\\
1 \\
1 \\
2 \\
1\end{array}$ & $\begin{array}{l}0 \\
0 \\
2\end{array}$ \\
\hline $\begin{array}{l}\text { Environmental Parameters } \\
\text { Barometric pressure } \\
\text { Car lights } \\
\text { Distracting lights, obstacles, and signs } \\
\text { Exits } \\
\text { Hand positions } \\
\text { O Right hand } \\
\text { o Left hand } \\
\text { Haze/dust } \\
\text { Humidity } \\
\text { Intersections } \\
\text { Lane vehicle is in } \\
\text { Noise } \\
\text { One- or two-way traffic } \\
\text { Parked vehicles } \\
\text { Pedestrians } \\
\text { Posted speed limits }\end{array}$ & $\begin{array}{l}3 \\
2 \\
2 \\
2 \\
3 \\
3 \\
2 \\
3 \\
2 \\
3 \\
2 \\
2 \\
2 \\
2 \\
2 \\
\end{array}$ & $\begin{array}{l}2 \\
2 \\
1 \\
0 \\
2 \\
2 \\
1 \\
2 \\
1 \\
1 \\
2\end{array}$ \\
\hline
\end{tabular}




\begin{tabular}{|c|c|c|}
\hline $\begin{array}{l}\text { Precipitation } \\
\text { Road } \\
\text { o Conditions } \\
\text { o Gradient } \\
\text { o Lighting } \\
\text { o Surfaces } \\
\text { o Types } \\
\text { Roadway delineation } \\
\text { Sound } \\
\text { Surrounding field of view } \\
\text { o Inside the vehicle } \\
\text { o Outside the vehicle } \\
\text { Temperature } \\
\text { Time of day } \\
\text { Traffic } \\
\text { o Conditions } \\
\text { - Congestion } \\
\text { - Mix } \\
\text { - Proximity } \\
\text { o Events } \\
\text { - Disturbances } \\
\text { - Situations } \\
\text { o Lights } \\
\text { Tums/hills } \\
\text { Visibility/sight distance } \\
\text { o Contrast } \\
\text { o Illumination } \\
\text { o Lumination } \\
\text { o Reflectance } \\
\text { Visual scanning } \\
\text { o Eye movements } \\
\text { o Head movements } \\
\text { Wind } \\
\text { o Direction } \\
\text { o Speed } \\
\text { - Gusts } \\
\text { - Steady }\end{array}$ & $\begin{array}{l}1 \\
2 \\
2 \\
2 \\
2 \\
2 \\
2 \\
2 \\
1 \\
2 \\
2 \\
1 \\
2 \\
3 \\
2 \\
2\end{array}$ & $\begin{array}{l}1 \\
1 \\
1 \\
2 \\
1 \\
2 \\
1\end{array}$ \\
\hline
\end{tabular}

\subsection{Definition of a Minimum Set of Parameters}

As a result of the work performed in the identification of parameters and measures, ORNL suggested that DASCAR could be designed so that a minimum set of parameters would be recorded. Sensors, equipment, and instrumentation for collecting additional parameters could then be included in the data acquisition system provided that they meet the overall goals and requirements of the project, and the gathering of the required data is not cost prohibitive.

A minimum set of parameters was defined by each of the three highway-safety consultants and two of the ORNL DASCAR team members. The five sets of parameters were subsequently folded into one. If the parameter was selected by at least three of the people, it was included in the finalized set. The minimum set of parameters is as listed in Table 8. 
Table 8. The Minimum Set of Parameters

\begin{tabular}{|c|}
\hline Driver Parameters \\
Driver Control Actions \\
Accelerator/throttle \\
Brake pedal \\
Steering \\
Steering wheel (coarse steering/lane changing) \\
\hline Vehicle Parameters \\
Acceleration (lateral and longitudinal) \\
Distance traveled \\
Elapsed time \\
Headway \\
Lane keeping (lateral) \\
Vehicle location \\
Velocity (forward) \\
\hline Environment Parameters \\
Traffic conditions (congestion) \\
Visual scanning (head movements) \\
\hline
\end{tabular}

\section{ANALYSIS TOOLS AND METHODS THAT COULD BE USED TO ASSEMBLE, ANALYZE, AND EVALUATE THE DASCAR DATA}

The objective of the "identify analysis tools and methods that could be used to assemble, analyze, and evaluate the gathered data in relation to safety issues" task was to review available research to identify data analysis tools, methods, and general approaches that could be used to assemble, integrate, analyze, and interpret driver performance and data associated with the identified parameters.

\section{$6.1 \quad$ Background}

Ideally, decisions related to data collection, storage, and analysis would be driven by the requirements of a specific experimental design. Since DASCAR will be a general purpose research platform, firm recommendations of specific data handling tools and procedures were not possible at the time this task was conducted. Therefore, this section provides a discussion of the issues and general requirements associated with the types of data which DASCAR will generate.

Assembling, integrating, analyzing, and interpreting collected driver performance, vehicle, and environmental data are diverse tasks. Different objectives, for example in studies of braking systems or the effects of alcohol on reaction times, may entail assorted parameters and measures, diverse measurement periods and sampling rates, various levels of quantization, and different approaches to data analysis. Because DASCAR will accommodate a wide variety of possible research, it will be designed to be flexible enough that data acquisition can be modified to accommodate differing analytical goals and new insights obtained through the development of the system itself. The data acquisition system will have open channels for possible new, unanticipated 
parameters and measures, and the sampling and multiplexing design will be supple enough (e.g., programmable) for variation in the allocation of the total sampling capability.

Similarly, it is not reasonable to delineate all specific methods that might be used in instrumented vehicle data analysis since specific analyses are problem dependent. Many haven't even been tried yet; examples in the literature are scarce. Thus a software system is needed for DASCAR that is flexible. This section describes general approaches and methods for data analysis for DASCAR, and general software tools for implementing them. Once a software tool is selected, and as data become available, techniques and software for data analysis will be developed and refined. But a goal of the DASCAR development will be flexibility.

\subsection{Data Analysis Objectives}

Strictly speaking, data analysis begins with the creation of a data set; digital signals are converted to convenient measurements (perhaps via calibration equations) and incorporated into a tractable form for subsequent analysis. Follow-on analysis may include screening for outliers, pattern recognition and image processing (PRIP), smoothing and filtering, graphics, statistical estimation and hypothesis testing, and maintenance of the data base (e.g., updating). However, just as data interpretation should drive data analysis, data analysis should drive data acquisition. Thus other issues in data analysis include calibration and experimental design -- what to measure, when, how accurately and at what frequency, how the measurements should be quantized (in analog-to-digital (A/D) conversion), etc.

In addition, sampling periods (i.e., when to sample certain channels) will affect the requirements for data storage and analysis. For example, if brake line pressures are only of interest when brakes are actuated, they should only be recorded then, thus reducing the volume of data. Measurement precision (reproducibility of measurements given the same conditions), accuracy (bias with respect to a calibrated standard), and range also affect data storage requirements through the number of significant digits that must be stored. For example, storing speeds in the range 0 - 160 kilometers/hour, accurate and precise to .01 kilometers/hour, can be done, in theory, with fourteen binary bits, this is because $2^{14}$ is $16,384 \approx 160 / .01$. (In practice 16 bits would probably be used, because of hardware standards.)

Requirements for sampling period, frequency, precision, accuracy, and range for individual parameters have yet to be determined. These requirements will be decided on a case-by-case basis depending on available technology, cost, and the needs for measuring the parameters themselves. The data management system should be tailored to meet these requirements.

Continuing advances in computer hardware are constantly expanding what is feasible in data acquisition and storage. Still, efficient data management will be important; tallying one highwaysafety consultant's sampling requirements, there could be about 1,150 measurements for each second of data acquisition. For single precision (four bits per measurement), this translates to about 16.5 megabytes $(\mathrm{Mb})$ per hour. Data reduction techniques should be used, where possible, 
to reduce storage requirements. Appropriate formats should be used to ensure efficient data storage. Data reduction techniques and formats are not enumerated here, again because they depend on precision, accuracy, range, and sampling frequency requirements for the parameters and measures. Once these requirements are determined, formatting, at least, is straightforward.

The key statistical issue in A/D conversion is quantization -- how closely, at any given instant, the discrete digital data represent the analog signal at that instant. Hardware capability often renders quantization error negligible, but, especially in high speed applications, it might not be, and should be considered. Once digital data are obtained (via a random access memory (RAM) buffer, data logger, storage module, etc.) they will be recorded, on a disk, onboard the vehicle and/or elsewhere, via a radio telemetry, cellular telephone, or satellite link.

From the disk, the digital data will be read into a database using software, discussed below. During database creation, the data will be converted into measurements using calibration information. Labels, identifiers, concomitant variables, and "meta-data" will be incorporated into the database, along with the measurements.

Initial and periodic calibrations will be an important part of the DASCAR procedures, and should be provided for in the overall capability for data analysis. Calibration curves are usually, but not always, calculated using linear or polynomial regression. Statistical calibration error should be accounted for, and if non-negligible, carried into the data analysis and interpretation.

Details of the database creation will depend on the particular software that is selected. The most likely data structure will be collections of tables. Data having the same sampling frequency and periods will make up one such table, with rows (records) corresponding to time (e.g., seconds) and columns corresponding to channels over time (e.g., ten measurements per second for each channel). For intermittently recorded signals (e.g., actuated by a brake or proximity detector), starting or actuation times will most likely be incorporated into the rows. For signals recorded continually, that will be unnecessary, because only the initial starting time and sampling rate will be needed to recover the time of a measurement. Starting times and sampling-rate information can also be stored in a separate table along with meta-data.

The DASCAR data-analysis software should be able to handle files that are compressed. (Compressed files have variable length records produced by a program that puts them into a form that is efficient for storage.) This will be particularly useful for intermittently sampled channels, which will have sections of missing values on table rows, because signals may start or terminate at any time. For such data, compression usually results in substantial reductions in disk space. Data compression can also be done directly through the operating system, rather than statistical software, often with even greater savings in disk space.

Once data are incorporated into a database, processing should continue with outlier detection. Techniques for detecting outliers should be ad hoc -- depending on both the measured phenomena and the instrumentation. An example of such an algorithm is the comparison of each data point in 
a time series to the average of the two points that are adjacent to it. For a reasonably smooth series, a large difference indicates a problem. Algorithms for outlier detection should be developed, along with DASCAR, as real data become available. For inherently noisy measurements, outliers can be good valid data; for smooth, slowly varying measurements, outliers are usually bad data. Bad data points should either be identified as such (through additional flag variables) or set to missing.

Most of the driver, vehicle, and environment parameters and measures of interest are not periodic, and therefore not particularly suited to Fourier or frequency analysis (i.e., transformation of the observations in time to frequencies as a function of signal amplitude). These include measurements of position (e.g., lane position and position relative to other objects), velocity and acceleration (e.g., pitch, roll, and yaw), controls (e.g., brake, steering wheel, and accelerator), environment (e.g., lighting and road gradient), and many of the physiological variables (e.g., galvanic skin response and blood pressure). For these parameters and measures, analysis of the untransformed data, or of averages over time periods or episodes, is appropriate. Sampling rates are best determined by analysis of interpolation errors.

Some of the variables are, however, suited to Fourier analysis. These include vehicle vibrations and physiological variables such as the electrocardiogram. For these variables, sampling rates are suggested by the so-called sampling theorem, which gives the minimum sampling frequency (the Nyquist frequency) necessary to exactly recover a finite Fourier series from observations of it. In practice, sampling is usually at a higher rate (e.g., twice the Nyquist frequency) because the assumption of a finite Fourier series is usually only approximate.

Data-analytical approaches should be tailored to the most suitable periodic or non-periodic paradigm. In either case, specifying optimal or even suitable sampling rates is not easy. Time and frequency-domain methods that, in conjunction with sampling limitations (e.g., due to recording rates, capacitance of circuits, and costs), can be used to determine appropriate sampling rates should be investigated. This should involve the analysis of interpolation error, and, where appropriate, an approximation by finite Fourier series. At least for some applications, these methods may lead to sampling-rate recommendations that differ from initial expert opinions.

PRIP are potentially important, timesaving tools for processing the DASCAR data, both sensor and video derived. Automatic techniques for identifying conditions, such as loss of control (an anomalous road friction and impending crash), or unusual human responses (in the electrocardiogram and galvanic skin response), could be extremely useful and should be developed to a reasonable extent in the data-processing software. The medical, space, and defense industries are sources of PRIP algorithms, though in those industries there are usually demands for real-time PRIP, which will be unnecessary for post-processing of the DASCAR data. (Some real-time PRIP may be needed in the onboard DASCAR software, for example to actuate data collection for channels that are needed only intermittently, or to increase sampling rates upon detection of, say, an impending loss of control.) 
Filtering and smoothing are closely related techniques for removing noise and thus making data better represent variables of interest. Filtering and smoothing can often greatly facilitate graphical interpretation. In smoothing, noise in observations is reduced by some kind of averaging process (such as moving averages or smoothing splines). In filtering, frequencies of interest, often low ones, are separated from other frequencies, considered to be noise. Smoothing and filtering can be implemented in both software (using, for example, linear least squares filters) and hardware (for example by charging capacitors, or with bandpass filters). Again, appropriate approaches depend on the instrumentation and parameters measured. Investigations and recommendations should be made about smoothing and filtering techniques for DASCAR.

Data analysis and interpretation require graphics -- from initial data exploration (e.g., visual outlier screening) to final report writing. Software for DASCAR should enable users to easily produce both rough and publication-quality one, two, and three-dimensional plots, contour plots, and bar and pie charts. Plots should be overlayable. The software system should have this capability.

The DASCAR data-analysis capability should also include standard statistical approaches for estimation and hypothesis testing, including summary statistics (e.g., means, medians, and standard errors), correlations, analysis of counts, analysis of variance, regression, and non-parametric statistics. These are all standard analytical techniques used in data interpretation. Regression and analysis of variance are often the keys to interpreting designed experiments. If possible, the statistical software capability should also include time series and spectral analyses, multivariate analysis (e.g., profile analysis), singular value decompositions, variance component models, and the ability to handle data that are censored (off-scale).

Finally, the software system should have the provision for customized programs specific to instrumented driver research. How this is accomplished will depend on the choice of the software, and may involve programming in the language of specific statistical software (e.g., SAS), or interfacing with a language such as Fortran.

\subsection{Software for Data Analysis}

Flexibility should also be a key in choosing and developing software for DASCAR data analysis. The capability to produce files suitable for exporting to other hosts and thus into other statistical software packages should be developed. How best to do this depends on the target host; one should probably use American Standard Code for Information Interchange (ASCII) files that are compressed (using programs like "zip" for PCs or "compress" in Unix).

Although the software tools should be developed using only one package, wherever possible, one should attempt to keep them simple enough that the same tools can be developed analogously in other packages. This is reasonable, because in many cases the important issues are the mathematical and statistical techniques, rather than the particular software in which they are 
implemented. A lot of time should not be spent developing, for example, user interfaces for particular software/hardware platforms.

Criteria for choosing statistical software for DASCAR should include:

- Capability - for database management, for statistical analysis, for tailoring procedures peculiar to the DASCAR data, and for add-on options.

- Interfaces with other systems.

- Support by the vendor.

- $\quad$ Progressiveness of the vendor.

- $\quad$ Ease of use (e.g., a graphical user interface).

- Ease of learning.

- Documentation.

- Portability (of programs to various platforms).

- Reliability (e.g., numerical stability).

- $\quad$ Efficiency (e.g., of data storage).

- Numbers of users, platforms, and operating systems.

- Cost.

- Capability and experience of the people developing DASCAR

Statistical software packages can be huge, and learning their intricacies can take a long time. For this reason, most people who use statistical software are most familiar with one package, which they prefer to the exclusion of others (thus perpetuating their preference). Furthermore, the capabilities, ease of use, etc., of software are constantly changing, as vendors steadily improve their products. It is rare to find someone who is recently familiar enough with two or more packages to have a sound basis for comparing them. ORNL is most familiar with SAS, so that is our preference. This is important, because the DASCAR software will be developed, and ORNL will be using it as we develop the entire data acquisition system.

Many packages can be made to do many kinds of statistical analysis, especially basics like summary statistics, correlations, or basic graphics. ORNL wrote for information about six software packages: SAS, Statistical Package for the Social Sciences (SPSS), Systat, Minitab, Stata, and S-Plus. There are others (e.g., Biomedical Data Program (BMDP)), but we reviewed only these six.

Wayner (1992) discussed five statistics packages -- Minitab, SPSS, SAS, Stata, and Systat -- for PCs and Minitab and Systat for Macintoshes and concluded that SAS is the best overall choice for PCs, and Systat is better for Macintoshes. Burgard (1992) discussed SAS and SPSS for Unix systems and also concluded that SAS is better.

Because much of the research using DASCAR will probably be done at large institutions, which already have statistical software, cost is probably not an important criterion. Much more important is the experience of the people who will be using it. ORNL understands that both SAS 
and SPSS are used extensively in NHTSA research. At ORNL, SAS is preferred because it has been widely used for years for both database management and statistical analysis. The wide base of users, particularly users on the DASCAR project team, is an important resource, which a choice of other than SAS would sacrifice.

SAS has vast capability, including the standard statistical procedures, time series and spectral analyses, multivariate analysis, singular value decompositions, variance component models, and the ability to handle data that are censored. SAS has the provision for custom programs through SAS language (data step) programs and a high level (interactive matrix) language (Proc MML). SAS is reliable and interfaces with other systems (e.g., SPSS and BMDP). The SAS documentation is vast, and SAS supports its users. There is a huge community of SAS users; SAS was installed at more than 22,000 sites in 1991. SAS Institute, Incorporated is the biggest statistical software vendor, seems progressive, and has the momentum to remain an industry leader for a long time. For these reasons ORNL recommends the SAS software as the primary data-analytical tool for DASCAR.

\section{MEASUREMENT TECHNIQUES AND HARDWARE TO SUPPORT DEVELOPMENT OF DASCAR}

The "identify measurement techniques and state-of-the-art hardware and software to support development of an in-vehicle data acquisition system" task had six goals. They include: to examine and evaluate various techniques for measurement of the identified parameters; to obtain and review available information on state-of-the-art technologies relevant to meeting the objectives of this project; to determine the optimal configuration and integration of technologies that will allow development of DASCAR; to examine the feasibility and desirability of transmitting information back to a test vehicle from a central data collection facility for either communications or controlling functions; to provide preliminary recommendations for hardware/software selection and architecture; and to address areas where development or pilot work is needed.

\subsection{System Overview}

In late 1993 DASCAR was envisioned as consisting of four major components: a power supply, a DAP, a data storage and transmission module, and a sensor suite. (A fifth element, a separate video data system, was added in early 1994 (see section 8.1.5).) A block diagram of the data acquisition system is depicted in Figure 1. It shows both the data links and the power distribution. Each of these major components is described in detail in the following sections.

\subsection{Power Supply}

The power supply must be capable of providing sufficient and clean power for the entire data acquisition system. It should provide power for volatile memory maintenance independently of 


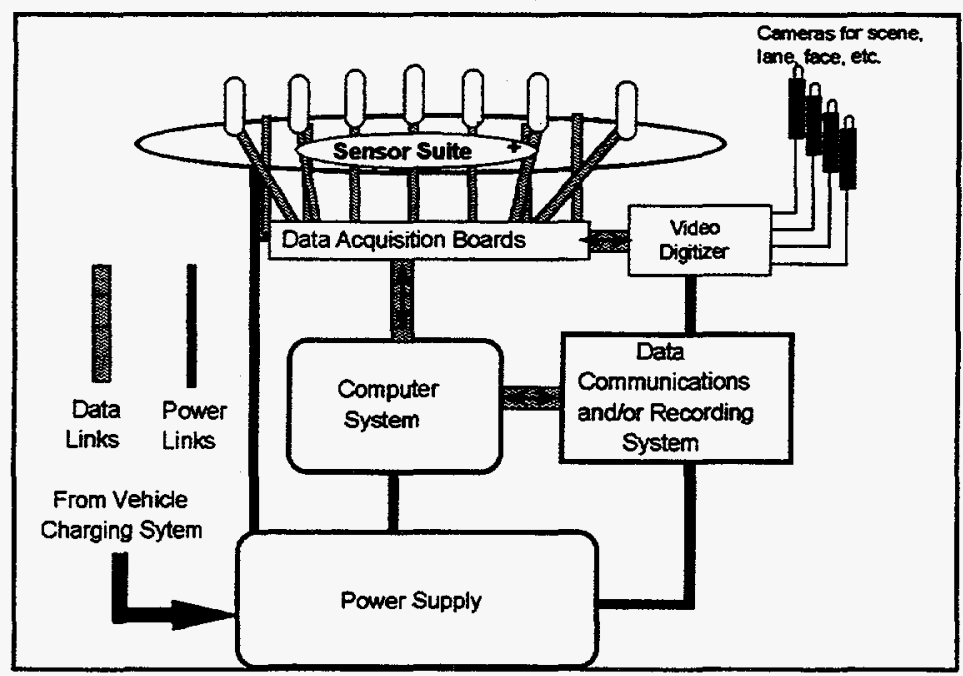

Figure 1. A block diagram of the conceptual design for the proposed modular data acquisition system for the DASCAR project.

the vehicle's electrical system, and be chargeable from the vehicle's factory-installed alternator/battery system.

\subsubsection{Design}

As presented in Figure 2, there will be three main components to the DASCAR power supply: electronic isolation from the vehicle electrical system, sealed lead-acid (gel-cell) storage batteries, and a switching-precision power supply.

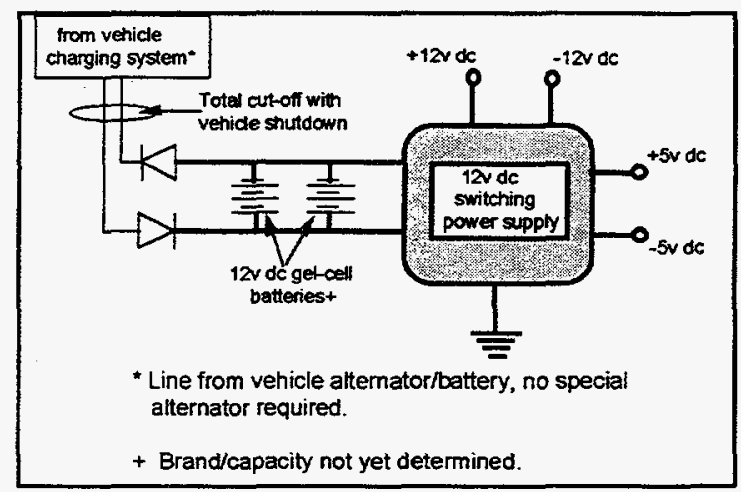

Figure 2. Power supply for DASCAR system. 


\subsubsection{Electronic Isolation}

An electronic-isolation system will provide total separation from the vehicle-power system when the vehicle is powered down. This capability prevents the DASCAR platform from draining the vehicle's battery during power-down, which could preclude the motorist from starting the vehicle. This electronic-isolation component will also preclude fluctuations in the vehicle chargingelectrical system from entering the DASCAR power system, when coupled with the gel-cell 12volt (V) storage batteries.

\subsubsection{Batteries}

Two 12-V gel-cell storage batteries will serve two purposes in the DASCAR design. First, they will serve a power-smoothing function, absorbing any ripples and spikes which may occur as a result of irregularities in the vehicle-charging system, and they will compensate for lowered voltages which may occur, for example, when the vehicle sits in traffic with the air conditioning going in summer heat. These batteries will also provide the power required for volatile memory preservation during power-down of the system. (It is also possible that lithium battery backup for memory will be required. This can be accommodated without any significant problems in this design.)

\subsubsection{Switching Power Supply}

The remaining power supply component will be a precision $12-\mathrm{V}$ direct current (DC) switching power supply. This component will provide the required voltages for the various items in the entire data acquisition system as shown in Figure 1. Technical data from two vendors (Powercube and Vicor) are presented in Appendix C. The Vicor Mega/Master series appears to provide the necessary flexibility for both the voltages and power output needed for this project. If necessary, several of these units could be used, either in parallel or cascaded.

\subsection{DAP}

The DAP should consist of boards, cables, and signal processing equipment necessary to capture and process signals from the various sensors installed within and around the vehicle. The interior of a vehicle is electronically very noisy, with numerous sources of both radio frequency and electromagnetic interference (RFI and EMI). These kinds of interference must be accounted for in the design of the instrumentation system, and the DAP is a good place to start. All signals must be converted from analog (as they typically come out of the sensor) to digital (as processed and stored in computers) format. This conversion can be done at the sensor, at the acquisition platform, or somewhere in between. Doing A/D conversion at the sensor is often not economical, although some sensors do come with the A/D boards installed. More frequently, the analog signal is passed to the acquisition platform, which does the $A / D$ conversion and any other signal conditioning required. 


\subsubsection{A/D Conversion}

Where the A/D conversion is accomplished, has an important impact on several aspects of the system design. A digital signal (being either zero or five $\mathrm{V}$ ) is much more resistant to RFI and EMI than is an analog signal. Thus, doing the AVD conversion at the sensor is the best solution strictly from the interference point of view. However, each $A / D$ board must be powered, a situation which increases the wiring complexity of the data acquisition system, since most sensors are not factory-wired for $\mathrm{A} / \mathrm{D}$ conversion. On the other hand, doing the conversion at the acquisition platform, while being economical from the standpoint of powering the boards, requires considerable wiring to carry the signal from the sensor to the platform. In addition, the wiring must be shielded to minimize the EMI and RFI effects.

A good compromise is to do the $A / D$ conversions and signal conditioning operations in several distributed processing "centers" within the vehicle. This option requires the placement of ADD conversion and signal conditioning boards at several locations in the vehicle, such as under the hood, within the driver/passenger compartment, and in the rear of the vehicle (trunk or rear cargo area). This solution provides a number of benefits. First, the powering of signal boards is accomplished in groups, which simplifies power requirements. Second, the shielded leads from the sensors to the boards are considerably shortened, both simplifying installation and reducing costs. Third, the cabling from the signal boards to the main platform is reduced to a single unit from each board to the platform, and because the signals being carried are digital, the problems of EMI and RFI are reduced. Thus, the DAP becomes a somewhat distributed system, as depicted in Figure 3.

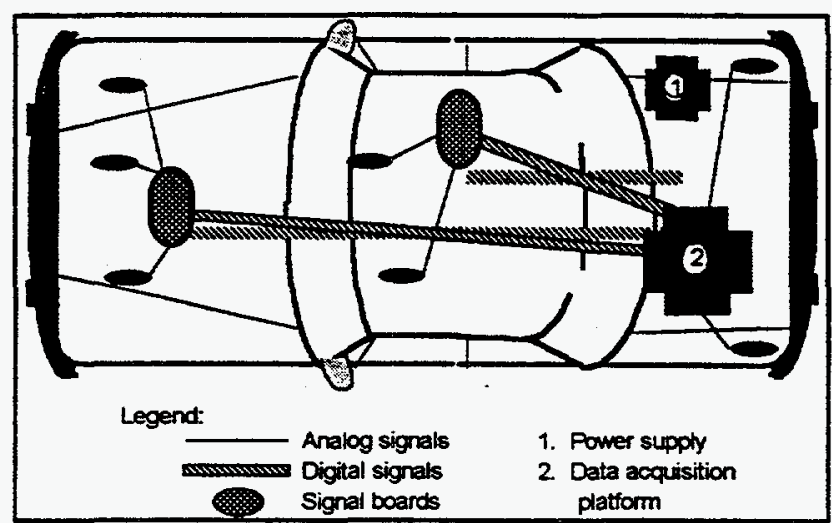

Figure 3. An illustration of distributed signal conditioning boards sending digital signals to the DAP. 


\subsubsection{Vendors for the Platform}

Five platform vendors emerged as major contenders from a study of available systems. Criteria for evaluating the platforms included: flexibility of the system, in terms of accommodating a variety of different kinds of signals; ability of the system to do signal processing and A/D conversion; prior experience of the vendor with vehicle instrumentation work; ability to distribute the system's signal-processing boards; completeness and flexibility of the accompanying software; and the type of available data output and ease of connection to radio link, cellular telephone, and satellite-communications systems. Each of these vendors is discussed briefly below, with technical material being presented in the associated appendices.

\subsubsection{Dianachart, Incorporated}

Contact: $\quad$ Bill McWilliams, 101 Round Hill Drive, Rockaway, NJ 07866, (201) 625-2299.

Dianachart was initially contacted at Sensors Expo West (March 2 - 4, 1993, San Jose, CA), where they displayed material on their data logging systems, including the TRAVELOGGER. This device is a portable system, line current or battery powered, which uses a laptop computer (80386 or 80486-central processing unit (CPU)) for control and display in the vehicle. The TRAVELOGGER comes as a six-channel device, expandable to 96 channels; the larger PROCESS-ACQ system is capable of carrying up to 192 channels (see quotations in Appendix D). As with most of the data acquisition systems reviewed, the Dianachart systems have a number of options available. These options permit the customizing of the system with off-theshelf components, including an $\mathrm{A} / \mathrm{D}$ converter and signal conditioning boards, additional input channels, sensor power circuits, and data processing software. Appendix D includes technical information on the two Dianachart data acquisition systems, taken from their promotional booklet "How to Measure in Lab and Industry." Options considered include: signal conditioning module, menu-driven software for data analysis, real time graphics display (on a PC), an on-line calculation package for user-defined formulas for data analysis, and an instant replay feature to review results of a "run." Further analysis of DASCAR data needs indicates that ORNL will not require the 192-channel capacity of the PROCESS-ACQ system. This system is primarily designed for in-factory installation, and is larger and more cumbersome than the TRAVELOGGER.

\subsubsection{OPTIM Electronics}

Contact: $\quad$ John W. Waldman, Middlebrook Tech Park, 12401 Middlebrook Road, Germantown, MD 20874, (301) 428-7200.

The OPTIM MEGADAC Data Acquisition and Control Systems offer a variety of features which can be used in numerous data acquisition settings. Some listed by the company are: in-vehicle, locomotive, and aerospace testing. The systems (such as the MEGADAC 5108DC on page 20 of their catalog, and the MEGADAC $6506 \mathrm{~S}$ on page 21) consist of a "mainframe" design with a 
passive backplane, which permits insertion of various input-output cards into slots, similar to the VME rack computer systems. The insertable modules include: signal input and conditioning for various kinds of signal sources, timing modules for time stamping and sampling control, analog output, constant current sensor-excitation modules, etc. Using this system, one can assemble a customized data acquisition system capable of meeting "your particular requirements" (catalog, page 2). Unfortunately, it appears very difficult to configure a general-purpose system using the OPTIM components, yet such a general-purpose system is what the DASCAR project requires. Material from OPTIM's catalog is presented in Appendix D.

\subsubsection{Schlumberger Technologies}

Contact: $\quad$ David Zimmerman, 3100 New Castle Lane, Riva, MD 21140, (410) 269-0948.

Contact was made with Schlumberger via a promotional brochure sent as a result of a reader interest card submitted in December 1992. Their information request card was returned in midJanuary, and the information packet was received in early February. Further contact was again made at Sensors Expo West, and a visit by Mr. Zimmerman took place on May 5, 1993. The meeting included exchange of cooperative research and development agreement (CRADA) ideas, and discussion of how their Scorpio system could meet DASCAR's needs. There appeared to be considerable interest on the part of Schlumberger, even in a CRADA. However, a letter dated May 28, 1993, (see Appendix D for this letter plus Schlumberger technical material) indicates that this company is not interested in this project.

Schlumberger offers the Scorpio Data Logger, which is capable of being expanded to a total of 140 input/output channels. It is capable of receiving signals from thermocouples, strain bridges (Scorpio-excited), and voltage and current transmitters. The Data Logger can also receive digital inputs. Schlumberger also has a Scorpio Data Acquisition System, which they advertise as having been used for "endurance testing of automobile engines," among other things. Capable of up to 50,000 measurements per second on multiple channels, the system includes software to transmit data to a PC Windows system for viewing and analysis. This system is International Business

Machines (IBM) - PC compatible ( $80386 \mathrm{CPU})$, and can serve as a complete system controller for data acquisition from a number of Schlumberger Data Loggers.

\subsubsection{Scientific Atlanta, Incorporated}

Contact: $\quad$ Donald R. Brady, Signal Processing Systems, 13112 Evening Creek Drive South, San Diego, CA 92128-4199, (619) 679-6291.

Scientific Atlanta has, to date, provided by far the most comprehensive system implementation. They have experience with satellite communications in the ITS TravTek program, and have also done vehicle instrumentation for the U.S. Army and Navy. They are poised to enter the market 
for instrumentation of road vehicles in the private sector, and have provided both an overall plan to do this and a proposal for a CRADA with this project.

There are three major components to Scientific Atlanta's system: a data logger, a data analysis station (DAS), and communications links for both satellite and two-way radio link transmission. The communications link will be discussed in the next section. The data logger is called the data processing unit (DPU), and consists of a number of input multiplexers which permit up to 42 analog inputs per board along with four digital inputs. A diagram from Scientific Atlanta is presented in Appendix D, which illustrates the multiplexers (input mux's) and the digital input (TAC/TRAK I/F). As the diagram shows, this board provides signal conditioning and A/D conversion, and terminates in a choice of either RS-232 or RS-422 outputs. These DPU boards would be the two "signal boards" illustrated in Figure 3. They can be mounted in either a singleboard case or a multi-board chassis with a passive backplane.

Each DPU contains four Mb of flash memory, permitting non-volatile storage of local datacollection programs and/or data, thus providing the flexibility necessary for changing sensor needs without changing hardware. This flexibility will be especially important since the DASCAR packages will be used in a variety of different research settings requiring different sensor suite configurations. In addition, software-based diagnostics can be easily upgraded as sensor technology changes over the life of the DASCAR package. A laptop computer with either a 386 or $486 \mathrm{CPU}$ serves as an onboard system controller and data storage platform, and is represented by item 2 in Figure 3, the DAP.

The DAS consists of a standard 80386- or 80486-CPU PC or a laptop computer, with four Mb of $\mathrm{RAM}$, and at least an $80-\mathrm{Mb}$ hard drive. This computer is in addition to the laptop computer which resides onboard the vehicle as the system storage and control platform. The software utilizes the Microsoft Windows interface, using Superbase four as the data storage mechanism. This package permits formatting of data for output to a major data analysis package (such as SAS, see section 6.3), which would reside on a mainframe computer connected to DAS by a local area network. Another feature of the DPU-DAS system is the use of credit-card memory to transfer data between units. This device is a "credit-card sized" memory module which can be loaded with data from, for example, the onboard platform, and then transferred manually to the DAS where the data is off-loaded. The relationships among these various components are presented in Figure 4, which is adapted from a diagram provided by Scientific Atlanta. Technical material on Scientific Atlanta's data collection system is presented in Appendix D.

\subsubsection{Smiths Industries}

Contact: $\quad$ Stephen Gresley, 4141 Eastern Avenue S.E., Grand Rapids, MI 49518-8727, (616) 241-7000

Smiths Industries (formerly Lucas Signal) produces a line of data management systems which has seen service, for instance, on the F-16 fighter aircraft. As an example of their data acquisition 


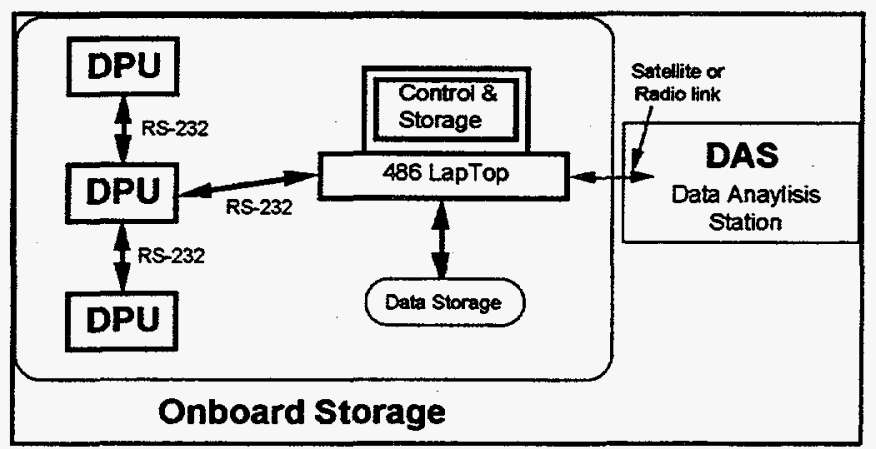

Figure 4. Onboard storage and central (off board) monitoring with Scientific Atlanta components (from Donald Brady).

system, Smiths Industries indicate that the F-16 data they collect are divided into four categories: accident/incident, individual aircraft tracking, structural integrity, and engine data. Smiths Industries has computer algorithms to process and store these data. Among other things, they can reconstruct an entire flight after it is terminated. Some discussion of the possibility of a CRADA with them was held with Lyle Reibling during his visit to ORNL, but the company has shown little interest in pursuing such an arrangement. The equipment produced by Smiths Industries is clearly designed for flight recording systems, and would need to be adapted to ground-vehicle use. Some material from Smiths Industries is shown in Appendix D.

\subsection{Data Storage and Communications Link}

\subsubsection{Storage and Communications Requirements}

The data storage and communications capabilities must include multiple ways of handling the data generated by the DASCAR equipment. There should be onboard data storage, as illustrated in Figure 4. This will provide backup capacity in case of radio-link failure, or in case of signal corruption during transmission. Transmission of data can be accomplished in either of two modes. A radio telemetry link can be used to transmit data from the vehicle to a base station during use at a test track. Closed circuit testing reduces the need for long-range data transmission, thus permitting use of such a link. Testing under open road conditions, when longterm and long-range data accumulation and transmission are involved, requires some kind of satellite transmission or cellular telephone system. Determination of specific transmission frequencies will be made at a later date, and any requirements to use government-only communications bands can and will be met.

Because of the close relationship between the acquisition platform and the transmission module, it appears prudent to use the same vendor for both of these components, if possible. This approach takes advantage of the vendor's engineering to provide signal processing from initial raw signal 
input, through to the point at which the digitized data are stored and/or transmitted off the vehicle. Thus, Scientific Atlanta's radio/satellite equipment is discussed in this section.

\subsubsection{Radio Telemetry}

Radio telemetry refers to the use of a (one-way) radio link to transmit information, in the case of DASCAR, from the test vehicle to a base station either at a central data collection center or aboard another vehicle. For DASCAR purposes, the link will serve for test-track conditions, as would exist, for example, at the NHTSA test facility in East Liberty, $\mathrm{OH}$. The goal for this system is to achieve reliable data transmission to a base station, with full coverage of the entire test facility. In the case of the East Liberty facility, problems exist due to the curvature of the terrain, such that a direct link cannot be established to a single receiving base station. Both physical and legal restrictions preclude erecting a receiving antenna high enough to achieve directline radio transmission. Thus, the solution at that facility appears to be the use of two receivers, one to cover each of the areas of the facility defined by the existing terrain.

\subsubsection{1 $\quad \underline{\text { Scientific Atlanta }}$}

Contact: Jack P. Tassos, Electronic Systems Division, 3845 Pleasantdale Road, Atlanta, GA 30340-4266, (404) 903-2377.

The base station receiver designed by Scientific Atlanta is the Series 930 Telemetry receiver. This receiver is military standard (MLL-STD) 461B qualified, and appears to have the flexibility and capacity needed to serve the DASCAR needs. The Scientific Atlanta literature on the 930 series telemetry receivers is provided in Appendix E. The 930 receiver is designed for closed-circuit testing, and might require more than one unit, depending on the track terrain. This receiver requires a transmitter made by some other vendor, but it is in wide use, including several cars on the European formula I circuit.

\subsubsection{Proxim, Incorporated}

Contact: $\quad$ Matt Aver, 295 North Bernardo Avenue, Mountain View, CA 94043, (415) 9601630 .

The Proxim family of wireless asynchronous RS-232 radio telemetry products utilizes a unique spectrum of radio frequency technology in the Federal Communications Corporation approved 902 - 928 megahertz (MHz) band. Their ProxLink XR spread-spectrum radio module offers range capabilities of 244 meters or more, depending on the specifics of the operational environment. Proxim's products provide multiple channel options and robust built-in network protocols which can support numerous modules operating simultaneously without interfering with each other. Telemetry units can be paired in a simple "pass through" point-to-point mode or operated in various other topologies, utilizing the programmable packetized mode capability. The 
radio module supports $1,200,2,400,4,800,9,600$, and 19,200 baud data rates. Literature on Proxim's radio telemetry products is exhibited in Appendix E.

\subsubsection{Communication Back to the Vehicle}

Communication from a base station to the vehicle can be accomplished in several ways. QualComm (see section 7.4.3.2) offers limited data transmission from their base station back to the vehicle as part of their OmniTRACS satellite system. However, this communication is via data packets sent from a base-station keyboard to a terminal located inside the vehicle. This communication is used by trucking firms, for example, to provide changes in travel orders for drivers. A second option is to install a second radio link which transmits from the base station to the vehicle; a more compact version of this would be to use a system which has two transceivers, one in the vehicle and one at the base station. Two-way hand-held transceivers (walkie-talkies) are used at the NHTSA test track in East Liberty, $\mathrm{OH}$, for communication between vehicles on the test track and the control tower. This will work in closed-circuit testing, but would not work well for over-the-road research. A third option is to install a cellular telephone in the vehicle. Such equipment would provide acceptable voice communication, but would only provide limited data transmission, because of the baud rates available for telephone use, and also because of signal interruption while driving.

\subsubsection{Satellite Transmission}

Satellite transmission refers to the sending of data through existing (stationary or rapidly-orbiting) satellite facilities. This transmission, for the DASCAR purposes, would consist of data sent from the vehicle to the satellite, for relay to a base receiving station located at a central data processing facility. Satellite transmissions can be received from all over the continent, thus making this type of communications system suitable for over-the-road, more long-range testing and data collection than would typically be done using the radio telemetry system described above. In addition, satellite systems can also provide for vehicle location, using the GPS, or some variant of that system. Vehicle location is important for over-the-road testing, since the path of vehicles being monitored is a random walk (from the point of view of the base station), as opposed to monitoring at a test facility, where the vehicle's path is determined by the layout of the facility, and path branchings are very limited.

\subsubsection{Scientific Atlanta}

Contact: $\quad$ Macy W. Summers, Mobile Satellite Systems, 4291 Communications Drive, Norcross, GA 30093, (404) 903-6168.

The remaining Scientific Atlanta component, from section 7.3, is the satellite communications link. Their experience with the TravTek program, as well as others, contributes to their ability to provide this capability to this program. Scientific Atlanta's TerraStar-C Satellite Terminal (Model 9805 ) is capable of global data communication (600 baud) through the Inmarsat Standard 'C' 
System. This terminal provides two-way communication, automatic data and position reporting, and can be linked to a GPS receiver for precise vehicle location, according to the Scientific Atlanta literature. The antenna is relatively inconspicuous -- it looks like an upside-down icecream cone, about 18 centimeters high and 15 centimeters in diameter, and attaches to the rear fender or bumper of the vehicle. The TerraStar-C was used in the TravTek program. Company material on the satellite communications equipment is presented in Appendix $F$. This component is illustrated as item 8 in Figure 5, which shows the overall component layout for the DASCAR system in a vehicle.

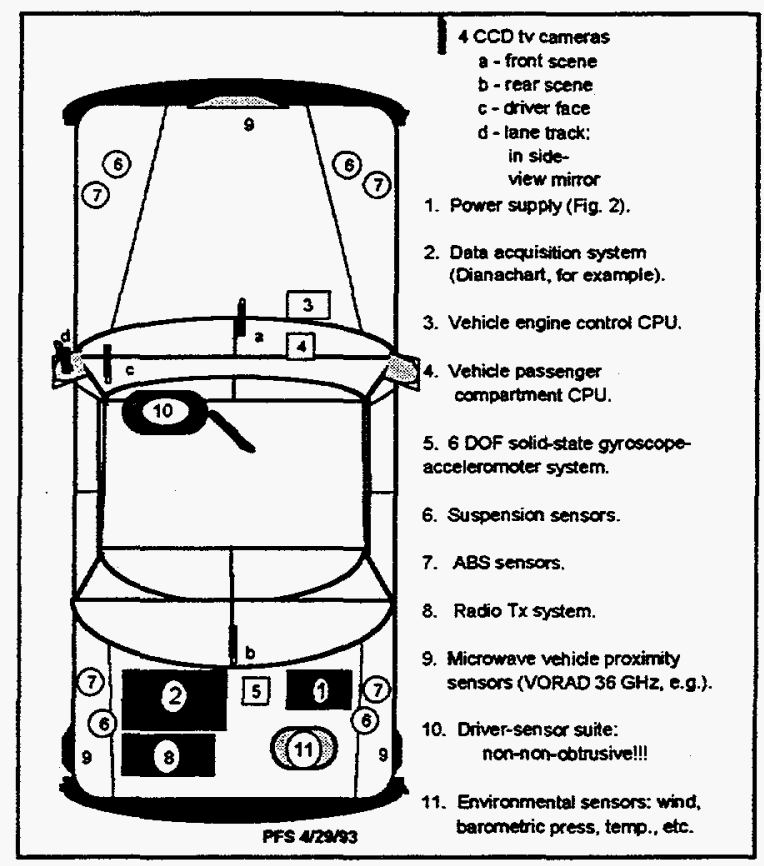

Figure 5. An illustration of the general layout of components of DASCAR, including sensors and the communications module.

\subsubsection{OmniTRACS by QualComm}

Contact: $\quad$ Jim Madsen, 10555 Sorrento Valley Road, San Diego, CA 92121-1617, (619) 597-5010.

Contact with QualComm, makers of the OmniTRACS vehicle tracking and communication system, was made through Nationwide Moving and Storage Company, located in Bloomfield, CT, agent for North American Van Lines. Conversations with Phillip Jenquin at the North American Van Lines Customer Service Fleet Division in Ft. Wayne, IN, (phone number (219) 587-1121, extension 5031) indicated that his company is satisfied with the OmniTRACS system. He 
reported a failure rate of less than one percent over the two years' use they have had from their installed systems. The system uses a Digital Equipment Corporation VAX computer located at the QualComm facility in San Diego to link with fleet trucks using two stationary satellites on which QualComm rents facilities. These two satellites provide QualComm with minimal GPS-like vehicle location capabilities, along with two-way data transmission. The vehicle location system uses a time-difference in signal transmission between the two satellites to triangulate on the vehicle, providing location to within 300 meters along the highway. The customer communicates with QualComm's base station via telephone lines. Each outgoing message packet, which is transmitted on the $\mathrm{Ku}$ band (14 gigahertz $(\mathrm{GHz})$ ), can contain up to 1,900 characters.

Information from the vehicle includes engine data, as well as any information entered by the driver using an onboard keyboard message-entry system. The return message is transmitted on the 12 $\mathrm{GHz}$ frequency band. Information on the OmniTRACS system is presented in Appendix F.

\subsection{Sensor Suite}

The selection of sensors to comprise the sensor suite is the most difficult part of the task of developing the DASCAR platform. Three general areas were assessed: the driver, the vehicle, and the external environment. Each of these data sources had its own set of challenges. As detailed below, state-of-the-art sensor technology presents a mixed view of capabilities. Generally, sensor technology for vehicle assessment is quite adequate, whereas that for physiological measurement of the driver is clearly not. Similarly, sensors for some environmental parameters are adequate, others are not. It is clear that compromises will be necessary in the final sensor suite determination.

It is expected that the sensor suite for a given study will consist of a subset of the entire list of sensors available in the DASCAR package. The modular design of the system will permit this type of sensor selection, as well as permitting upgrade of various components as technology improves the capabilities of those components. Information on the sensor suite is divided into three sections: the vehicle itself, the driver, and the external environment.

\subsubsection{Vehicle Parameters}

Sensor technology for vehicle operation is by far the most advanced of the three areas of concern to the DASCAR program. This is due partly to the nature of the data needed to evaluate vehicle performance, partially to the demands from various sources such as the military and non-road transportation, as well as the automobile and truck manufacturers themselves. Many functions which are of interest to this project are already being measured, either by sensors in place in production vehicles or in various specialty vehicles such as race cars. As a result of these factors, coupled with the long history of machine sensing in industry in general, the data acquisition in this area can be considered largely a mature technology.

One goal of the project was to use as many of the manufacturer-installed data sources as possible. This philosophy requires that the DASCAR platform be able to access the data bus or buses 
present in production vehicles. Discussions with the automobile manufacturers revealed that each manufacturer has its own proprietary data structure and data-transmission system. Moreover, some original equipment manufacturers have more than one type of data bus, sometimes on the same vehicle. This state of affairs precludes a simple solution to accessing manufacturers' data streams. That it is possible to do so is illustrated by one research laboratory's successful effort to acquire data from a vehicle data bus without degrading the vehicle's performance. However, this effort required significant input from that vehicle's (foreign) manufacturer.

Information from the Sensors Expo West meeting revealed the chaotic state-of-affairs in the area of vehicle data collection among the various automobile manufacturers, with differences even existing between European, Japanese, and American manufacturers. Efforts are under way to develop an industry standard data structure and bus system, but any success is four or five years away, at best. Probably the most that can be hoped for within the time frame of this project (the next two to three years) is that each American manufacturer will arrive at a single data system for both drive train and driver/passenger compartment monitoring and control, so that access to that data stream will be simplified within and among a manufacturer's vehicles.

\subsubsection{Overall Vehicle Performance}

This category includes sensor data necessary to establish the overall orientation, positioning, and performance of the vehicle relative to its lane and/or road, as well as other vehicles on the roadway. Information under this heading falls into categories of sensor data such as acceleration, braking, headway, tailway, and lane tracking.

\subsection{General Vehicle Orientation}

General vehicle orientation refers to positioning and accelerations in roll, pitch, and yaw of the vehicle, as well as linear acceleration (lateral, longitudinal, and vertical) and braking, as it travels along the highway. These categories are generally measured by gyroscopes for position and accelerometers for accelerations. Traditionally, gyroscopes and other devices such as accelerometers have been electromechanical devices which require a measurable amount of time to "spin up" to operational speed, and which are subject to electrical drift and mechanical wear. Recent technological developments have created a new family of solid-state gyroscopes and accelerometers which have no moving parts. This type of design precludes mechanical wear and significantly reduces electrical drift. Thus, the devices detailed in this section meet these design criteria as much as possible.

\subsection{Quartz Gyro-Sensors}

Contact: Gary W. Felsing, Systron Donner Inertial Division, 2700 Systron Drive, Concord, CA 94518-1399, (510) 671-6582.

Systron Donner manufactures a variety of quartz rate sensors (QRS), some of which have been 
combined into a package called the MOTIONPACK. This sensor is a six DOF orientation system which uses three GyroChips (see below) and three quartz flexure accelerometers to measure vertical, lateral, and longitudinal accelerations. These devices are sealed into a metal case sized at approximately eight cubic centimeters, with a pin-out which receives power and signal inputs, and provides both angular rate and acceleration in the $\mathrm{x}, \mathrm{y}$, and $\mathrm{z}$ axes, along with a temperature sensor for external temperature compensation. Rates are sensed using three GyroChips, which are subminiature oscillating quartz elements. Accelerations are sensed using a servoed quartzflexture pendulum. Systron Donner also markets a variety of other devices, including linear and angular accelerometers, and vibration transducers. A brief technical note, as well as literature from the company, is included in Appendix G.

\subsection{Electromechanical Gyroscopes}

Contact: $\quad$ Roy A. MacDonald, GRA-MAR, Incorporated, 5125 Curry Ford Road, Suite 100, Orlando, FL 32812.

GRA-MAR represents Humphry, Incorporated, makers of electromechanical gyroscopes, rate sensors, vertical indicators, north-seekers, etc. Sample specification sheets are presented in Appendix G. Generally, these electromechanical devices are more expensive, larger, heavier, and draw more power than solid-state devices. ORNL's recommendation is that these devices not be used.

\subsection{Electronic Compass/Tilt Sensor}

Contact: John Lee, Precision Navigation, Incorporated, 1350 Pear Avenue, Suite A, Mountain View, CA 94043.

The Precision Navigation electronic compass (model TCM1) combines a three-axis magnetometer with a two-axis tilt sensor, capable of sensing $+/-30$ degree angles. This device provides compass, magnetic field, and electronic tilt data in an integrated package which has low power requirements. It is capable of sampling rates up to $10 \mathrm{~Hz}$, which is quite adequate for DASCAR purposes. Because it is based on a three-dimensional magnetometer, the compass automatically compensates for changes in pitch and roll without requiring the gimbal system typically needed for compass accuracy. Thus, the system is fixed with respect to the vehicle in which it is installed. Its output is compatible with RS-232C interfaces, among others. Technical literature on the electronic compass is provided in Appendix $\mathrm{H}$.

\subsection{Electronic Tilt Sensor - Dual Axis Clinometer}

Contact: $\quad$ Scott Kohler, Lucas Schaevitz, 7905 N. Route 130, Pennsauken, NJ 08110-1489, (609) 662-8000. 
Alternate: Fred Lieb, MicroSpec, Incorporated, Technical Representatives, 1804 Linden Avenue, Nashville, TN 37212, (615) 383-4064.

The Lucas Schaevitz AccuStar II is an electronic dual-axis tilt sensor capable of 0.01 degree sensitivity with a range of $+/-20$ degrees. It is a replacement for mercury based electromechanical devices of less accuracy and durability. Its operating temperature range and sensitivity range make it suitable for in-vehicle use in this project. Technical material is provided in Appendix $\mathrm{H}$.

\subsection{Headway/Tailway Monitoring}

At present, there appear to be two ways of gathering information on headway and tailway: video information from forward- and rearward-looking cameras, and some type of range sensor. The range sensor might be ultrasonic, laser, or microwave (radar).

\subsection{Non-Radar Sensors}

Automated processing of video information (frequently referred to as "machine vision") provides a major impediment to the use of video information for many aspects of this project (see section 7.4.5.1.3 on lane-tracking). Object detection and recognition in machine vision is a tedious and computational intensive process, and is frequently error prone. The alternative to machine vision is to use a human to "process" the video information. This alternative, however, while being highly robust, is labor-intensive and therefore quite expensive. It is not an option for systems which will record many hours of driving video. Since use of video is thus precluded, the alternatives lie with one or more of the sensors mentioned above.

All three of the sensor types have a set of problems associated with the emission and receipt of a signal. All are affected by temperature, humidity, and the possibility of ice or other contaminants on the transceiver. Ultrasonic devices (sonar, such as the one Polaroid cameras use) are extremely sensitive to temperature and humidity, and they require that the transceiver not be covered with ice, mud, or other environmental contaminants, or even with a "clear" lens to protect the transceiver. In addition, they are subject to a variety of noise-induced errors, such as spectral reflections and detection of spurious noises from the environment that fall within their sensitivity frequency. In addition, accuracy of the sonar units is somewhat restricted over the wide range of distances needed for this application. Finally, mud or ice covering the transceiver would effectively shut the device off.

\subsection{2 $\quad$ Laser Range Detectors}

Contact: $\quad$ TRW Electronic Systems Group, One Space Park, Redondo Beach, CA 90278.

Laser sensors provide a more accurate distance and presence detection over a wider range of distances than does sonar. However, laser sensors are also subject to the problems of mud and/or 
ice covering the beam and detector. In addition, lasers can have the potential of causing eye damage to humans and animals in their path. Even if the power levels of lasers for sensing headway are low enough to cause no harm, the public perception of the potential for such harm might argue against their use for DASCAR. The greatest problem with laser distance detectors, however, lies with their severe attenuation in the presence of rain and/or fog -- the very conditions under which one would want such detectors to function to warn drivers of impending collision. The chart and graph (published in October 1986) presented in Appendix I illustrate the problems with laser sensors as compared with Doppler radar. The upper chart (Frequency Band Letter Designations) identifies a variety of electronic signal bands which are used for various tasks. The second row, IEEE Radar Bands, shows the location in the electromagnetic spectrum of the Ku and $\mathrm{K}$ bands, in the 15.5 to about $26.5 \mathrm{GHz}$ range. These are the bands in which the VORAD Doppler radar system operates (see section 7.5.1.2.3). The lower graph (Attenuation by Fog, Rain, Gases Versus Wavelength) is the illustration of interest here, for this graph shows the electromagnetic spectrum from about $10 \mathrm{GHz}$ at the left through the visible light spectrum at the right, about 0.3 micrometers. It should be noted that infrared (IR) lasers (the eye-safe kind) operate in the range of about 1.0 to about 0.8 micrometers, just to the left of the visible light spectrum on this graph.

The various curves in this graph show the attenuation of a signal (in decibels/kilogram) for various types of atmospheric contaminants, such as rain and fog. Most noteworthy are the curves for Fog and for Heavy Rain, for they show the vital difference between radar signals in the $15-25$ $\mathrm{GHz}$ (or about one millimeter wavelength) range, compared with the IR laser signals in the 600 $800 \mathrm{GHz}$ ( 1.0 micrometer to 0.8 micrometer wavelength) range. Note that in fog, the attenuation of laser signals is something more than 100 decibels, whereas that for Doppler radar signals is between 0.01 and 0.1 decibels Compared to radar, this attenuation effectively renders laser sensors "blind." These problems, coupled with the problems of ice, snow, and mud covering the laser transceiver, argue quite strongly and convincingly in favor of radar over IR laser sensors.

\subsection{Doppler Radar System}

Contact: $\quad$ Donald O. Murphy, VORAD Safety Systems, Incorporated, 10802 Willow Court, San Diego, CA 92127, (619) 674-1450.

VORAD has a Doppler-effect radar system which is capable of providing a variety of types of information of relevance to this project. The heart of the system, as it is currently manufactured, is a $24.125 \mathrm{GHz}$ radar system. This system has been installed on all Greyhound buses, and provides the driver with indications of closing speed and distance to a vehicle ahead of the bus, as well as indicating the presence of a vehicle on the right side of the bus. At the present frequency, the front antenna is a 15 by 20 centimeter phased-array device which emits a pencil-thin beam to detect objects as much as 137 meters ahead of the bus. The right side proximity sensor is a five by eight centimeter wide-beam antenna which detects the presence of a vehicle in the lane beside the bus. The system also records the latest 15 minutes of driving activity, in a manner similar to a flight recorder on a commercial airliner. The system, as installed on Greyhound buses, records 
information on speed, closing rate with other vehicles, time of brake application, and steering movements.

The system, as installed on the buses, uses a rather large antenna on the front. This antenna, mounted on a VORAD company Lincoln, covered the center half of the grill. VORAD representatives indicated that they have some experimental experience with a 36-GHz system, which would significantly reduce the antenna size. Moreover, should the U.S. adopt the 60and/or 77-GHz frequencies for collision-avoidance radar, currently proposed for Europe and Japan, further reduction in antenna size would occur, since antenna size is inversely proportional to signal frequency. At the same time, component price is directly proportional to frequency, so the higher frequency units would cost more. Technical material and several articles on the VORAD system are provided in Appendix I.

\subsection{Lateral Position Lane Tracking}

Lateral-position lane tracking and detecting lane change present one of the major challenges for the DASCAR project. Since no sensors or signal sources will be used on roadways for this program, all information pertaining to this parameter must come from sensors within the vehicle. Existing lane tracking systems use video cameras to record the progress of the vehicle. As indicated in the previous section, processing this video information is quite costly, either in terms of human monitoring, or in terms of computer processing by machine-vision systems. Highest reliability is gained by using humans to monitor and score a videotape record of the driving session. However, this is a long, tiring, and tedious task, and would be quite expensive over the course of the research programs planned for this system.

Machine vision, or automated processing of digitized video signals, provides the alternative to human monitoring. While there is considerable research and application of computer vision for work in robotics and manufacturing, relatively little has been done for lane tracking. The typical machine vision system uses a digital camera (CCD -- charge-coupled device -- array camera, usually 512 by 512 elements, or pixels), whose output can be directly processed by computer. The output is processed pixel-by-pixel, which produces a data-driven, or "bottom-up", picture interpretation process (perception). As can be imagined, processing approximately 262,000 pixels requires a considerable amount of time and/or CPU power, as well as intelligence, to be able to classify each pixel into its proper relationship with its neighbors, and then interpret the emerging pixel collections. If images are to be processed at frame rate $(30 \mathrm{~Hz}$, the rate for "real-time" image processing), the requirement then is for CPU power.

The requirements for lateral-position lane tracking are much more specific than general machine vision -- lane tracking requires only that the system be able to "recognize" and track a sharp brightness gradient (e.g., white line on blacktop paving) in order to be able to measure the distance of the vehicle to the lane marker. Therefore, several lane-tracking systems have been designed which rely on specialized cameras to sharply reduce the number of pixels to be processed. These cameras use a 1 by 256 element array which scans across the lane markers or 
roadway edge as the vehicle moves parallel to them. At present, there is no off-the-shelf lane tracking system available. The ones described below could become available, given the right set of circumstances.

\subsection{Essex Corporation}

Contact: C. Dennis Wylie, 5775 Dawson Avenue, Goleta, CA 93117, (805) 964-0591.

The Essex system will be discussed only briefly because it is no longer available (the camera has gone out of production) and it was quite expensive. The camera was a line-scan camera, as discussed in the previous section, with an array of 256 photodiodes and electronic components to detect the position of the lane-marking lines. The camera could be electronically modified with a thresholding device which permits it to be adapted to different lighting conditions. The system required special headlights in the vehicle for nighttime operation.

This system used a large camera, which was conspicuous even when mounted on the outside of a tractor-trailer rig. Observation of data recorded from the Essex lane-tracking system showed that the data are highly erratic, and are difficult to interpret by themselves. In fact, it may be very difficult to make sense out of any lane-tracking data in the absence of other corroborating information to indicate what the driver and vehicle are doing during the recorded session.

\subsection{Williamson Associates}

Contact: $\quad$ Glen A. Williamson, 6613 Lynndale Drive, Raleigh, NC 27612, (919) 848-3618.

A system proposed by Williamson Associates is similar, in principle, to the Essex system just discussed. Several features, however, make the Williamson system appear better. One feature is the use of a camera with a 1 by $256 \mathrm{CCD}$ array, rather than the photodiodes used in the Essex system. CCD use improves sensitivity and resolution of the camera over the photodiodes. The camera is also considerably smaller than the one used in the Essex system. A second feature is the use of an IR source coupled with an IR lens. The system would operate at 830 nanometers. This feature would make the system insensitive to visible light conditions, including both ambient light level and the glare of oncoming headlights. The inclusion of an active IR source would also eliminate the need for thresholding operations, since the camera would be "tuned" to be most sensitive to the light emitted by the source. Examination of the Williamson schematics, and review of the system description, suggested that this system should work quite satisfactorily. Technical information on the Williamson Associates lane-tracking system is included in Appendix J.

\subsection{TNO Lane Tracker}

Contact: Hans Godthelp, Kampweg 5, P.O. Box 23, 3769 ZG Soesterberg, the Netherlands, +31346356211 . 
The TNO Institute for Human Factors IZF has built a lane-tracking device to accomplish the same goals as the previous two systems. Their system, which is roof-mounted, uses a mechanical optical scanner, similar to ones used in laser-range cameras, consisting of a fast rotating prism and a photo amplifier, to scan the light reflected from the roadway ahead of the vehicle. The prism angle at the peak luminance intensity (produced by the lane delineation) is used in calculating the lateral position of the vehicle relative to the lane. This system also requires special lights for nighttime operation, and might be subject to glare from oncoming headlights. ORNL received documentation indicating that the TNO Lane Tracker can be purchased from the designers. Documentation on this lane tracker is presented in Appendix $\mathrm{J}$.

\subsection{Netrologic, Incorporated}

Contact: James Johnson, 1150 Richfield Center, Beavercreek, OH, (513) 427-1908.

About six-years ago NHTSA awarded two small business innovative research (SBIR) contracts for the design of state-of-the-art tracking devices for motor-vehicle lane position monitoring and steering assistance. Netrologic was one of the two SBIR contractors. Their system uses a computer-vision system to detect lane marks and deduce the position of a vehicle in a lane. The lane-tracking system utilizes a neural network to automatically control brightness and contrast of the input images at a uniform level for subsequent processing. The system employs a linearregression method to generate candidate lane-boundary marks and then uses an expert system to reason about the geometry of the road-edge candidate lines relative to the vehicle to select the appropriate road-edge lines from the possibilities generated by the regression equation. A driving history module provides continuity in cases of missing and ambiguous data to supply information regarding lane-edge trends. A number of pages from Netrologic's final report are shown in Appendix $\mathbf{J}$.

\subsection{Aerometrics, Incorporated}

Contact: $\quad$ William D. Bachalo, 755 North Mary Avenue, Sunnyvale, CA 94086, (408) 7386688 .

The other company which had an SBIR contract with NHTSA was Aerometrics. They designed a laser-diode device that can scan the roadway on either side of the vehicle and determine the lateral position relative to the line marking the lane. A diode laser is used to generate a collimated-laser beam which is swept onto the roadway surface employing a multifaceted rotating mirror. The same mirror is employed to receive the reflection of the laser beam back from the roadway surface and direct it back to a photo-detector. A master clock is coupled to the mirror, and a count start is generated every time a scanning sweep begins. The signal coming from the photo-detector is employed to stop the clock count. A processor is coupled to the counter and uses the timing information to calculate the distance between the vehicle and the roadway line. The first few pages of Aerometrics' final report are exhibited in Appendix $\mathbf{J}$. 


\subsection{Other Units}

ORNL has observed two other lane tracking systems in operation. One was at GM, where the laboratory staff at the GM Technical Center designed and built several vision-processing boards to detect the lane marking stripes on roadways. The system was demonstrated on a sedan, where it was used to control steering to guide the vehicle along an unopened portion of a superhighway in the Detroit area. Because the system is proprietary, no details were available, and this system is not available. It does, however, represent a state-of-the-art application and development.

The second system was designed and installed in a vehicle at the University of Michigan's Transportation Research Institute (UMTRI). The UMTRI system is mounted in the left-hand side rear-view mirror, with only the last two centimeters or so of the camera protruding down and to the left of the vehicle. This system uses a standard CCD camera, and handles the lineidentification and vehicle tracking primarily in software. Details of this system are available, if they are desired, and the system could be purchased for this project. However, it appears that the Williamson system will be more state-of-the-art, and therefore more reliable.

\subsubsection{Distance and Time}

Distance and time measures are necessary for a variety of functions in the DASCAR program. They provide the mechanisms for such functions as time-stamping the data acquired and for locating critical incidents during the recording period, as well as for other derived data that might be required.

Distance refers to the linear distance the vehicle travels from the beginning of the session to its conclusion. These data can be acquired directly from the odometer using a takeoff gear, or from the onboard computer's data stream. Similarly, time refers to the elapsed time from the startup of the system until shutdown. The time data can be obtained from the system clock in the DASCAR data acquisition computer onboard the vehicle, or from a separate time-stamp board inserted into the computer's backplane (see information in Appendix $\mathrm{K}$ ). If the data are time-stamped, which is highly desirable, then time information is automatically taken care of.

\subsubsection{Engine and Drive Train}

Information on the engine/drive train is primarily centered on engine revolutions per minute and transmission gear selected. Availability of this information permits a variety of derived data to be obtained, such as road speed, engine efficiency, etc. Computer-based engine control units (ECU), presently installed on vehicles for efficiency and pollution control, provide a variety of measures in the data stream flowing into the ECU. This data stream has been successfully tapped for information by the team at UMTRI, without degrading vehicle performance. These data can be sent directly into a digital port on the DAP. 
Determination of suspension activity serves as an additional source of data in support of the data acquired from the six-DOF orientation sensor mounted on the vehicle chassis. Recording of suspension travel and rates completes the picture obtained about vehicle performance such as lean in a turn or pitch in acceleration or deceleration. These data can also provide information about the road surface over which the vehicle travels; moreover, they can provide information which will identify, for example, whether some wheels of the vehicle were off a paved surface while others were on. The kinds of data provided by these sensors are used in the so called "active suspensions" employed by a number of the formula I cars on the European road-racing circuit. The active-suspension systems provide nearly instantaneous feedback from suspension parts to a control computer which adjusts the suspension rates to keep the car essentially level under extreme acceleration, braking, and cornering conditions.

Sensors used for suspension monitoring must have several characteristics. They should be environmentally hardened, since the suspension parts are exposed to all types of weather and road contamination. Second, they should be capable of both sensitive measurements for small and rapid changes, and sensing the full suspension travel should the vehicle become airborne or fully compress the suspension. Full extension of the suspension can, at least, be expected whenever the vehicle is jacked up off the ground for service. Thus, the ruggedness and sensitivity range become important for these sensors. Two types of sensors were identified as potentially useful for these measurements.

\subsection{Linear Position Cable Extension Transducers}

Contact: Tom W. Peterson, UniMeasure, Incorporated, 7055 NW Grandview Drive, Corvallis, OR 97330, (503) 757-3158

Linear position cable extension transducers (string pots) are discussed in section 7.5.2.1.1.1. The technical data for these devices are presented in Appendix L. The two crucial issues for string pots used in suspension monitoring are extent of full-scale travel compared to the extent of actual travel during normal vehicle operation, and ease of mounting. Because these are electromechanical devices, their mounting and ruggedness become major concerns for DASCAR. The biggest problem for string pots in suspension travel is the normal travel versus full extension. If the string pot cannot move to accommodate full suspension travel, the "string" will break and no further data will be obtained. On the other hand, when an electronic sensor goes off scale, data are lost while the sensor is off-scale, but normal sensor functioning returns when what is being measured returns to within the sensor's operating range.

\subsection{GyroChip}

Contact: Gary W. Felsing, Systron Donner Inertial Division, 2700 Systron Drive, Concord, CA 94518-1399, (510) 671-6582. 
The GyroChip is a new, relatively low cost solid-state inertial sensor which responds to motion with an output which is proportional to the input angular velocity -- the velocity of a moving suspension part, in the case of this application for DASCAR. Because it has no mechanical moving parts, the GyroChip is more stable and resistant to wear than electromechanical devices. At the time of contact with Systron Donner, the price of this device had not been fixed, but was expected to be in the range of about $\$ 250.00$ for a single unit. As indicated in the previous section, this device is not subject to permanent loss of data due to over extension of suspension systems. Technical data and a brief article about the internal workings of the GyroChip are presented in Appendix L.

\subsection{Silicon Accelerometers}

Contact: $\quad$ Kurt Peterson, Lucas NovaSensor, 1055 Mission Court, Fremont, CA 94539, (510) 770-0645.

Silicon accelerometers also represent a new application of an existing technology, resulting from innovative manufacturing techniques. The device is a piezoresistive quad-beam device which is made possible by a novel micro-machining technology which has recently been perfected at Lucas NovaSensor. These sensors are targeted at ABSs, active suspensions, and air-bag systems in the automotive industry. They represent a different technology than the GyroChip, and may provide for greater ruggedness. The accelerometers are so new that, at the time of completion of this task, the price and availability had not been determined. Technical information on these silicon accelerometers is presented in Appendix $\mathrm{L}$.

\subsubsection{Wheel Rotation}

Wheel rotation data are available from one of two sources. One is the ABS which is becoming more and more standard on vehicles. Obtaining these data require accessing the data bus used in the vehicle for transmitting wheel rotation to the control system to prevent wheel lock up. As with data acquired from the vehicle ECU, access to these data must be done in a manner which does not inhibit normal functioning of the ABS. Again, as with the ECU, this appears to be a viable option.

The second manner to assess wheel rotation is by use of Hall-effect sensors. The Hall effect is the production of transverse voltages in a semiconductor or coil when inserted into a magnetic field. Commercial Hall-effect sensors cover a range of about 0.5 Gauss (G) to about 10,000 G. (The earth's magnetic field is about $0.5 \mathrm{G}$, whereas a strong permanent magnet produces a field of about 3 or $4,000 \mathrm{G}$ ). Good commercial Hall-effect sensors are made by Texas Instruments and Sprague, among others. These sensors come in a variety of packages, including TO-92 threeterminal plastic. They are presently used on the front wheels of drag racers to monitor vehicle speed. In this application, the permanent magnets are mounted on the wheel rims, and the sensor is fixed to the suspension piece to sense the passing of the magnets. This type of sensor is also 
used on after-market cruise controls, with the magnets mounted to the drive shaft. Material on Hall-effect sensors can be found in Horowitz and Hill (1989).

\subsubsection{Driver Parameters}

\subsubsection{Driver Control Actions}

Driver control actions derive from control actions which the driver takes to control the vehicle during the driving test period. They provide measures of general driver alertness and responsivity, and might also provide indirect indicators of driver alertness and tension.

\subsubsection{1 $\quad$ Steering}

Sensing of steering activity can be accomplished by a variety of means. Absolute or relative encoders can be placed at the steering wheel, with the moveable part on the wheel and the fixed part on the steering column. Such an arrangement was used on the GM van viewed in Detroit. However, this is a cumbersome and very noticeable installation. At least two other methods are more applicable to the DASCAR system. One is a rotary encoder placed somewhere in the steering system. This would sense rotary angles through which the steering apparatus is turned.

\subsection{Linear Position Cable Extension Transducer}

Contact: $\quad$ Tom W. Peterson, UniMeasure, Incorporated, 7055 NW Grandview Drive, Corvallis, OR 97330, (503) 757-3158.

The other alternative is to use a linear position cable extension transducer. This is a device with a spring-loaded potentiometer (a variable resistor) with a line attached. When the line is attached at the other end to a moving device, it is pulled out and retracted to reflect the travel of the device. ORNL observed two string pots on a tractor-trailer rig at the NHTSA test track in Ohio -- one was wrapped around the steering column itself, and the other was attached between the pitman arm and the frame. String pot technical information is included in Appendix L.

Steering data can be of importance in the development of base rate driving performance for a variety of drivers in a number of different kinds of vehicles and settings. However, such data are highly susceptible to noise from road vibrations and other sources. Moreover, use of such data by themselves for indicating lane change activity will be essentially useless for several reasons. First, steering corrections to account for wheel hop over road bumps will mask any steering inputs for all except the most abrupt lane changes. Second, lane changes can easily be affected by either more or less gradual steering while going around curves in the road. Third, lane changes can occur from uncorrected wheel hop in the appropriate direction. Thus, resulting in no apparent steering input associated with the lane change. It is possible that correlating steering input with some other means of establishing lane change (such as video data) would make steering input data useful, but redundant if lane change can be established by other means. Thus, the type of 
measurement of steering data and source (e.g., wheel or pitman arm) should be determined by the use to which the data are to be put. Data used for monitoring driver attention/input, etc., should be taken from the steering wheel, while data on (road) wheel turning, for path correction and/or lane change, should be taken from lower down in the steering apparatus.

\subsection{Accelerator/Throttle}

There are two sources for this parameter, one is the vehicle data bus and the other is from a sensor attached to the accelerator. The sensor for this parameter should be a string pot, as discussed in section 7.5.1.4.1 and Appendix L.

\subsection{Brake Pedal}

Brake pressure is an individual parameter which is based on physical strength and other physical attributes of the driver. Two sensor types are appropriate for measuring this parameter. One is a strain gauge applied directly to the brake pedal. This would provide data from which brake pressure could be calculated. A second method is to insert a pressure gauge in the brake hydraulic line, from which pressure could be directly obtained.

\subsection{Accelerator-Brake Time Interval}

This parameter can be calculated from data obtained from accelerator and brake pedal use. It represents a derived measure of driver-reaction time.

\subsubsection{Equipment Status}

This category of driver parameters covers a wide variety of driver/passenger compartment controls, most of which relate to driver/passenger comfort and/or entertainment. Three, however, correlate to vehicle operation and safety.

\subsubsection{1 $\quad$ Driver In}

"Driver in" is a binary parameter which indicates that the driver has entered the vehicle and sat in the driver's seat. A contact switch mounted under the seat will provide data on this parameter.

\subsubsection{2 $\underline{\text { Seat Belts }}$}

Data for this parameter can be obtained from the switch which controls the shut-off of the dash panel-warning light for seat belt use.

\subsection{Engine}

Data for the "engine on or off" parameter can be acquired from either of two sources. The 
vehicle data bus will provide indication of engine operation. Otherwise, a simple relay switch can be wired into the ignition switch to provide contact closure upon a key turn to start the engine.

\subsection{Other Equipment Status Parameters}

Various other possible equipment status parameters were listed in Table 2. Among these are turn signals, windows, windshield wipers, and radio/tape player/compact disk player. Sensors to monitor these parameters come from the same set of sensors described in the preceding sections, e.g., contact switches, strain gauges, etc. These sensors will be selected and installed as the parameters need to be monitored.

\subsubsection{Physiological Measures}

Recording of the driver-physiological parameters is the single most difficult aspect of the entire DASCAR sensor suite. Of all the spheres of measurement, driver characteristics must be the most unobtrusive since any reminders that the driver is actually serving as a subject might very well contaminate the data produced. Moreover, drivers, serving in the longer range over-the-road testing, will not want to tolerate the requirements to don and doff elaborate recording equipment every time they enter and exit the vehicle. Therefore, this domain is the single most sensitive area to obtrusiveness of measurement, or, to say it the other way, it is the single area that is least tolerant of obtrusive measures.

At the same time that these measurements must be especially unobtrusive, the area of biosensors is undergoing a considerable sensor upgrade. The problem is that these improvements are not making the sensors unobtrusive, only non-invasive. An example of the new and improved sensors is the UFI Corporation amplified contact electrode for electrocardiogram assessment (see the next section). From the medical point of view, these non-invasive sensors are a great improvement. However, from the standpoint of the DASCAR program, the need to attach electrodes, pressure transducers, and other contact sensors directly to the driver presents a real problem, especially for over-the-road research as opposed to test-track testing where the drivers may be employees of NHTSA and/or ORNL hired specifically to do test driving.

The Emergency Care Research Institute in Plymouth Meeting, PA was contacted in regards to vendors who have state-of-the-art physiological recording equipment. They identified three companies: Delmar Avionics ((800) 854-0481), Space Labs Medical ((408) 369-0222), and UFI ((805) 772-1203). Each was subsequently called and catalogues were ordered. Material from Space Labs Medical did not include any technical details, but it was clear that all their sensors are contact units. Nothing was received from Delmar Avionics except a publicity brochure, and their products do not appear to include non-contact sensing. Material from UFI is presented in the next section.

Marquette Electronics (Phillip Weinfurt, 8200 W. Tower Ave., Milwaukee, WI 53223, (800) 5585120) and Hewlett Packard Medical (Barry Willis, 350 Deer Creek Road, Building 26U, P.O. 
Box 10350, Palo Alto, CA 94303-0867, (415) 857-6014) were contacted and a series of lengthy discussions took place on the interest of both parties in generating unobtrusive physiological recording instrumentation. Both were initially quite interested; eventually, they both decided that given their current resources and the economy they could not at the present time pursue this type of R\&D. A letter from Marquette Electronics is displayed in Appendix M.

\subsection{Electronic Contact Sensors}

Contact: $\quad$ Marty Loughry, UFI Corporation, 545 Main Street, Morro Bay, CA 93442 , (805) 772-1203.

UFI manufactures a number of state-of-the-art biosensors, all of which require contact with the individual. A good example of one of their most up-to-date sensors is the FETRODE electronically amplified skin-contact electrode. The name apparently derives from the use of a field effect transistor (FET) in the very small amplifier which snaps onto the back of the electrode (RODE). This device eliminates skin preparation (either use of a liquid/paste couplant or scraping of the skin) to reduce the electrode-skin resistance. However, no matter how efficient any of these sensors is, there still remains the problem of wiring to connect the sensor to some kind of signal receiver/processor, whether this is a radio unit on the driver or an acquisition platform in the vehicle. Data on the FETRODE, as well as other UFI sensors, is presented in Appendix M.

\subsection{Current and Pending Research on Biosensors}

Several opportunities to develop non-contact biosensors presently exist. These opportunities arise from proposed $R \& D$ at ORNL or from a potential CRADA.

\subsection{Proposed ORNL R\&D}

Contact: $\quad$ Bernard E. Bernacki, Instrumentation and Controls Division, ORNL, P.O. Box 2008, Oak Ridge, TN 37831-6006, (423) 574-4730.

Bernacki, Hutchinson, and Simpson, of ORNL's Instrumentation and Controls Division, have proposed research on two types of unobtrusive sensing of respiratory and cardiac rates: passive and active. The decision was made not to pursue the following two options at the present time because of the perceived excessive costs associated with this R\&D.

\subsection{1 Passive Electrocardiogram and Respiration Measurement}

The team proposes to investigate methods of providing unobtrusive instruments which monitor changes in electrocardiogram and respiration and to construct these instruments. The proposal was made at the solicitation of the DASCAR project leader because current state-of-the-art technology cannot provide unobtrusive monitoring of these vital signs with off-the-shelf 
equipment. It is assumed that these measurements are not needed at the accuracy required by a physician, and that secondary or tertiary indicators of these vital signs might be exploited.

Passive respiratory monitoring can be accomplished using IR sensing methods. This approach detects exhaled carbon dioxide $\left(\mathrm{CO}_{2}\right)$ (which is related to respiratory rate and oxygen uptake) by exploiting the absorption of IR radiation by the $\mathrm{CO}_{2}$ molecules. Strong $\mathrm{CO}_{2}$ absorption bands occur at 4.3 micrometers and 16 micrometers which can be detected with broadband IR detectors combined with narrow-band optical filters to tune the detectors to these two wavelengths. There are some minor complications listed by Bernacki, Hutchinson, and Simpson, but they are relatively easily overcome for this type of passive IR monitoring system.

Passive electrocardiogram monitoring can be done using passive acoustic methods. This technique would use a removable seed pad/backrest instrumented with acoustic sensors to detect heartbeat or pulse. A major problem is detecting the sounds through variable layers of clothing. This might be overcome using sensor arrays and advanced signal processing. Other possibilities are to equip lap belts and/or shoulder belts with sensors, since these belts pass near major arteries and the heart, respectively. A shoulder belt sensor coupled with a sensing backrest would provide simultaneous sensing of the chest cavity from both front and rear, thereby providing a stronger signal.

\subsection{2 Active Electrocardiogram and Respiration Measurement}

Active respiratory monitoring can be performed by detecting secondary indications of respiratory activity -- water vapor. A near-field laser radar instrument can detect water vapor exhaled by the driver by illuminating the water droplets and measuring the degree of scattering that occurs due to the presence of such droplets. This type of laser radiation is eye-safe, since it is of low power, is pulsed, and illuminates the field-of-view diffusely.

Active electrocardiogram monitoring can be sensed by actively probing the body with microwave or acoustic probes. This technique would use a removable seed pad/backrest instrumented with acoustic or microwave transducers and/or receiving electronics to detect heartbeat or pulse. The need for the active probe to traverse several material interfaces (air, clothing, and skin) complicates the detection process, and dictates the wavelength of probe radiation needed to minimize spurious signals. As with the passive technique, a transducer could also be positioned on the shoulder belt to work in a differential configuration with the instrumented backrest to attain a better signal-to-noise ratio.

\subsection{Other Proposed R\&D}

Contact: Glen A. Williamson, Williamson Associates, 6613 Lynndale Drive, Raleigh, NC 27612, (919) 848-3618.

The R\&D work proposed by Williamson Associates uses Doppler radar to detect sound waves 
transmitted by the beating heart of the subject driver. In fact, this technique, which is used in a variety of weather detection and other applications, can detect any movement of the driver, and thus can serve to monitor breathing as well as the electrocardiogram. The Doppler-radar signal is an aggregate of all motions in a direct line with the incident and reflected microwave signal. Thus, orthogonal-motion vectors have little or no impact on the Doppler system. Such vectors might arise from vertical or sideways motion of the driver, as might arise from driving over a rough road, for example. The proposed strategy for extracting the three signals (breathing, heart rate, and other motions) is as follows. The return signal is first amplified and then passed through three selective bandpass filters which filter specifically for breathing rate $(.1 \mathrm{~Hz}$ to $1 \mathrm{~Hz}$, or between 10 and 60 inhalations per minute), for heart rate derivative (di/dt, filtered at about 6.5 $\mathrm{Hz}$ and $13 \mathrm{~Hz}$ ), and for direct heart rate (about $0.6 \mathrm{~Hz}$ to $3.3 \mathrm{~Hz}$ to cover 40 to 200 beats per minute). The system would also include detection and gating for excessive signal generation to eliminate interference due to external electronic artifacts and/or gross driver movements. The design of this system has been attentive to Environmental Protection Agency standards for exposure of critical body areas to microwave radiation. A block diagram of the proposed system is presented in Appendix $\mathbf{M}$.

\subsubsection{Environment Parameters}

Assessment of environment parameters involves the measurement of a subset of all possible parameters which describe the environment surrounding the vehicle as it travels its path. Table 2 exhibits 26 environmental items (some items include additional subparts) which were identified as being of potential interest to measure. In general, these parameters can be grouped into one of three categories: natural (e.g., weather conditions, time of day, and temperature), man made (e.g., road conditions and surfaces, and traffic conditions and events), and a combination of both (e.g., lighting, road gradient, and sound). Another way to characterize the parameters is by whether they are permanent (e.g., road surface and gradient) or changing (traffic conditions and lighting). The permanent parameters may be obtainable from archival records independently of when the vehicle travels the roadway, especially in the case of closed-circuit test tracks.

Many, if not all, of the visible characteristics (e.g., road surfaces and weather conditions) can be gathered from video tape recordings of the forward and aft scene cameras aboard the vehicle. This method of recording these data, however, appears to be quite costly, as these measures will require a human viewer to make the determinations. Certain features of the external environment, however, are not visible, and these are the parameters on which this section will focus.

\subsubsection{Wind Speed and Direction}

Wind speed and direction are difficult to assess, especially since direction and speed of the vehicle influence measures taken during vehicle motion. One sensor has been located which may serve the DASCAR purposes in this area. 


\subsection{Armtec Industries, Incorporated}

Contact: $\quad$ Andrew S. Walton, 3 French Drive, Manchester, NH 03103-7406, (603) 6690940 .

Armtec has developed an airflow measurement device which uses thermal resistive film to determine wind direction and speed. The sensor accomplishes this because air flowing past the device cools the upwind element faster than the downwind one, with wind speed calculated from the amount of current required to maintain even heading of the elements. This sensor is used in military combat vehicles to provide crosswind data to onboard gun fire control systems. Thus, the sensor system appears to have adequate accuracy, speed, and ruggedness. Technical data for the Armtec airflow sensor are presented in Appendix N.

\subsubsection{Non-Visible Weather Factors}

The non-visible weather parameters include humidity, temperature, and barometric pressure. They are measurable by means of remote probes, with outputs which can be integrated into the DASCAR platform.

\subsection{Vaisala, Incorporated}

Contact: Dick Gershaw, 100 Commerce Way, Woburn, MA 01801, (617) 933-4500.

Vaisala sensors provide relative humidity and temperature directly, and thus permit calculation of other parameters such as dewpoint, mixing ratio, and absolute humidity. Technical data on recommended Vaisala sensors are presented in Appendix N.

\subsubsection{3 $\quad \underline{\text { Road Surfaces }}$}

\subsection{Technische Hochschule, Institute for Ergonomics}

Contact: Walter Rohmert, Fachgebiet Fahrzeugtechnik, Petersenstrabe 30, D-6100 Darmstadt, Germany 06151/16-6573.

The Institute for Ergonomics at the Technische Hochschule in Darmstadt, Germany uses a sensor on its instrumented vehicles which measures road surface wetness and texture. This instrument was observed during a visit to the technical university by one of the highway-safety consultants. The sensor uses laser technology and is installed underneath the front left bumper of the vehicle. The device is a prototype produced by one of the industrial partners involved in the European DRIVE II program. ORNL has requested technical material on the sensor. Our request is currently under consideration; we are not sure however whether proprietary information on the prototype will be forthcoming. 


\subsubsection{Fixation/Eye Point of Regard}

Several systems are currently available in the open market to track, measure, and report eyegaze. These systems all share a common problem -- the fact that not only do the human's eyes move within their heads, but their heads move in addition. Head movement complicates eye-tracking both because of the extra DOFs added to the system and because head movement often takes the human's eye out of camera range, thus precluding any eyegaze assessment. Three solutions to the head movement problem exist. One is to place a head movement detector on the individual's head and feed output from this sensor to an eye-camera control. Such head movement sensors are usually magnetic field detectors. These systems are used in virtual reality computer systems, in which the user wears a variety of sensor-equipped clothing to feed control signals into a computer system. These devices are expensive, and they are hardly unobtrusive. A second solution is to mount a reflective device or small camera on the person's head which moves with the head. This solution effectively removes the DOFs associated with head movement from the eyegaze system. The third solution is to fix the subject's head in a chin rest, thus precluding head movement, and thereby permitting the eye to remain within the camera's field of view.

\subsection{Fixed-Head Eyegaze Assessment}

Contact: $\quad$ LC Technologies, Incorporated, 4415 Glenn Rose Street, Fairfax, VA 22032, (703) 425-7509

The LC Technologies eyegaze system was originally designed to provide computer input for quadriplegic and other disabled individuals who have limited use of hands and arms. Research has been done at ORNL to try to use eyegaze not only for control, but also as a means to infer cognitive activity in participants performing various tasks. The LC Technologies system works well, as long as the individual's head is rigidly fixed in a single position by use of a chin rest. This system uses the pupil-center/corneal-reflection method to determine eyegaze location. Using this information, the LC Technologies system can provide control over whatever function is selected by the area of the screen being fixated. One example is the use of this system to provide an eyegaze keyboard for typing into a computer. Information on the LC Technologies system is presented in Appendix N.

\subsection{Head-Mounted Eye-Tracker}

Contact: $\quad$ Rikki Razdan, ISCAN Incorporated, 125 Cambridgepark Drive, P.O. Box 2076, Cambridge, MA 02238, (617) 868-5353.

ISCAN systems are primarily oriented toward military applications, as indicated by the names of their two systems: EVIL EYE Eye Slaved Target Acquisition System and HEADHUNTER Head and Eye Slaved Pointing System. These systems use a helmet-mounted system consisting of eyetracking and head-monitoring equipment, coupled with data acquisition and tabulation equipment. 
The price range for ISCAN systems is between $\$ 30,000$ and $\$ 60,000$. Information on ISCAN systems is presented in Appendix $\mathrm{N}$.

\subsection{Eye Point of Regard Assessment}

As the discussion in the previous paragraphs indicates, there are presently no eye-tracking systems which perform their task without attaching something to the human's head. An alternative approach, which has been demonstrated at the NHTSA test facility in Ohio, is to assess eye point of regard. Eye point of regard refers to the general area of the environment at which the participant is looking, rather than the specific item. Thus, one can assess whether a driver is looking out the windshield, down at the dash board, or out at the side rear-view mirror. This assessment must be made from video tape recording of the driver's head during the driving session. At present, such assessment must by done by human observation. It might be possible to develop an automated computer-based eye point of regard system, although no investigation of this possibility has been made.

\subsection{Video Digitization}

\subsubsection{Scientific Atlanta}

Contact: $\quad$ Larry Grunewald, Digital Video Compression Division, 4357 J Park Drive, Norcross, GA 30093, (404) 903-5250.

In June 1993 Scientific Atlanta marketed a moving picture experts group (MPEG) CVDSRS. The CVDSRS digitally compresses analog video and audio source material in real time through an MPEG encoder. This process includes converting the signals and storing them as a computer data file. A record board, which is located within the PC that is interfaced to the encoder, formats the MPEG compressed video and audio from the encoder into a single bit stream suitable for direct storage on a hard drive disk, digital tape, optical disk, or any other digital storage device. The record board interfaces with a digital storage device via high-speed SCSI-two technologies to provide real-time digital capture of the compressed material. The data file is passed to either a local video server or a PC uplink board for distribution over a satellite. Compressed data files can be transported via dial-up modulators-demodulators (modems), TI links, fiber or microwave circuits, or satellite. One or more PC decoders are installed in the PC where they receive the compressed video data files in either real time or from a digital storage device. The decoders convert the digital data stream back into National Television Systems Committee video and stereo audio components for transmission through the analog cable plant or for display on a television or monitor. Technical data on the Scientific Atlanta CVDSRS are presented in Appendix O.

\subsection{Recommendations}

Specific recommendations are difficult to make, especially in the area of sensors to be applied to the vehicle and driver, without a specification of the critical parameters to be measured and/or 
knowledge of the specific questions to be answered by the research for which DASCAR will be used. These same difficulties apply to the specification of statistical procedures to be used for data analysis. Nevertheless, a number of recommendations, both general and specific, can be made.

In general, especially with the great increase in manufacturing techniques for solid state devices, the recommendation is to opt for solid-state devices instead of electromechanical ones wherever possible. This stems from four factors. First, solid-state devices tend to be more accurate and less expensive. Second, there is virtually no "warm up" or spin-up time for solid-state devices as compared with electromechanical ones. Third, electromechanical systems are subject to both drift and to long-term wear, both of which effect the quality of the data obtained. Fourth, electromechanical systems can break from out-of-range movements.

In the sections which follow, recommendations and supporting reasons will be presented wherever possible. (Since these recommendations were derived in late 1993, some of them have been superseded by suggestions in later sections of this report.) The paragraphs correspond to the sections above which present information about the items discussed.

\subsubsection{Power Supply}

The recommendation is to use Vicor switching-power supplies. The reason is that ORNL has extensive experience with these devices on mobile robotic platforms, and they have performed quite well.

\subsubsection{DAP}

There are so many vendors marketing data loggers that it is impossible to cover the entire field. The ones presented in this report are those which appear to be the most reliable and with the most fielded experience. Several of the data platforms are designed for applications other than road vehicles (such as aircraft, helicopters, or ships). These systems would probably need to be adapted to the DASCAR program. One such system is that offered by Scientific Atlanta, Signal Processing Systems. This system was designed for use in tracking and balancing helicopter main rotor blades, and thus has a proven track record of withstanding vibration and extreme environmental conditions. Moreover, Scientific Atlanta is serious about adapting this system to the specific needs of DASCAR, and to that end, they are negotiating a CRADA with ORNL. Thus, the recommendation is to use Scientific Atlanta's data acquisition system. In addition, as will be detailed below, other divisions of Scientific Atlanta produce components which are needed for DASCAR, and using a number of major components from the same vendor assures that the system can be well integrated and that the components will work well together.

\subsubsection{Data Storage and Communications Link}

\subsubsection{1 $\quad$ Radio Telemetry}


As with the DAP, Scientific Atlanta is providing systems engineering in this area, and has chosen a telemetry system by Proxim which will integrate seamlessly with their platform.

\subsubsection{Satellite Transmission}

Only two vendors were found who provide a satellite transmission system for road vehicles. Scientific Atlanta has experience with the TravTek program in Orlando, FL and can provide a satellite system which is integrated with their DAP.

\subsubsection{Sensor Suite}

\subsubsection{Vehicle Orientation}

In this area, the principle of preferring solid state to electromechanical devices argues for the Systron Donner sensors. Systron Donner has a history of providing reliable sensors, and they are continually developing new ones.

\subsubsection{Direction Sensing}

No recommendations can be made in regards to direction sensing systems without further investigation of available products. This investigation can be done quickly and quite early in phase II of the project.

\subsubsection{Headway/Tailway}

Only one viable and available system was located, that by VORAD.

\subsubsection{Lateral Position Lane Tracking System}

Only one lane tracker is presently available for purchase, that developed by TNO, and it is quite expensive. There are, however, two proposed systems (Williamson Associates and Aerometrics), either of which appears to be workable. Choice of a lateral-position lane tracking system will have to await further development by these two companies.

\subsubsection{Suspension/Steering Sensors}

Again, the choice of solid state over electromechanical applies for suspension and steering sensors, except for the use of the string pot. These devices appear to work quite well, as evidenced by the data being collected on the tractor-trailer at the NHTSA test track in Ohio. Choices from among the variety of different types of sensors and vendors will be made at the time of purchase, with the choice being determined by a combination of electronic characteristics, data integrity, price, and availability. 


\subsubsection{Biosensors}

No recommendations can be made about biosensors at the present time because of the lack of unobtrusive sensing techniques.

\subsubsection{Environmental Sensors}

Choices of the environmental sensors will be made at time of acquisition, as with the steering and suspension sensors, since more information is needed about exactly which parameters will be measured.

\subsubsection{Video Digitization}

Video digitization and compression provides for required reduction in the volume of data to be stored and/or transmitted to a base station. Scientific Atlanta has just completed R\&D on such a system, which can be easily integrated with their DAP and data transmission technologies.

\section{DESIGN REQUIREMENTS AND SPECIFICATIONS FOR A PORTABLE DASCAR}

The objectives of the "develop design requirements and specifications for a portable driver performance data acquisition system" task were to examine a variety of alternative approaches to meeting the technical approaches of the project, and to develop a set of recommended design requirements and specifications for the construction of the driver-performance data acquisition system. The DASCAR design was to be based on sound technical judgement using proven technologies. Particular attention was to be paid to system cost, data integrity, maintainability, security, user friendliness, and flexibility that will allow future upgrading of the system (to accommodate new vehicles and/or new technology).

\subsection{Alternative Approaches to Meeting the Technical Objectives}

\subsubsection{DAPs}

The DAP will capture and process signals from the various sensors installed within and around the vehicle. Five DAPs were considered for DASCAR. They include platforms designed by Dianachart, OPTIM Electronics, Schlumberger Technologies, Scientific Atlanta, and Smiths Industries. (Each of these DAPs was briefly discussed in section 7.3.2; material on the five platforms is presented in Appendix D.) ORNL's recommendation in late 1993 was (and it still is in early 1994 when this task was completed) to use the Scientific Atlanta DAP.

\subsubsection{Data Storage and Communications Systems}

The DASCAR data storage and communications system will comprise four components: radio 
telemetry, satellite-transmission equipment, a PC, and a laptop computer. These systems will be used to receive, assemble, transmit, store, integrate, analyze, evaluate, and interpret the parameter data collected via the DASCAR sensor suite.

Two radio telemetry (Scientific Atlanta and Proxim) and two satellite-transmission (QualComm and Scientific Atlanta) systems were examined for incorporation within the data-acquisition system. These systems were described in sections 7.4.2 and 7.4.3, respectively; literature on the radio telemetry and satellite-transmission technology is exhibited in Appendices E and F. ORNL's recommendation at that time was (it has not changed) that the Proxim radio telemetry and the Scientific Atlanta satellite-transmission systems be utilized with DASCAR.

The PC will be installed within a CDC/AF which will be assembled to manage all of the DASCAR sensor and video data. It will consist of the needed hardware and software to assemble and store the digital data received via credit card memory or SCSI from the laptop computer installed within the vehicle. The PC will also handle digital data transmitted via radio telemetry or satellitetransmission equipment. It will be Intel 80486 based and comprise both hard and floppy disk drives, a color video monitor, and two operator input devices (i.e., keyboard and mouse). The PC will have enough memory to integrate, analyze, evaluate, and interpret the parameter data collected via the DASCAR sensor suite.

Four 486-DX2, 66-MHz PCs were evaluated for the CDC/AF. They include computers made by IBM, Northgate, System-DFI, and Austin. Documentation on the four PCs can be found in Appendix P. Based upon both computing power and cost, ORNL recommends that the PC sold by Austin Computer Corporation be purchased for the DASCAR CDC/AF.

The laptop computer will be mounted inside the vehicle and contain the hardware and software necessary to receive, assemble, and temporarily store digital data transmitted from the DAP. It will be Intel 80486 based and include both a floppy and a hard disk drive, a monochromatic video monitor, and two operator input devices (i.e., keyboard and track ball). The laptop computer will have sufficient memory to integrate the parameter data collected via the DASCAR sensor suite.

Four 486-DX2 laptops were assessed for incorporation within DASCAR. They include computers built by IBM, Northgate, Ultra, and Austin. Material on the four laptop computers is exhibited in Appendix P. Based upon both computing power and cost, ORNL recommends that the laptop marketed by Austin Computer be procured for DASCAR.

All three methods of storing and transmitting the DASCAR collected data (i.e., onboard via a laptop computer, radio telemetry, and satellite transmission) are technically feasible. Recording data with the laptop computer is the cheapest way (but it does have limited storage capacity), followed by radio telemetry and satellite transmission. NHTSA, with ORNL's assistance, should determine whether one, two, or all three methods should be part of the data acquisition system. 


\subsubsection{Power Systems}

The DASCAR power system will consist of two components, batteries and a switching-power supply. Table 9 presents the power consumption of the data acquisition system. These requirements were used to direct the power system component assessment.

Two types of gel-cell storage batteries were considered for DASCAR. They include batteries supplied by Power Sonic and Gates Energy Products. Batteries were briefly covered in section 7.2.2.2; information on the two vendors is shown in Appendix $Q$. Based upon ORNL's experience with batteries on other projects, it is recommended that batteries developed by Gates be used with the data acquisition system.

Two power supplies were investigated for inclusion within DASCAR. They are power supplies designed by Powercube and Vicor. Power supplies were addressed in section 7.2.2.3; material on the Powercube and Vicor power supplies is furnished in Appendix C. ORNL recommended then and now that Vicor be selected as the power supply vendor because their units provide the necessary flexibility for both the voltages and power output required by the data acquisition system.

\subsubsection{Sensor Suite}

The prototype DASCAR sensor suite will comprise transducers, systems, devices, sensors, and meters to gather parameter data from the driver, vehicle, and environment. The suite will include: a linear position transducer, pedal force transducers, an accelerometer, an ADRS, a six-DOF orientation sensor, a Hall effect sensor, an electronic compass, range sensors, radiometers/photometers, a sound level meter, a meteorological sensor, and a lateral position lane tracking system.

The linear position transducer will be employed to collect accelerator/throttle and steering wheel data from the vehicle. Only one source (UniMeasure) of this type of transducer was identified during ORNL's review of state-of-the-art hardware. The transducer was discussed in sections 7.5.1.4.1 and 7.5.2.1.1.1; information on UniMeasure is presented in Appendix $L$. More detailed documentation from UniMeasure is shown in Appendix R.

The pedal force transducers will be utilized to record brake pedal application force. ORNL has identified two vendors (Sensors Development, Incorporated and GSE Incorporated) who produce this type of sensor. Literature from the vendors is exhibited in Appendix R. Based upon a review of the transducer assemblies and construction, it was decided that the ones designed by GSE will better suit the DASCAR technical objectives.

The accelerometer, mounted under the driver's seat, will be used to collect fidget index data from the vehicle driver. In sections 7.5.1.4.2 and 7.5.1.4.3 two vendors (Systron Donner and Lucas NovaSensor) with state-of-the-art accelerometers and their sensors were described; more 
Worst Case Power Consumption (2/17/94)

\begin{tabular}{|c|c|c|c|}
\hline Product & Current & Voltage & Power(W) $=v \cdot 1$ \\
\hline Meteorological Sensor & & $28 \mathrm{~V}$ & 1.0 \\
\hline Data Acquisition Plattorm & & $\pm 5 \pm 12 \pm 15 \mathrm{~V}$ & 30.0 \\
\hline 4860X2-66 Lap Top & $3.5 / 2.3 \mathrm{~A}$ & $6 \mathrm{~V} / 11 \mathrm{~V}$ & 30.0 \\
\hline Radio Telemetry Tx & $350 \mathrm{~mA}$ & $9.5 \vee \max$ & 3.4 \\
\hline Satellite Tx & & $10.5-32 \mathrm{~V}$ & 80.0 \\
\hline Video Digitizer \& Compression & & AC 98 to 240 & \\
\hline 6 Degree of Freedom Sensor & & \pm 12.8 to $\pm 18 \vee(15 V$ & 3.3 \\
\hline Laser Lane Tracker & & $12 \mathrm{~V}$ & 30.0 \\
\hline CCD Lane Tracker & & $12 \mathrm{~V}$ & 20.0 \\
\hline Micro-camera & $500 \mathrm{~mA}$ & $12 \mathrm{~V}$ & 6.0 \\
\hline VITC Generator & $250 \mathrm{~mA}$ & $12 \mathrm{~V}$ & 3.0 \\
\hline DC SVHS Recorder & & $12 \mathrm{~V}$ & 19.0 \\
\hline Quad-Picture Processor & & $12 \mathrm{~V}$ & 10.0 \\
\hline Electronic Compass & $40 \mathrm{~mA}$ & $12 \mathrm{~V}$ & 0.5 \\
\hline Linear position transducer & & $25 V$ (max) & 1.0 \\
\hline Pedal Force transducer & $34.3 \mathrm{~mA}$ & $10 \mathrm{~V}(\max )$ & 0.5 \\
\hline Accelerometer & & 8 to $12 \mathrm{~V}$ & 0.7 \\
\hline Hall Effect Sonsor & & $\pm 5 \mathrm{~V}$ & 0.5 \\
\hline Ambulatory Data Rec. System & $5 \mathrm{~mA}$ & $8 \mathrm{~V}$ & 0.1 \\
\hline Doppler Radar Seneor & & $121024 \mathrm{~V}$ & 20.0 \\
\hline Laser Sensor & & 11 to $18 \mathrm{~V}$ & 10.0 \\
\hline Padiometer/Photometer & $26 \mathrm{~mA}$ & $6 \mathrm{~V}$ (up to $24 \mathrm{~V})$ & 0.2 \\
\hline Sound Level Meter & $20 \mathrm{~mA}$ (max) & $\pm 9 V$ & 0.2 \\
\hline Controlaser & & $12 \mathrm{~V}$ & 5.0 \\
\hline
\end{tabular}


elaborate information is also furnished in Appendix L. Since the Lucas NovaSensor accelerometer is still not available on the open market, ORNL recommends that we go with Systron Donner's version for the DASCAR prototype.

ADRS will be employed to collect core temperature, electrocardiogram, electroencephalogram, electromyogram, electrooculogram, galvanic skin response, respiration, and skin temperature data from the driver. ORNL evaluated a number (i.e., Delmar Avionics, Space Labs Medical, and UFI) of physiological measurement equipment producers. They were identified in section 7.5.2.3. UFI's technology using electronic contact sensors was briefly covered in section 7.5.2.3.1; some literature is exhibited in Appendix M. As a result of an evaluation of state-of-the-art technology, it was determined that UFI's is best suited to the DASCAR technical objectives. Appendix $R$ presents more technical documentation which has been received by ORNL since the, identify measurement techniques and state-of-the art hardware and software to support development of an in-vehicle data acquisition system, task was completed.

The six-DOF orientation sensor will be utilized to record acceleration (lateral, longitudinal, and vertical), pitch, roll, and yaw data from the vehicle and road gradient data in the environment. A number of solid-state, gyroscopic-based sensors were considered for DASCAR. Two were described in sections 7.5.1.1.1.1 (Systron Donner) and 7.5.1.1.1.2 (GRA-MAR); documentation is also presented in Appendix G. It was ORNL's recommendation in late 1993 that the electromechanical type of gyroscope produced by GRA-MAR not be used with DASCAR. Since ORNL has not identified a better six-DOF orientation sensor than that produced by Systron Donner, we recommend that their sensor become part of the data acquisition system.

The Hall-effect sensor will be used to collect distance traveled and velocity data from the vehicle. Section 7.5.1.5 discussed this kind of sensor. When the "identify measurement techniques and state-of-the-art hardware and software to support development of an in-vehicle data acquisition system" task was completed, ORNL had identified two sources (Texas Instruments and Sprague) of Hall-effort sensors. Since that time we have come across two other vendors (American Electronic Components, Incorporated and Pro Sports Engineering) who manufacture a Hall-effect sensor. Material from American Electronic Components is presented in Appendix $R$. Since the Hall effect sensor is a relatively simple device, ORNL recommends, based strictly on cost, that the one designed by Pro Sports Engineering be purchased for inclusion within the data acquisition system.

The electronic compass will be employed to record heading data from the vehicle. Two compasses (Precision Navigation and Lucas Schaevitz) were covered in sections 7.5.1.1.1.3 and 7.5.1.1.1.4; additional documentation is shown in Appendix H. Since late 1993 ORNL has identified and utilized another electronic compass, designed by KVH Industries, Incorporated, on another project. Literature on the compass is furnished in Appendix R. Based upon experience with the electronic compass developed by KVH Industries, ORNL recommends that it be included in the DASCAR package. 
The range sensors will be used to collect headway and tailway data from the vehicle. Two types of range sensors (laser and Doppler radar) were described in section 7.5.1.1.2. Section 7.5.1.1.2.3 discussed the Doppler radar system developed by VORAD; Appendix I presents more specific information on the sensor. Since the "identify measurement techniques and state-of-theart hardware and software to support development of an in-vehicle data acquisition system" task was completed, ORNL has identified two companies (Riegl and Silicon Heights, Limited) which produce and sell laser-based range sensors. Literature on laser products manufactured by Riegl and Silicon Heights is exhibited in Appendix $\mathbf{R}$.

As stated in section 7.5.1.1.2.1, both methods of collecting headway and tailway data have a set of technical problems associated with them in regards to emission and receipt of a signal. Costwise the two laser-based range sensors run the gamut of extremes; Riegl's are expensive, Silicon Heights' is relatively cheap. VORAD's Doppler-radar system is in the middle of the other two. NHTSA, with ORNL's assistance, should determine which type of sensor, and, if it is the laser technology, which vendor should be selected for the data acquisition system. There is the possibility that one might want to have both kinds of range sensors as part of DASCAR to take advantage of the strengths of each and compensate for the weaknesses of the other.

The radiometers/photometers will be employed to record illumination and lumination data from the environment outside the vehicle. Two sources (Bruel and Kjaer Instruments, Incorporated and International Light, Incorporated) who have state-of-the-art devices were identified during ORNL's review of hardware. Documentation from the vendors can be found in Appendix $R$. Based upon size and obtrusiveness, ORNL recommends that International Light's device be incorporated within the data acquisition system.

The sound level meter will be utilized to collect steady state sound and impulse noise as heard by the driver inside the vehicle. ORNL has identified three companies (Larson Davis, Bruel and Kjaer, and Quest Electronics) who produce top quality sound level meters. Information from the manufacturers is shown in Appendix R. After examining the documentation, ORNL has determined that the sound level meters produced by Quest meet the technical objectives of DASCAR at the lowest cost.

The meteorological sensor will be used to record wind direction and speed data in the environment outside the vehicle. In section.7.5.3.1.1, a vendor (Armtec Industries) and their meteorological sensor were described; material is also exhibited in Appendix N. Other information on Armtec, received since late 1993, is shown in Appendix R. ORNL has recently identified another source (Larson Davis) who produces meteorological instrumentation. Documentation from Larson Davis is also furnished in Appendix R. Based upon size and obtrusiveness, it is ORNL's recommendation that the Armtec meteorological sensor become part of the data acquisition system.

The lateral-position lane tracking system will be employed to collect lane keeping data from the vehicle. ORNL has determined that there is currently only one system (that developed by TNO) 
available off-the-shelf; it is however quite expensive. A number of other potential lane tracking systems (e.g., Essex, Williamson Associates, Netrologic, and Aerometrics) were covered in section 7.5.1.1.3; material is presented in Appendix J. ORNL recommends that NHTSA fund either Aerometrics or Williamson Associates or both to develop their concepts further. It might be possible to have a CRADA with Aerometrics. In recent discussions with them, they seemed quite interested in that option.

ORNL has identified one system which measures luminance contrast. The device, sold by Bruel and Kjaer, evaluates lighting quality and the effects of veiling reflections off display screens and paper in offices or classrooms. It does not, however, appear to be appropriate for recording contrast data from the environment outside the vehicle. Literature on Bruel and Kjaer's luminance contrast meter is exhibited in Appendix $\mathbf{R}$.

\subsubsection{Video Data Systems}

In early 1994 a fifth major element was added to DASCAR. It consists of a video data system. The component will comprise micro cameras, a VITC generator, a digital quad picture processor, the CVDSRS, and a super-VHS recorder. A schematic of the video data system is shown in Figure 6.

The micro cameras will be utilized to record video data inside the vehicle and in the outside environment. They will consist of camera heads, lenses, control units, and cables. Both color and black-and-white video micro cameras are available in the marketplace. ORNL has identified two vendors (Cohu, Incorporated, and Panasonic Broadcast and Television Systems Company) who manufacture micro cameras. Literature from the suppliers is furnished in Appendix S. Based upon a review of the technical specifications from the two vendors, it was determined that the Panasonic micro cameras will better suit the DASCAR objectives. NHTSA, in consultation with ORNL should decide whether black-and-white, color, or both types of cameras should be purchased for the data acquisition system.

The VITC generator will be used to time code the video output from the micro cameras and to provide video data synchronization with the sensor data. Three developers (Skotel, American Video Equipment, and Horita) of the generator were identified during ORNL's investigation of video data system components. Material from the vendors can be found in Appendix S. Based strictly upon cost, ORNL recommends that the VITC generator supplied by Horita become part of DASCAR.

The digital quad picture processor will be employed to display, tape record, and transmit images from four video micro cameras at one time. ORNL identified two manufacturers (American Video Equipment and Robot Research, Incorporated) of this kind of processor. Documentation from the vendors is furnished in Appendix S. Based upon an evaluation of technical specifications, ORNL recommends that the Robot Research digital quad picture processor be incorporated within the data acquisition system. 


\section{Micro-CCD Video System}

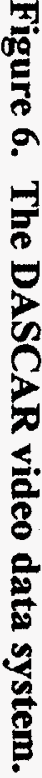

(Digital and Analog Time Stamped Recordings)

Remote Camera Head IIIIDOD

$7.5 \mathrm{~mm}$ Lens assembly

$2 \mathrm{~m}$ Cable assembly

Remote Camera Head

DIIDOD

$7.5 \mathrm{~mm}$ Lens assembly

$2 \mathrm{~m}$ Cable assembly
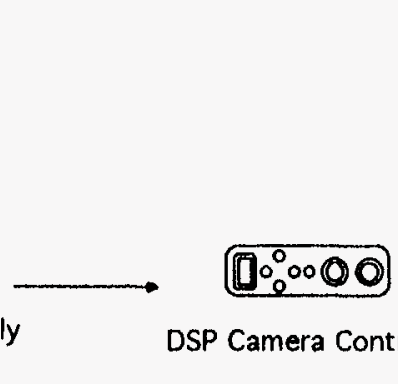

DSP Camera Control Unit

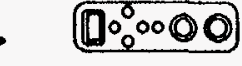

DSP Camera Control Unit

Remote Camera Head DIIIDOD

$7.5 \mathrm{~mm}$ Lens assembly $2 \mathrm{~m}$ Cable assembly
0000000

Quad Digital Color Picture Processor

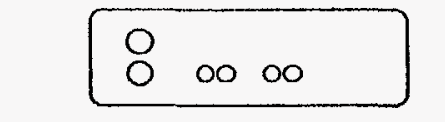

S-VHS Portable DC Recorder

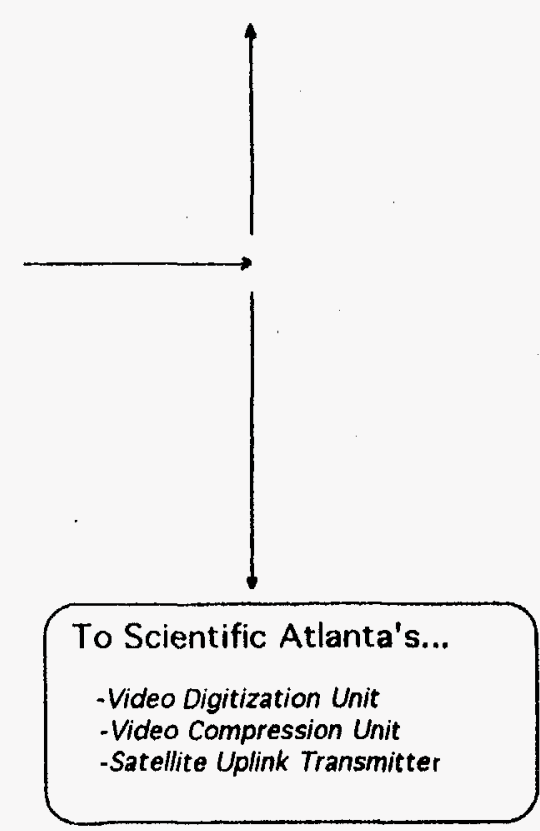

ISB; $2 / 3 / 94$ 
The CVDSRS will be utilized to handle video from the micro cameras installed within and around the vehicle. It will digitize and compress analog video material in real time. Scientific Atlanta's system was discussed in section 7.6.1; documentation on the CVDSRS can be found in Appendix O.

The super-VHS recorder will be used to collect video from the micro cameras installed within and around the vehicle. During ORNL's examination of state-of-the-art technology, only one recorder (designed by JVC Professional Products Company) was identified which has a 12-V DC input. Information on the super-VHS recorder is furnished in Appendix $\mathbf{S}$.

The DASCAR video data can be compressed and stored either digitally via the CVDSRS, or in an analog format and analyzed through use of the super-VHS recorder. NHTSA should determine which method should become part of DASCAR. It is ORNL's recommendation, since we are receiving the CVDSRS at no expense to the project via a CRADA with Scientific Atlanta, that both systems be incorporated within the data acquisition system prototype.

\subsection{Design Requirements and Specifications for the Construction of DASCAR}

ORNL's current thinking on the design and configuration of the data acquisition system is shown in Figure 7. The drawing exhibits the major DASCAR hardware components and the sensor suite, along with their relative placement within a vehicle. Table 10 presents the recommended source for each product and lists the point of contact and phone number for each company.

Design specifications were assembled for each DASCAR element, except for the lateral-position lane tracking systems (because they are development efforts). The specifications were prepared in sufficient detail to allow a third party to use them to design, develop, procure, and subsequently construct the data acquisition system. The design specifications were generated using MIL-STD490 (Department of Defense, 1968) as a guideline. Specifications are presented in Volume three by category (i.e., DAP, data storage and communications systems, power systems, sensor suite, and video data systems).

\section{COST OF ONE OR MORE COPIES OF THE PROPOSED DASCAR}

The objective of the "determine the cost of one or more copies of the proposed data acquisition system" task was to prepare cost estimates for the purchase, development, and fabrication of the prototype DASCAR and for the construction of additional systems. (For the purpose of these estimates, ORNL assumed that fifteen additional vehicle units and one additional CDC/AF will be constructed.) The estimates were to include all costs associated with the: purchase/development of hardware; purchase/development of software; systems engineering; installation and calibration of units; maintenance and operation; and training on installation and use of the system. 


\section{Data Acquisition System For Crash Avoidance Research}

18.

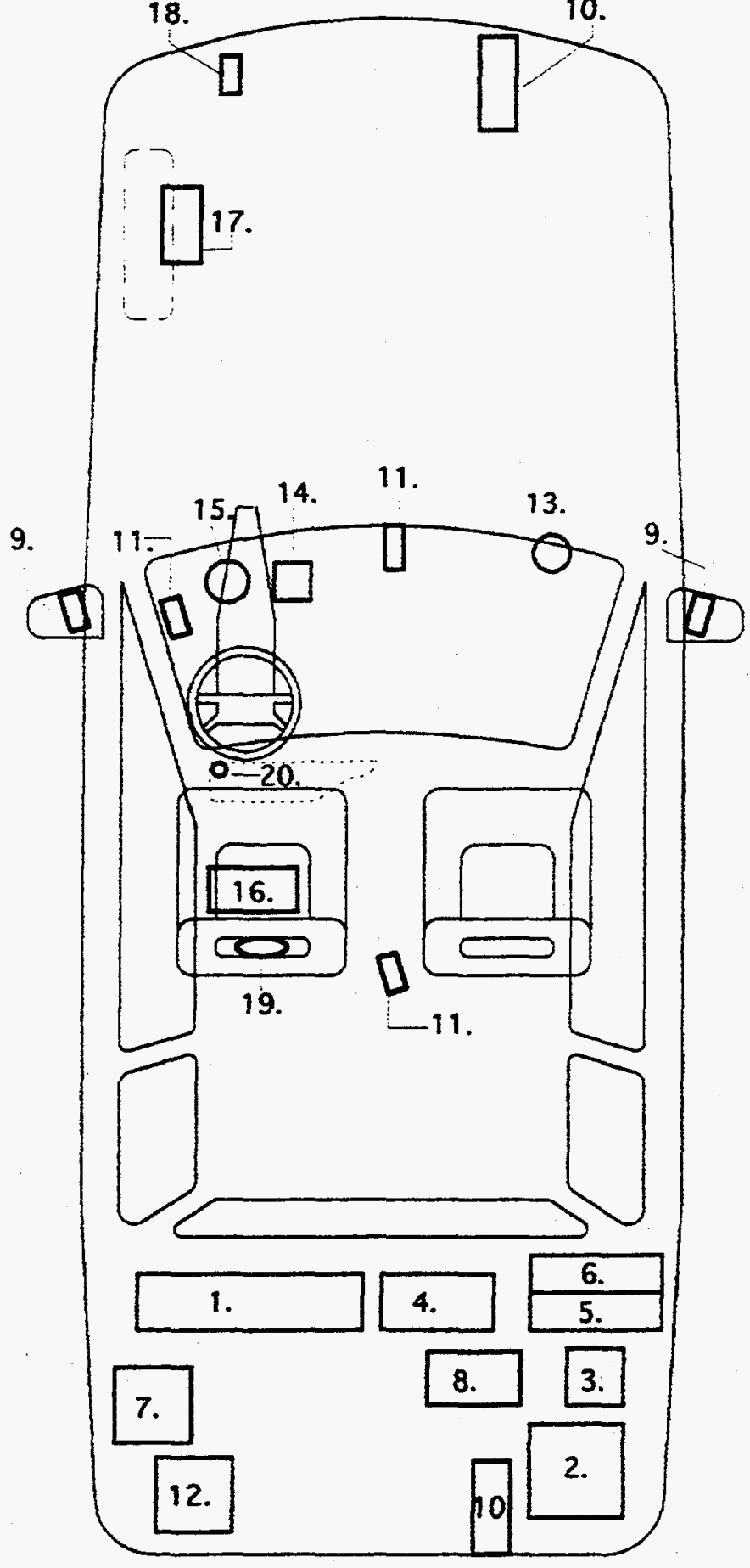

\section{Major Hardware Components}

1. Data Acquisition Platform

2. DC-DC Power Supply $(15 \mathrm{~V} ; 12 \mathrm{~V} ; 5 \mathrm{~V})$

3. $12 \mathrm{~V}$ Battery System

4. $4860 \times 2-66 \mathrm{MHz}$ Lap-Top Computer

5. Radio Telemetry Tx

6. Satellite Uplink $T x$

7. Video Digitizer \& Compression System

\section{Sensor Suite}

8. Six-Degree of Freedom Sensor

9. Lane Tracking Unit

10. Headway / Tailway Measuring Device

11. Micro CCD Video Camera \{3\}

12. VITC; SVHS; Quad Picture Processor

13. Electronic Compass

14. Linear Position Transducers (string pots)

15. Pedal Force Transducer (load cell)

16. Accelerometer

17. Hall Effect Sensor

18. Meteorological Sensor

19. Sound Level Meter

20. Photometer / Radiometer

- Various Activation Switches \& Contacts

"*arious Sensors for Physiological

Measurements

- Many locations near driver

** Sensors located on driver

Figure 7. Design and configuration of DASCAR. 


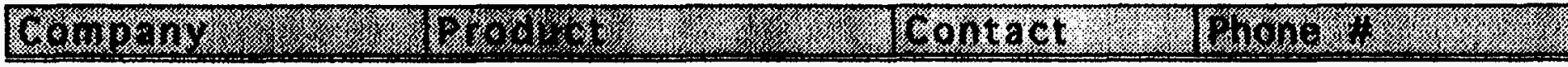




\section{$9.1 \quad$ Updates to DASCAR}

A number of changes and modifications had been made to DASCAR by mid-1994. The updates are as follows. The data storage and communications system will now contain seven components (i.e., cellular telephone equipment, radio telemetry, satellite-transmission equipment, a laptop computer, a laptop computer docking station, a SCSI hard drive, and a cartridge tape system). The power system will include two items, one (in lieu of two) battery and two (in place of one) power supplies.

The sensor suite will have two (instead of one) linear position transducers. One string pot will be employed to collect accelerator/throttle data from the vehicle; the other will be utilized to record steering wheel data. The video data system will contain (besides the VITC generator, the digital quad picture processor, and the super-VHS recorder) four color video micro cameras, a CVDSRS encoder, and a digital picture transmission system.

The CDC/AF will now consist of components that will support, analyze, and collect parameter data from the DASCAR prototype. Support systems will include: a CVDSRS decoder, radio telemetry hardware, satellite-reception equipment, a digital quad picture processor, a super-VHS recorder, a super-VHS video monitor, and a digital picture receiver system. Analysis of the acquired parameter data will be facilitated by the $\mathrm{PC}$ and special supporting software. Collection of the DASCAR sensor and video data at the CDC/AF will be handled in several ways: it will be received through radio telemetry equipment; it will be transferred via satellite equipment; and/or it will be received through cellular/land lines. The $\mathrm{CDC} / \mathrm{AF}$ will also contain data storage devices compatible with the DASCAR prototype devices. They will be used for archiving information and have the ability to directly download parameter data from the prototype.

\subsection{Hardware and Software Supplied Through CRADA}

\subsubsection{DASCAR Prototype}

A CRADA was signed with Scientific Atlanta in April 1994 for $\$ 205,000$ to support this project. In accordance with the CRADA, more than $\$ 80,000$ of equipment will be furnished for DASCAR at no expense. Scientific Atlanta will supply the following hardware for the prototype system: a data acquisition platform; cellular telephone equipment (i.e., a modem, cellular data interface, and cellular telephone); radio telemetry hardware; satellite-transmission equipment; a laptop computer, docking station, and SCSI hard drive; a super-VHS recorder; and a CVDSRS encoder.

The cellular telephone system will be used to transmit sensor suite data and digital pictures from the vehicle to the $\mathrm{CDC} / \mathrm{AF}$ in near real time, and to receive data back from the facility. It will be capable of processing data at 14,400 bits per second (bps). Brief material on the cellular telephone modem is exhibited in Appendix $\mathrm{P}$ in the Austin Computer documentation. 
ORNL has determined that the hard drive for the laptop computer should be $545 \mathrm{Mb}$ instead of $340 \mathrm{Mb}$. The laptop-computer docking station will provide the required ISA slots for the CVDSRS encoder. Information on the docking station is also presented in Austin Computer's literature. The SCSI hard drive will be a $2.9 \mathrm{~Gb}$ device which will be utilized to assemble and integrate the video data digitized and compressed by the CVDSRS. Documentation on the CVDSRS encoder is furnished in Appendix T.

\subsection{2 $\mathrm{CDC/AF}$}

In accordance with the CRADA with Scientific Atlanta, the following hardware and software will be supplied for the CDC/AF at no expense: CVDSRS decoder; radio telemetry, and satellitereception equipment (i.e., Macintosh II computer, GPS receiver, Inmarsat Standard C transceiver with antenna, and Mapstar software).

Mapstar is a graphic display, communications, and database-management system for vehicle tracking applications. With this software a user is able to track vehicles, send and receive messages, establish data communications, and obtain vehicle status reports. Vehicle locations are displayed on maps, which may be customized to the human's specific requirements, providing an interface for the individual to the map display and two-way communications. Using Mapstar, the $\mathrm{CDC} / \mathrm{AF}$ will be able to monitor, in near real time, the location and speed of all vehicles in the fleet, and send and receive messages. Additional material on the Mapstar system is supplied in Appendix T.

\subsection{Procurement of Hardware}

\subsubsection{DASCAR Prototype}

The DASCAR prototype will incorporate state-of-the-art technology that is currently available off-the-shelf. Purchase orders will be placed for the procurement of this equipment. The following systems will be procured: a cartridge tape system; a battery; switching power supplies; linear position transducers; pedal force transducers; an accelerometer; an ADRS; a six-DOF orientation sensor; a Hall-effect sensor; an electronic compass; range sensors; a sound level meter; radiometers/photometers; a meteorological sensor; color video micro cameras; a VITC generator; a digital quad picture processor; and a digital picture transmission system.

The cartridge tape system is state-of-the-art equipment which will not be available on the open market until early 1995 . It will be used to store the CVDSRS data onboard the vehicle. The tape system will save data on eight-millimeter tape and be able to store up to $20 \mathrm{~Gb}$ uncompressed on each cartridge. The digital picture transmission system will be capable of sending high quality black-and-white pictures to the CDC/AF in near real time (i.e., every six seconds). By lateSeptember 1994 the picture transmission system will be upgraded so that it will be able to facilitate color transmission. Material on the cartridge tape and digital picture transmission systems is supplied in Appendix U. 


\subsection{2 $\mathrm{CDC} / \mathrm{AF}$}

Most of the hardware for the DASCAR CDC/AF is available off-the-shelf. The following equipment will be purchased: a PC system (i.e., 486-DX2, 43 centimeter super-video graphics array (SVGA) monitor, a 1.8-Gb SCSI-two hard disk, and a 14,400 bps modem); mass storage devices for archiving both sensor suite and compressed video data; a digital quad picture processor; a digital picture receiver system; a super-VHS recorder, and a super-VHS video monitor

ORNL has determined that the hard drive for the 486-DX2 PC should be a 1.8-Gb SCSI-two device instead of $340 \mathrm{Mb}$. The mass storage device for the sensor suite data will be a two $\mathrm{Gb}$ DAT tape; the archiving system for the compressed video will be a 20-Gb cartridge tape system identical to that installed within the vehicle. The digital picture receiver system will consist of: a 486, 25-MHz PC platform with an SVGA monitor, a 14,400 baud modem, a 3.5-inch disk drive, a $120-\mathrm{Mb}$ hard drive, and a mouse. The digital picture receiver system will also include Microsoft disk operating system 5.0 and system specific software. The super-VHS recorder will be alternating current powered and, as a result, be less expensive than the recorder inside the vehicle. The super-VHS video monitor will have a 64 centimeter screen.

\subsection{Development of Hardware for the DASCAR Prototype}

Some of the hardware for the DASCAR prototype is not available off-the-shelf and, as a result, will have to be developed. Currently a state-of-the-art, off-the-shelf device for measuring lateral lane positioning is not available. A DASCAR lane tracking system will be developed using a CCD camera-based system. It will be designed by Williamson Associates. Design and construction of the CCD camera-based lateral-position lane tracking system is priced at $\$ 42,000$. The effort will be conducted via a subcontract with Williamson Associates. The cost estimate is supplied in Appendix V.

\subsection{Prototype Hardware Cost}

\subsubsection{DASCAR Prototype}

The cost estimates for the DASCAR prototype hardware are exhibited in Table 11.

\subsection{2 $\mathrm{CDC} / \mathrm{AF}$}

The cost estimates for the CDC/AF hardware are displayed in Table 12 .

\subsubsection{Complete Prototype Hardware Cost}

The total cost estimates for the DASCAR hardware are shown in Table 13. 
Table 11. DASCAR Prototype Hardware Cost Estimates

\begin{tabular}{|c|c|}
\hline Hardware Item & Cost \\
\hline $\begin{array}{l}\text { CRADA Hardware } \\
\text { - Data acquisition platform } \\
\text { - Cellular telephone equipment } \\
\text { - Radio telemetry hardware } \\
\text { - Satellite transmission equipment } \\
\text { - Laptop computer } \\
\text { - Laptop computer docking station } \\
\text { - SCSI-2 hard drive } \\
\text { - Super-VHS recorder } \\
\text { - CVDSRS encoder } \\
\text { CRADA Hardware Subtotal }\end{array}$ & $\begin{array}{l}\text { \$No cost } \\
\text { \$ No cost } \\
\text { \$No cost } \\
\text { \$ No cost } \\
\text { \$ No cost } \\
\text { \$ No cost } \\
\text { \$ No cost } \\
\text { \$ No cost } \\
\text { \$ No cost } \\
\text { \$ No cost }\end{array}$ \\
\hline $\begin{array}{l}\text { Off-the-Shelf Hardware } \\
\text { o Cartridge tape system } \\
\text { o Battery } \\
\text { o Switching power supplies } \\
\text { - Linear position transducers } \\
\text { - Pedal force transducers } \\
\text { - Accelerometer } \\
\text { - ADRS } \\
\text { - Six-DOF orientation sensor } \\
\text { - Hall effect sensor } \\
\text { - Electronic compass } \\
\text { - Range sensors } \\
\text { - Sound level meter } \\
\text { - Radiometers/photometers } \\
\text { - Meteorological sensor } \\
\text { - Color video micro cameras } \\
\text { - VITC generator } \\
\text { - Digital quad picture processor } \\
\text { - Digital picture transmission system } \\
\text { Off-the-Shelf Hardware Subtotal }\end{array}$ & $\begin{array}{rr}\$ & 3,300 \\
\$ & 409 \\
\$ & 1,483 \\
\$ & 750 \\
\$ & 1,895 \\
\$ & 1,315 \\
\$ & 10,000 \\
\$ & 11,994 \\
\$ & 75 \\
\$ & 695 \\
\$ & 3,250 \\
\$ & 1,223 \\
\$ & 3,069 \\
\$ & 7,500 \\
\$ & 9,080 \\
\$ & 318 \\
\$ & 1,300 \\
\$ & 1,946 \\
\text { s } & 59,632\end{array}$ \\
\hline $\begin{array}{l}\text { Development Hardware } \\
\text { o Development cost for CCD camera based lateral position } \\
\text { lane tracking system } \\
\text { o CCD camera based lateral position lane tracking system (two } \\
\text { required: must buy eight) } \\
\text { Development Hardware Subtotal }\end{array}$ & $\begin{array}{l}\$ 42,000 \\
\$ 37,500 \\
\$ 79,500\end{array}$ \\
\hline DASCAR Prototype Hardware Total & $\$ 139,132$ \\
\hline
\end{tabular}

Table 12. CDC/AF Hardware Cost Estimates

\begin{tabular}{|l|l|}
\hline \multicolumn{1}{|c|}{ Hardware Item } & Cost \\
\hline CRADA Hardware & \\
0 CVDSRS decoder & $\$$ No cost \\
o Radio telemetry & $\$$ No cost \\
o Satellite reception equipment & $\$$ No cost \\
CRADA Hardware Subtotal & No cost \\
\hline
\end{tabular}




\begin{tabular}{|c|c|}
\hline $\begin{array}{l}\text { Off-the-Shelf Hardware } \\
\text { o PC system } \\
\text { o Mass storage devices } \\
\text { o Digital quad picture processor } \\
\text { o Digital picture receiver system } \\
\text { o Super-VHS recorder } \\
\text { o Super-VHS video monitor } \\
\text { Off-the-Shelf Hardware Subtotal }\end{array}$ & $\begin{array}{rr}\$ & 3,688 \\
\$ & 4,199 \\
\$ & 1,300 \\
\$ & 4,796 \\
\$ & 1,650 \\
\$ & 580 \\
\text { \$ } & 16,213\end{array}$ \\
\hline CDC/AF Hardware Total & S 16,213 \\
\hline
\end{tabular}

Table 13. DASCAR Hardware Total Cost Estimates

\begin{tabular}{|l|l|}
\hline \multicolumn{1}{|c|}{ Hardware Item } & \multicolumn{1}{|c|}{ Cost } \\
\hline DASCAR Prototype Hardware Total & $\$ 139,132$ \\
\hline CDC/AF Hardware Total & $\$ 16,213$ \\
\hline DASCAR Hardware Grand Total & $\$ 155,345$ \\
\hline
\end{tabular}

\subsection{Procurement of Software for the CDC/AF}

Two pieces of software for the CDC/AF are available off-the-shelf. They include: SAS and Test PAES. (Earlier in its development cycle Test PAES was entitled the "performance assessment and workload evaluation system".) SAS is the statistical software package proposed by ORNL as the primary data-analytical tool for DASCAR. It can perform standard statistical procedures, time series and spectral analyses, multivariate analysis, and singular value decompositions. SAS can deal with variance components models, has a sophisticated graphics package, and is capable of handling data that is censored. It was more fully described in section 6.3. Since NHTSA already has a SAS license, the project will not have to pay for this software.

Test PAES is a software-based evaluation system developed by the U.S. Air Force Armstrong Laboratory at Wright-Patterson Air Force Base, $\mathrm{OH}$. It was designed to help the Air Force plan for crewstation flight evaluations, prepare flight test materials, process flight test data, and report crewstation evaluation results in a timely and responsive manner. Test PAES includes a structured process, a set of structured test procedures, and a set of comparable measures. The system includes, among other things, data analysis tools and a statistics package. The software can present cathode-ray tube based graphical presentations of performance data and facilitate playback of digitized video. Table 14 summarizes the basic Test PAES capabilities. Further documentation on Test PAES is furnished in Appendix W. Test PAES is government-domain software and, as a result, is available to the DASCAR project at no added expense.

\subsection{Development of Software}

\subsubsection{DASCAR Prototype}


Table 14. Test PAES Capabilities

\begin{tabular}{|c|c|}
\hline Capability & Description \\
\hline Process support & $\begin{array}{l}\text { This capability provides guidance in performing the structured } \\
\text { test and evaluation process (STEP). A graphical representation } \\
\text { of STEP is presented along with appropriate tools, documents, } \\
\text { and forms to assist the Test PAES user in performing and } \\
\text { tracking progress throughout system testing and evaluation. }\end{array}$ \\
\hline Database access & $\begin{array}{l}\text { This capability provides access to the Test PAES databases } \\
\text { throughout STEP. The available databases are: dictionary, } \\
\text { lessons learned, measures, card catalog, note pad, structured } \\
\text { test procedures, event log, and time sampled data. }\end{array}$ \\
\hline Multimedia data analysis playback & $\begin{array}{l}\text { This capability provides playback of video, audio, and } \\
\text { engineering unit data simultaneously in resizeable windows. } \\
\text { The playback is controlled using video cassette recorder like } \\
\text { controls with forward and reverse play at selectable speeds. }\end{array}$ \\
\hline Multimedia authoring & $\begin{array}{l}\text { This capability provides the hardware and software necessary to } \\
\text { digitize video and audio data into various Windows media } \\
\text { formats (such as audio video interleave file format). Because } \\
\text { digital video is storage intensive, the hardware necessary is } \\
\text { dependent on individual site requirements. }\end{array}$ \\
\hline Integrated commercial peripheral and application support & $\begin{array}{l}\text { This capability provides compatibility with commercial } \\
\text { hardware peripherals and software applications that are useful } \\
\text { in performing STEP. These hardware and software items are } \\
\text { optional and should be evaluated individually to determine if } \\
\text { their capability is necessary. }\end{array}$ \\
\hline
\end{tabular}

A significant amount of software development is required to support the design and integration of the DASCAR prototype. Software needs to be generated to interface the data storage and communication system, and the sensor suite to DAP. Software must also be developed for data decompression (i.e., conversion of all raw sensor data into a format that can be viewed and/or stored for later post-processing). ORNL, through a subcontract with Scientific Atlanta, has identified the system engineering and software development requirements for development and fabrication of the data acquisition system during phase II of the project. The letter report from that effort is displayed in Appendix X. Scientific Atlanta's work breakdown in person months (PM) worth of effort and the cost projection for software development is listed in Table 15.

\subsection{2 $\mathrm{CDC} / \mathrm{AF}$}

Although no hardware development is needed, software development is required to support the $\mathrm{CDC} / \mathrm{AF}$. Software engineering and design is needed for interpretation of the DASCAR parameter data. The software will be used to analyze, perform reduction, and evaluate and interpret the acquired sensor suite information. This work will be undertaken by ORNL and will consist of the following tasks: 
Table 15. Work Breakdown for Software Development

\begin{tabular}{|c|c|c|}
\hline Task & Person-Months & Cost \\
\hline $\begin{array}{l}\text { - Sensor interface definition } \\
\text { - Sensor suite to DAP integration } \\
\text { - Data storage and communications } \\
\text { system to DAP integration } \\
\text { - Data decompression development }\end{array}$ & $\begin{array}{l}0.50 \mathrm{PMs} \\
\text { 2.00 PMs } \\
\text { 3.75 PMs } \\
\\
\text { 4.00 PMs }\end{array}$ & $\begin{array}{l}\$ \quad 8,064 \\
\$ 30,240 \\
\text { \$ } 60,481 \\
\text { \$ } 63,505\end{array}$ \\
\hline $\begin{array}{l}\text { Total Development Cost for DASCAR } \\
\text { Prototype Software }\end{array}$ & 10.25 PMs & $\$ 162,290$ \\
\hline
\end{tabular}

- Real time data reduction, calibration, formatting, and process control.

- Database design and creation - including post-acquisition calibrations, hardware modification to accommodate large data sets, and file compression procedures.

- Standard statistical analyses, summary statistics, and graphics.

- General statistical consulting and experimental design for DASCAR development and validation.

- Outlier detection software.

- Analysis of interpolation error or frequencies for sampling rate determination.

- Transforming, filtering, and smoothing.

The development work for the CDC/AF software will take about six PMs; direct labor is priced at $\$ 66,220$.

\section{$9.8 \quad$ Installation and Calibration of Units}

\subsubsection{Installation}

Installation of the various DASCAR sensors and hardware will be case specific from vehicle to vehicle. The cost of installation will vary by vehicle make and model because of different trim molding, dash space, and wire routings. Some vehicle designs will allow for the data acquisition system to be installed relatively easily, while others will require more time because of their internal organization and structure. Until several DASCAR systems have actually been installed, an accurate estimate on the cost of installation cannot be determined.

\subsubsection{Installation Hardware}

Mounting hardware and equipment will be needed for the installation of the DASCAR prototype and follow-on systems. They include tools, electrical components, and fans. The tools, fans, and excess electrical components will be delivered to NHTSA as part of the data acquisition system at the end of the project. The tools are composed of: a digital multimeter; crimpers; mini-strippers; mini-screwdrivers; ratchets, sockets, and wrenches; screwdrivers (snap-on ratcheting and general purpose), allen wrenches, and nut-drivers; tin snippers; pliers (long-nose, locking, and duckbill); a 
nibbling tool; cutters (diagonal and multipurpose); adjustable wrenches; hammers (claw and softtip); levels; drills (cordless and corded); a rotary tool; and tool boxes. The electrical components consist of: a 120-ampere dual battery isolator, distribution blocks, voltage regulators, rails, rail mounted terminals, rail mounted fused terminals, rail end barriers/terminators, wires $(4,8,12,16$, and 18 American wire gauge (AWG)), heat shrink tubing, wire tap-ins, insulated butt connectors, male/female quick disconnects, ty-wraps and mountings, and split loom tubing. The prices for the tools, electrical components, and fans are shown in Table 16.

\subsubsection{Calibration}

The calibration of DASCAR will also be case specific from vehicle to vehicle. An accurate estimate on the cost of calibration cannot currently be determined because of changing factors such as size and mechanical design of the automobile. The following list exhibits sensor suite calibration considerations.

- Linear position transducer - Calibration will vary from vehicle to vehicle due to variances in mechanical design.

- Pedal force transducer - Calibration is dependent on excitation voltage and will vary due to braking systems (e.g., ABS and hydraulic).

- Accelerometer - Calibration is factory preset.

- $\quad$ ADRS - Calibration is factory preset.

- Six-DOF orientation sensor - Calibration is factory preset.

- Hall-effect sensor - Calibration will vary due to changing circumferences of wheels from vehicle to vehicle.

- Electronic compass - Calibration will be dependent on specific installation location.

- Range sensor - Calibration is factory preset, however, depending on the location of installation an offset calibration may be required.

- Radiometer/photometer - Calibration is factory preset against National Institute of Standards and Technology standards.

- Sound level meter - Calibration is factory preset and an optional portable calibrator is available.

- Meteorological sensor - Calibration is factory preset.

- Lateral-position lane tracking system - Calibration of this system will vary due to the different heights and styles of side-view mirrors.

\subsection{Operation and Maintenance}

\subsubsection{Satellite and Cellular Telephone Transmissions}

The satellite-transmission equipment proposed for use with DASCAR has a few inherent problems associated with it. The Standard $\mathrm{C}$ terminal will not be able to adequately handle the transmission of collected sensor suite data or the vast amount of video data digitized and compressed by the CVDSRS. The $\mathrm{C}$ terminal uses Inmarsat-C technology, which supports a 
Table 16. Cost Estimates for Tools, Electrical Components, and Fans

\begin{tabular}{|c|c|}
\hline Hardware Item & Cost \\
\hline $\begin{array}{l}\text { Tools } \\
\text { o Digital multimeter } \\
\text { o Crimpers } \\
\text { o Mini-strippers } \\
\text { o Mini-screwdrivers } \\
\text { o Ratchets, sockets, and wrenches } \\
\text { o Screwdrivers, allen wrenches, and nut-drivers } \\
\text { o Tin snippers } \\
\text { o Pliers } \\
\text { o Nibbling tool } \\
\text { o Cutters } \\
\text { o Adjustable wrenches } \\
\text { o Hammers } \\
\text { o Levels } \\
\text { o Drills } \\
\text { o Rotary tool } \\
\text { o Tool boxes } \\
\text { Estimated Cost for Tools }\end{array}$ & $\begin{array}{lr}\text { S } & 60 \\
\$ & 16 \\
\$ & 16 \\
\$ & 11 \\
\$ & 300 \\
\$ & 89 \\
\$ & 20 \\
\$ & 63 \\
\$ & 11 \\
\$ & 20 \\
\$ & 30 \\
\$ & 29 \\
\$ & 10 \\
\text { S } & 220 \\
\text { S } & 70 \\
\text { S } & 100 \\
\$ 1,065\end{array}$ \\
\hline $\begin{array}{l}\text { Electrical Components } \\
\text { o Dual battery isolator } \\
\text { o Distribution blocks } \\
\text { o Voltage regulators } \\
\text { o Rails } \\
\text { o Rail mounted terminals } \\
\text { o Rail mounted fused terminals } \\
\text { o Rail end barriers/terminators } \\
\text { o } 4 \text { AWG wire } \\
\text { - } 8 \text { AWG wire } \\
\text { - } 12 \text { AWG wire } \\
\text { o } 16 \text { AWG wire } \\
\text { o } 18 \text { AWG wire } \\
\text { o Heat shrink tubing } \\
\text { - Wire tap-ins } \\
\text { - Insulated butt connectors } \\
\text { o Male/female quick disconnects } \\
\text { o Ty-wraps } \\
\text { o Ty-wrap mountings } \\
\text { o Split loom tubing } \\
\text { Estimated Cost for Electrical Components }\end{array}$ & $\begin{array}{lr}\text { \$ } & 50 \\
\$ & 15 \\
\$ & 34 \\
\$ & 10 \\
\$ & 8 \\
\$ & 294 \\
\$ & 3 \\
\$ & 254 \\
\$ & 116 \\
\$ & 59 \\
\$ & 32 \\
\$ & 22 \\
\$ & 2 \\
\$ & 12 \\
\$ & 14 \\
\$ & 19 \\
\$ & 21 \\
\$ & 16 \\
\$ & 30 \\
\text { \$1, } & 011\end{array}$ \\
\hline Estimated Cost for Fans & $\$ 150$ \\
\hline $\begin{array}{l}\text { Total Estimated Cost for Tools, Electrical Components, } \\
\text { and Fans }\end{array}$ & $\$ 2,226$ \\
\hline
\end{tabular}

transmission rate of $600 \mathrm{bps}$. This rate is too slow for massive amounts of data to be transmitted either in real time or post real time.

Inmarsat-C is very inefficient when dealing with data files that are larger than 32,000 bytes. Due to its slow transmission rate one hour of data acquisition from all of the sensors within the 
DASCAR sensor suite, when recording at their projected sampling rates (see Table 2), would take approximately 7.4 hours to be transmitted to the CDC/AF from the vehicle. Priced at current (1994) tariff rates this transmission would cost approximately $\$ 17,500$.

After some investigation of faster transmission methods, ORNL has determined that cellular technology should be added to the DASCAR communications network. It offers a cost effective and portable solution for DASCAR's transmission needs. Supporting a transmission rate of 14,400 bps, sensor suite data may efficiently be downloaded to the CDC/AF. Although cellular technology is much faster than Inmarsat- $C$, digitized and compressed video data will still not be able to be transmitted via cellular technology. Transmission time for sending one hour's worth of sensor suite data at the highest sampling rates will take approximately 18.51 minutes.

The total cost of the cellular transmission will depend on the choice of service plans, and whether the transmission is local or long distance. A one-year service agreement is generally required and transmission rates will vary slightly from city to city. Listed below are some example services obtainable from Cellular One in Knoxville, TN. More literature is furnished in Appendix Y.

\begin{tabular}{|c|c|c|c|}
\hline Plan Name & Basic* & Minutes Included & Cost/Minute \\
\hline Diamond Plan & $\$ 209.95 /$ month & 800 free & $\$ 0.25$ \\
\hline Gold Plan & $\$ 149.95 /$ month & 400 free & $\$ 0.28$ \\
\hline Silver Plan & $\$ 89.95 /$ month & 200 free & $\begin{array}{l}\$ 0.35 \text { Peak } \\
\text { (\$0.22 Off Peak) }\end{array}$ \\
\hline
\end{tabular}

* The plan includes unlimited weekend calling which includes local calls from 7:00 p.m. Friday to 7:00 a.m. Monday. Long distance, roaming, and taxes are not included.

Due to the advantages and disadvantages of the two systems, DASCAR will incorporate both Inmarsat- $C$ and cellular technologies. The Inmarsat- $C$ system will provide a mobile link for the transmission of global positioning data. Mapstar (automatic vehicle location (AVL) software) will process the data at the CDC/AF providing a worldwide GPS. The cellular system will provide a mobile link allowing collected data from the sensor suite to be downloaded from its storage devices and transmitted to the CDC/AF. Because of the variations in cellular performance, data transmissions will generally occur while the vehicle is stationary for a period of time, such as when it is parked overnight. Cellular communication will also provide DASCAR with a two-way link between the vehicle and the CDC/AF. While DASCAR is in the field, sensors may be remotely reconfigured for various types of testing.

For phase II of the project, a one-year agreement on the silver plan should be taken out. The total estimated cost for cellular service will be $\$ 1,079$. 


\subsubsection{General Operation and Maintenance}

At this point in the project, ORNL cannot make a realistic estimate of the life-cycle costs associated with the maintenance and operation of the DASCAR prototype, CDC/AF, and additional systems. There will be costs for technicians to install, remove, and reinstall data acquisition systems and/or components. In addition, spare parts will have to be purchased, and there will be charges associated with the maintenance of the DASCAR units and the data acquisition system components in the CDC/AF. Finally there will be costs for technicians to operate the $\mathrm{CDC} / \mathrm{AF}$ and for statisticians to reduce the DASCAR parameter data.

\subsection{Work Breakdown Structure for Phase II}

In ORNL's proposal to NHTSA, dated July 1992, a preliminary work breakdown structure for personnel and the cost for this direct labor for phase II of the project was provided. In that proposal ORNL stated: "The cost estimate for phase II is highly dependent on the results from phase I. It is contingent upon the amount of development versus off-the-shelf purchase of hardware and software. As a result, there are too many unknowns at the present time to ensure that the cost estimate provided is realistic. The estimate is, however, ORNL's best-educated guess and is submitted for planning purposes."

As phase I comes to a close, a more accurate estimate of phase II work can be made. ORNL's updated work breakdown structure for phase II is shown in Table 17. PMs by job category for each of the four tasks (see section 1.1) are presented. Since estimates for the computer programmer (Scientific Atlanta) and the statistician have already been addressed in section 9.7, they are not exhibited again here.

The direct labor for conduct of phase II is estimated to be $15 \mathrm{PMs}$; direct labor is priced at $\$ 165,550$.

\subsection{Updated Cost Estimate for the Development and Test of the Data Acquisition System}

In ORNL's proposal to NHTSA a detailed cost estimate for phase II of the project was provided. Now that phase $I$ is coming to an end, ORNL is in a much better position to make a more accurate estimate on the phase II work. ORNL's cost estimate for phase II is itemized in Table 18. The table summarizes all of the cost estimates presented in sections 9.5 , and 9.7 through 9.10. GA/GPS is the acronym for general administrative and general plant services.

\subsection{Hardware for Additional Units}

The projected costs associated with the procurement of 15 additional DASCAR vehicle units are listed in Table 19. Price quotes for 15 units from most of the vendors are displayed in Appendix Z. 
Table 17. Updated Work Breakdown Structure for Phase II

\begin{tabular}{|c|c|}
\hline Personnel Type & Person-Months \\
\hline $\begin{array}{l}\text { Development Plan and Construction of the Prototype } \\
\text { Driver Performance Data Acquisition System } \\
\text { o Program manager/project director/principal investigator } \\
\text { o Electronics engineer } \\
\text { o Senior human factors specialist } \\
\text { o Mechanical engineer } \\
\text { o Instrumentation engineer } \\
\text { - Technician } \\
\text { Total - Task } 1\end{array}$ & $\begin{array}{l}1.00 \mathrm{PMs} \\
1.50 \mathrm{PMs} \\
1.00 \mathrm{PMs} \\
1.50 \mathrm{PMs} \\
1.50 \mathrm{PMs} \\
1.50 \mathrm{PMs} \\
\text { 8.00 PMs }\end{array}$ \\
\hline $\begin{array}{l}\text { Evaluation Plan } \\
\text { o Program manager/project director/principal investigator } \\
\text { o Senior human factors specialist } \\
\text { Total - Task } 2\end{array}$ & $\begin{array}{l}0.50 \mathrm{PMs} \\
1.50 \mathrm{PMs} \\
\text { 2.60 PMs }\end{array}$ \\
\hline $\begin{array}{l}\text { Evaluation, System Update, and Pilot Research } \\
\text { o Program manager/project director/principal investigator } \\
\text { o Electronics engineer } \\
\text { o Technician } \\
\text { Total - Task } 3\end{array}$ & $\begin{array}{l}1.00 \mathrm{PMs} \\
1.00 \mathrm{PMs} \\
2.00 \mathrm{PMs} \\
\text { 4.00 PMs }\end{array}$ \\
\hline $\begin{array}{l}\text { Demonstration, Delivery of the System, and Training } \\
\text { o Program manager/project director/principal investigator } \\
\text { o Senior human factors specialist } \\
\text { o Instrumentation engineer } \\
\text { o Technician } \\
\text { Total - Task } 4\end{array}$ & $\begin{array}{l}0.25 \mathrm{PMs} \\
0.25 \mathrm{PMs} \\
0.25 \mathrm{PMs} \\
0.25 \mathrm{PMs} \\
1.00 \mathrm{PMs}\end{array}$ \\
\hline
\end{tabular}

Table 18. Cost Estimate for Development and Test of DASCAR

\begin{tabular}{|l|l|}
\hline \multicolumn{1}{|c|}{ Type of Cost } & Cost \\
\hline Direct labor - 21 PMs & $\$ 231,770$ \\
GA/GPS & $\$ 108,932$ \\
Subtotal \#1 & $\$ 340,702$ \\
\hline Subcontracts & \\
o Prototype DASCAR development hardware & $\$ 79,500$ \\
o Prototype DASCAR software & $\$ 162,290$ \\
O Cellular telephone & $\$ 1,079$ \\
GAGPS & $\$ 21,130$ \\
Subtotal \#2 & $\$ 263,999$ \\
\hline Direct material & \\
o Off-the-shelf hardware for DASCAR prototype & $\$ 59,632$ \\
o Off-the-shelf hardware for the CDC/AF & $\$ 16,213$ \\
o Tools, electrical components, and fans & $\$ 2,226$ \\
Capital use tax & $\$ 6,831$ \\
Subtotal \#3 & $\mathbf{8 4 , 9 0 2}$ \\
\hline Department of Energy added factor & $\$ 22,067$ \\
\hline Total estimated cost for phase II & $\$ \mathbf{7 1 1 , 6 7 0}$ \\
\hline
\end{tabular}


Table 19. Hardware for Additional Vehicle Units

\begin{tabular}{|c|c|c|}
\hline Hardware Item & & Cost \\
\hline DAP & \$ 8,000 each & \\
\hline $\begin{array}{l}\text { Data Storage and Communications System } \\
\text { - Cellular telephone equipment } \\
\text { - Radio telemetry hardware } \\
\text { - Satellite transmission equipment } \\
\text { - Laptop computer } \\
\text { - Laptop computer docking station } \\
\text { - SCSI-2 hard drive } \\
\text { - Cartridge tape system }\end{array}$ & $\begin{array}{lr}\$ & 417 \text { each } \\
\$ & 405 \text { each } \\
\$ & 5,500 \text { each } \\
\$ & 2,573 \text { each } \\
\$ & 279 \text { each } \\
\$ & 2,099 \text { each } \\
\$ & 3,300 \text { each }\end{array}$ & \\
\hline $\begin{array}{l}\text { Power System } \\
\text { o Battery } \\
\text { o Switching power supply }\end{array}$ & $\begin{array}{lc}\$ & 409 \text { each } \\
\$ & 1,483 \text { each set of five }\end{array}$ & \\
\hline $\begin{array}{l}\text { Sensor Suite } \\
\text { - Linear position transducer } \\
\text { o Pedal force transducer } \\
\text { o Accelerometer } \\
\text { o ADRS } \\
\text { o Six-DOF orientation sensor } \\
\text { - Hall effect sensor } \\
\text { - Electronic compass } \\
\text { - Range sensor } \\
\text { - Sound level meter } \\
\text { - Radiometer/photometer } \\
\text { - Meteorological sensor } \\
\text { - Lateral position lane tracking system } \\
\text { - Remote heart rate and respiration rate monitoring system } \\
\text { - Video eye tracking system }\end{array}$ & $\begin{array}{lr}\$ & 348 \text { each } \\
\$ & 1,706 \text { each } \\
\$ & 1,028 \text { each } \\
\$ & 7,967 \text { each } \\
\$ & 9,923 \text { each } \\
\$ & 75 \text { each } \\
\$ & 695 \text { each } \\
\$ & 1,500 \text { each } \\
\$ & 842 \text { each } \\
\$ & 1,305 \text { each } \\
\$ & 5,140 \text { each } \\
\text { \$ } & 3,600 \text { for two } \\
\$ & 6,295 \text { each } \\
\text { \$ } & 30,000 \text { each }\end{array}$ & \\
\hline $\begin{array}{l}\text { Video Data System } \\
\text { - Color video micro cameras } \\
\text { o VITC generator } \\
\text { - Digital quad picture processor } \\
\text { - Digital picture transmission system } \\
\text { - CVDSRS encoder } \\
\text { - Super-VHS recorder }\end{array}$ & $\begin{array}{lr}\$ & 2,195 \text { each } \\
\$ & 275 \text { each } \\
\$ & 1,250 \text { each } \\
\$ & 2,420 \text { each } \\
\$ & 17,500 \text { each } \\
\$ & 2,398 \text { each }\end{array}$ & \\
\hline $\begin{array}{l}\text { Electrical Components } \\
\text { - Dual battery isolator } \\
\text { - Distribution block } \\
\text { - Voltage regulator } \\
\text { o Rails } \\
\text { - Rail mounted terminal } \\
\text { - Rail mounted fused terminal } \\
\text { - Rail end barriers/terminators } \\
\text { - } 4 \text { AWG wire } \\
\text { - } 8 \text { AWG wire } \\
\text { - } 12 \text { AWG wire } \\
\text { 16 AWG wire } \\
\text { - 18 AWG wire } \\
\text { - Heat shrink tubing } \\
\text { o Wire tap-ins }\end{array}$ & $\begin{array}{ll}\$ & 50 \text { each } \\
\$ & 7 \text { each } \\
\$ & 17 \text { each } \\
\$ & 10 \text { for six feet } \\
\$ & 1 \text { each } \\
\$ & 10 \text { each } \\
\$ & 3 \text { for eight } \\
\$ & 254 \text { for } 1,000 \text { feet } \\
\$ & 116 \text { for } 1,000 \text { feet } \\
\$ & 59 \text { for } 1,000 \text { feet } \\
\$ & 32 \text { for } 1,000 \text { feet } \\
\$ & 22 \text { for } 1,000 \text { feet } \\
\$ & 2 \text { for seven } \\
\$ & 2 \text { for } 10\end{array}$ & \\
\hline
\end{tabular}




\begin{tabular}{|l|ll|}
\hline O Insulated butt connectors & $\$$ & 1 for 10 \\
O Male/female quick disconnects & $\$$ & 1 for eight \\
o Ty-wraps & $\$$ & 3 for 30 \\
o Ty-wrap mountings & $\$$ & 2 for 10 \\
o Split loom tubing & $\$$ & 5 for five feet \\
\hline Fans & $\$$ & 15 each \\
\hline
\end{tabular}

\subsection{Hardware and Software for an Additional CDC/AF}

The projected costs associated with the procurement of hardware and software for an additional DASCAR CDC/AF are shown in Table 20.

Table 20. Hardware and Software for an Additional CDC/AF

\begin{tabular}{|l|l|}
\hline \multicolumn{1}{|c|}{ Hardware/Software Item } & \\
\hline Hardware & \\
O CVDSRS decoder & $\$ 17,500$ each set \\
o Radio telemetry & $\$$ 405 each \\
o Satellite reception equipment & $\$ 9,375$ each \\
o PC system & $\$ 3,688$ each \\
o Mass storage device for sensor suite data archiving & $\$ 899$ each \\
o Mass storage device for compressed video data archiving & $\$ 3,300$ each \\
o Digital quad picture processor & $\$ 1,300$ each \\
O Digital picture receiver system & $\$ 5,800$ each set \\
o Super-VHS recorder & $\$ 1,650$ each \\
o Super-VHS video monitor & $\$ 580$ each \\
\hline Software & \\
o Mapstar & $\$ 17,000$ each \\
o SAS & $\$ N o$ cost \\
o Test PAES & $\$$ No cost \\
\hline Total Estimated Price for an Additional DASCAR & $\$ 61,497$ \\
CDC/AF & \\
\hline
\end{tabular}

\subsection{Additional Hardware and Software Development}

\subsubsection{Unobtrusive Physiological Monitoring}

A remote heart-rate and respiration-rate monitoring system could be designed by Williamson Associates. It would be constructed using very low power $\mathrm{X}$ or $\mathrm{Ku}$ band Doppler radar. The remote heart-rate and respiration-rate monitoring system was briefly described in section 7.5.2.3.2.2; a block diagram of the system is exhibited in Appendix M. The work, costed at around $\$ 30,000$, could be performed under either a subcontract with Williamson, via a CRADA, or a combination of both. A letter of interest and a cost breakdown are supplied in Appendix AA. 


\subsubsection{Unobtrusive Visual Scanning}

A video eye-tracking system is proposed by DBA Associates. A demonstration of the prototype system was presented at NHTSA's OCAR in late September 1993. Some material on the video eye-tracking system and the estimated cost is furnished in Appendix AA. At the time of the briefing in Washington, D.C., DBA estimated that they would need approximately $\$ 250,000$ to fully develop a stereo system. Things have changed since then; they have received other contract work which would compliment the DASCAR effort. DBA now estimates that they can design and construct a stereo video eye-tracking system for around $\$ 75,000$. They have expressed an interest in conducting part of the work under a CRADA.

A second development effort, which is being proposed by Mnemonics, Incorporated, would be oriented toward the generation of software to deal with head movement parameter data.

Mnemonics has proposed two approaches. One has some intrusion; the other is unobtrusive. The first method would require some type of marker to be placed on the forehead of the vehicle operator, such as an " $\mathrm{X}$ " or an "O" positioned above each eye brow. These could be affixed with adhesive tape or a non-caustic adhesive. The markers could be tracked by the use of one of Mnemonics' standard software package, "Align." The second approach would make use of natural vehicle operator characteristics for performing the tracking. Perhaps the inner/outer canthus of the eyes, or other relatively stable prominences could be used. More information on Mnemonics and its proposal is exhibited in Appendix AA. The budgetary estimate for the first method is $\$ 45,000$; the second is costed at $\$ 60,000$.

\subsubsection{Doppler Range Sensor}

The Doppler-radar range sensor developed and manufactured by VORAD Safety Systems is currently used as a warning system. This range sensor was described in section 7.5.1.1.2.3; Appendix I presents more specific information on the sensor. In order to be utilized by DASCAR, the range sensor would have to be modified to provide digital headway and tailway data output. The cost for this effort is priced at between $\$ 20,000$ and 25,000. Part of the work could be performed via a CRADA. A letter of interest is exhibited in Appendix AA.

\subsubsection{Lane Tracking}

A diode laser-based, lateral-position lane tracking system could be devised by Aerometrics, Incorporated. They developed a prototype system under an SBIR contract with NHTSA a few years ago. Their lane tracking system was briefly addressed in section 7.5.1.1.3.5; other documentation is exhibited in Appendix J. Design of Aerometrics' diode laser-based lateralposition lane tracking system would be accomplished via a CRADA. The work, priced at more than $\$ 50,000$, would be performed at no expense to the project.

\subsubsection{Advanced Communications Technical Satellite}


During 1995 use of the Advanced Communications Technical Satellite (ACTS), operated by the National Aeronautics and Space Administration (NASA), may become a viable option for DASCAR satellite transmissions. ACTS operates in the frequency range of 20 to $40 \mathrm{GHz}$ and is capable of transmission speeds up to 622,000 bps. With this type of speed, compressed and digitized video would be able to be transmitted quickly and inexpensively. With digital video encoded at approximately one $\mathrm{Mb} /$ second, it would take approximately 46.3 seconds to transmit one hour's worth of digitized video. Sensor suite data could also be transmitted at this rate. To transmit $540 \mathrm{Mb}$, which is approximately 270 hours' worth of data, it would take only 6.95 seconds. This system is economically attractive as well since use of the satellite is free and the only expense is for operator time.

ACTS, however, is not able to transmit data from a moving vehicle. The system would require data to be collected at land earth stations (LES). Once at an LES, data is then transmitted by an operator and can be received at the CDC/AF for processing. LES locations are proposed to be located in five of the following six cities: Nashville, TN, Cleveland, OH, Tampa, FL, Pasadena, CA, Washington, D.C., and San Francisco, CA. Since the ACTS system is a possible solution for DASCAR's needed transmission speeds, its development will be closely monitored.

\section{DEVELOPMENT PLAN FOR THE PROTOTYPE DASCAR}

The "design a development plan and construct the prototype driver-performance data acquisition system" task had four goals. They include: to prepare a development plan that describes in detail the process and schedule that will be used in the acquisition of the components, and the assembly and construction of the prototype system; to assemble and construct DASCAR; upon completion of the first DASCAR prototype, to carry out a preliminary "shakedown" of the system; and to demonstrate and brief the system to NHTSA at the East Liberty, OH test track facility. (The fourth activity will include an on-the-road demonstration of DASCAR and a description of its various systems operations.) This section of the technical report will address and discuss the development plan.

\subsection{Background Information and Testing}

DASCAR will comprise several major systems consisting of multiple pieces of hardware. Each of the systems is to be portable, inconspicuous, unobtrusive, modular, and flexible so that the DASCAR package may be installed in a wide variety of vehicles in a relatively short-time span. In some cases where several models, technologies, and/or manufacturers of similar products have been identified, ORNL will acquire the equipment on a consignment basis to further test and evaluate their effective operation. These cases are described in the following paragraphs.

\subsubsection{Rack Mounting}

Since DASCAR is to be installed in a relatively short-time frame, wherever possible, the hardware 
will be rack mounted. Current model year (1994) vehicles will be researched and relative dimensions of their cargo space will be gathered. This information will be used to determine the maximum-sized equipment rack which can be mounted inside a large range of vehicle trunks and cargo areas. Careful considerations will be noted, making sure that the opening of the trunk or cargo space will permit the insertion of the equipment housing(s). Preliminary information on 1994 vehicle cargo space is displayed in Figure 8. Pending an investigation of vehicle storage areas, and the respective size and weight of the hardware to be contained, equipment will be mounted in either a single enclosure or several enclosures. A scaled-dimensional drawing of a proposed equipment rack in a single enclosure is exhibited in Figure 9. Regardless of the number of equipment enclosures used, the power supplies and battery will be housed separately to reduce the amount of heat to which the hardware is subjected and to help reduce electronic noise. The enclosure(s) will contain female sockets on the rear of it to allow for simple hook up to be made with DASCAR fabricated wiring harnesses. Hardware that is susceptible to damage or malfunction due to shock and vibration will be mounted with dampening hardware. Materials such as rubber, foam, and springs will be used to isolate these components. Fans and airflow ducts will also be incorporated for the dissipation of heat generated by the electronics and to compensate for high temperatures inside the vehicle caused by the outside environment (see section 12). Throughout the assembly and construction effort, these parameters will be monitored and concessions will be made when necessary for proper operation.

\subsubsection{Micro Cameras}

Color video micro cameras will be used to collect data from the surrounding vehicle environment that cannot be quantitatively measured through the use of conventional sensors. Since DASCAR is to be unobtrusive and inconspicuous, camera size and placement are crucial to maintain this requirement. Based on the information found during phase I, ORNL will obtain both a Panasonic GP-KS152 and a Cohu 8290 micro camera for testing purposes (see section 11). Upon completion of this testing, ORNL will generate a report and video tape of the results. Four micro cameras will be used to monitor the driver's face and hand positions, and forward and rearward fields of view. Although their placement will be vehicle specific to achieve maximum inconspicuousness, ORNL will investigate the possibilities of standardizing mounting locations. One such location may be inside of the rearview mirror, which is pictured in Figure 10.

\subsubsection{Equipment Status Bus}

Currently, there is no universal standard among vehicle data buses. Until such time, DASCAR will employ the use of an ESB to monitor the use of turn signals, headlights, hazard flashers, parking lights, heater/air conditioning, rear window defogger, cellular telephone, radio/tape player/compact disk player, cruise control, windshield wipers, horn, and seat belts. The ESB will simply recognize the device as "on" or "off." A basic diagram of the ESB is pictured in Figure 11. Throughout this task, three methods of connecting the equipment to the bus will be investigated. The first method will utilize inductance to sense current flow through a voltage induced wire. This technique will require no original vehicle wires to be spliced or tapped, thus not degrading 
Figure 1: $199+$ Car Models and Cargo Space (ft. ${ }^{3}$ )

General Motors Corporation

Bulck-...

\begin{tabular}{|c|c|c|c|c|c|c|c|}
\hline -Road Master & 21 & -Cenlury & 16 & -Skylark (2\& 4 Dr.) & 13 & -Park Avenue & 20 \\
\hline -Poad Mas. Wag. & 55 & -Cenlury Wagon & 41 & -Regal & 16 & -Lesabre & \\
\hline \multicolumn{8}{|c|}{ Cadillac--- } \\
\hline -DeVille/Concours & 20 & -Eldorado & 15 & -Fleetwood & 21 & $-\mathrm{SeVIIIO}_{\mathrm{O}}$ & {$[14$} \\
\hline \multicolumn{8}{|c|}{ Chevrolet-- } \\
\hline -Berretla & 13.5 & - Corsica & 13.5 & -Caprice & 20.4 & -Cavalier & 13.2 \\
\hline \begin{tabular}{|l} 
LLumina \\
\end{tabular} & 16 & -S-Blazer (2-Dr.) & 28.1 & -Caprice wagon & 55 & -Cavalier wagon & 34.4 \\
\hline - Lumina Van & $N / A$ & -S-Blazer (4-Dr.) & 35.2 & -K-Blazer & 51.8 & -Suburban & 49.5 \\
\hline -Astro van & $N / A$ & -S\&K Series Pickups & $N / A$ & - Corvelte & N/A & - Camaro & 13 \\
\hline \multicolumn{8}{|c|}{ Chevrolet / Geo-- } \\
\hline -Metro & 10.3 & -Prizm & 12.7 & -Tracker & 8.7 & & \\
\hline \multicolumn{8}{|c|}{ Pontlac-- } \\
\hline Fireblid & 12.9 & -Bonneville & 18.0 & -GrandAm & 13.2 & -Trans Spon & 112.6 \\
\hline $\begin{array}{l}\text {-Sunbird } \\
\end{array}$ & 10.4 & - Grand Prix & 15.5 & & & & \\
\hline \multicolumn{8}{|c|}{ Oldsmobllo-- } \\
\hline -Ninety-Eight & 20.2 & -Eighty-Eight & 17.5 & -Cutlas Supreme & 15.5 & -Cullas Siera & 15.8 \\
\hline \begin{tabular}{|l}
-Bravada \\
\end{tabular} & 74.3 & $\begin{array}{l}\text {-Achieva } \\
\end{array}$ & 14.0 & - Cutlas Cnuiser & 74.4 & -Silhouette & 112.6 \\
\hline
\end{tabular}

GMC-..-

\begin{tabular}{|l|l|l|l|l|l|l|}
\hline Suburban & N/A & -Yukon & N/A & -Vimmy & N/A & -Safari \\
\hline
\end{tabular}

Saturn---

\begin{tabular}{|l|l|l|l|l|l|l|}
\hline$-S C$ & 11 & $-S L$ & 12 & $-S W$ & 29 & \\
\hline
\end{tabular}


Figure 1: $199+$ Car Models and ('argo Space (ft. $\left.{ }^{3}\right)$

Ford Motor Corporation

Ford-...

\begin{tabular}{|l|l|l|l|l|l|l|l|}
\hline -Tauns & 18.0 & -Taurus Wagon & 30.3 & -Crown Viclorian & 20.6 & -Crown Vic Wagon & 90.4 \\
\hline -Thunderbird & 14.7 & -Escon & 12.1 & -Escort Wagon & 28.0 & -Festiva & 11.7 \\
\hline -Tempo (2Dr) & 13.2 & -Club Wagon (VAN) & N/A & -Probe & 11.0 & -Aerostar Wagon & 139.3 \\
\hline -Tempo (4Dr) & 12.9 & -Bronco & N/A & -Bronco II & 23.4 & -Ranger & N/A \\
\hline -F-Series & N/A & -Astro Van & N/A & -Explorer & N/A & & \\
\hline -Mustang LX sedan & 10.8 & -Mustang GT conv. & 8.5 & -Mustang (hatch) & 12.2 & & \\
\hline
\end{tabular}

Lincoln--

\begin{tabular}{|l|l|l|l|l|l|l|}
\hline- Continental & 19 & -Mark VII & 18 & -Town Car & 22 & \\
\hline
\end{tabular}

Mercury-

\begin{tabular}{|l|l|l|l|l|l|l|l|}
\hline- Tracer & 12.1 & - Topaz & 12.9 & - Cougar & 14.7 & -Sable wagon & 38 \\
\hline- Sable & 18.5 & - Grand Marguis & 20.6 & - Grand Mar. Wag & 52.5 & -Capri & \\
\hline -Villager & 126.0 & & & & & \\
\hline
\end{tabular}

Chrysler Corporation--

Dodge-...

\begin{tabular}{|l|l|l|l|l|l|l|l|}
\hline -Intrepid & 16.7 & - Viper & N/A & -Steallh & 11 & -Ram Pickup & N/A \\
\hline -Caravan & N/A & -Neon & & -Shadow & 13.1 & -Spirit & 14.4 \\
\hline - Ram Van & N/A & -Dakota & N/A & & & & \\
\hline
\end{tabular}

Plymouth---

\begin{tabular}{|l|l|l|l|l|l|l|l|}
\hline -Laser & 8 & -Duster & 13 & -Sundance & 13 & -Acclaim & 14 \\
\hline -Voyager & N/A & -Colt & 11 & -Colt/Vista & 24.6 & & \\
\hline
\end{tabular}

Chrysler-

\begin{tabular}{|l|l|l|l|l|l|l|l|}
\hline LHS & 18 & -LeBaron/conv & $14 / 10$ & -New Yorker & 18 & -Concorde & 19 \\
\hline
\end{tabular}

Joep / Eaglom...

\begin{tabular}{|l|l|l|l|l|l|l|}
\hline -Wrangler & 12.5 & -Talon & 8 & -Cheeroke & 40.1 & \\
\hline -Summit & 11 & -Summit wagon & 35 & -Vislon & 19 & \\
\hline
\end{tabular}


Top View
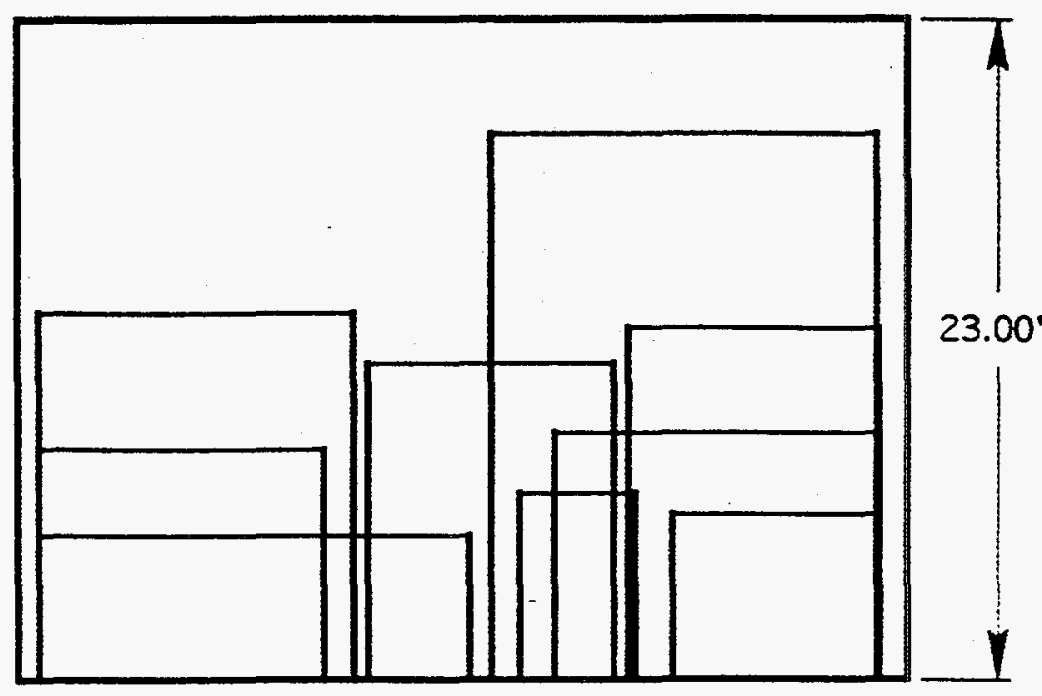

\section{3-D View}

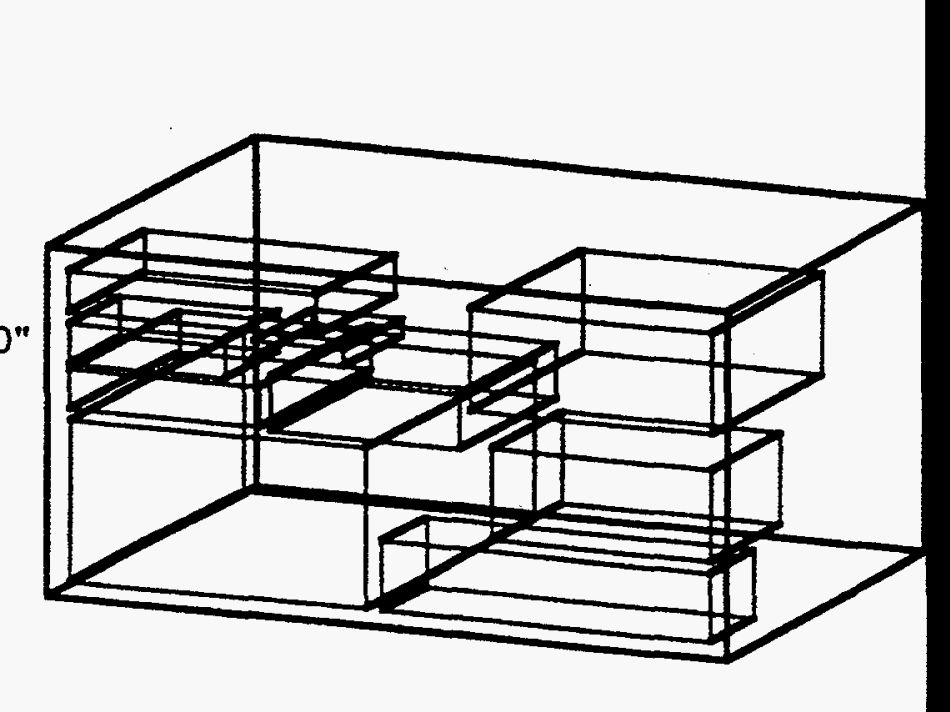

Side View

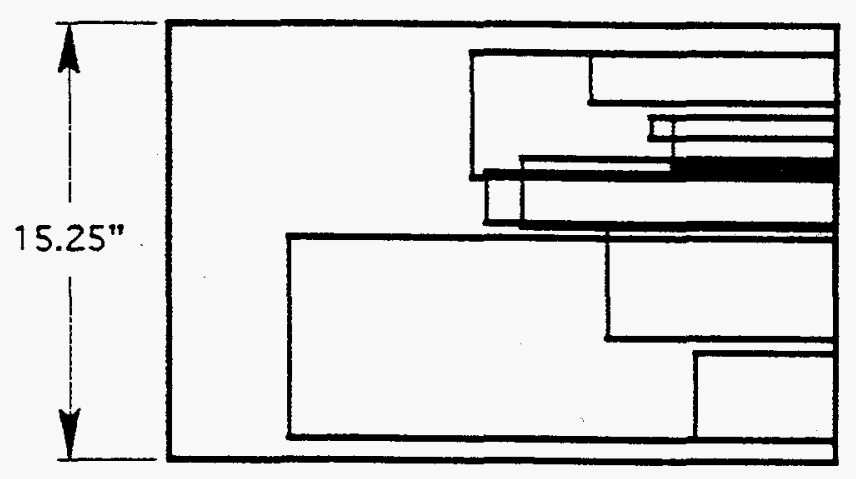

Figure 9. A proposed equipment rack in a single enclosure. 
Rear view mirror with camera placed behind etched glass surface
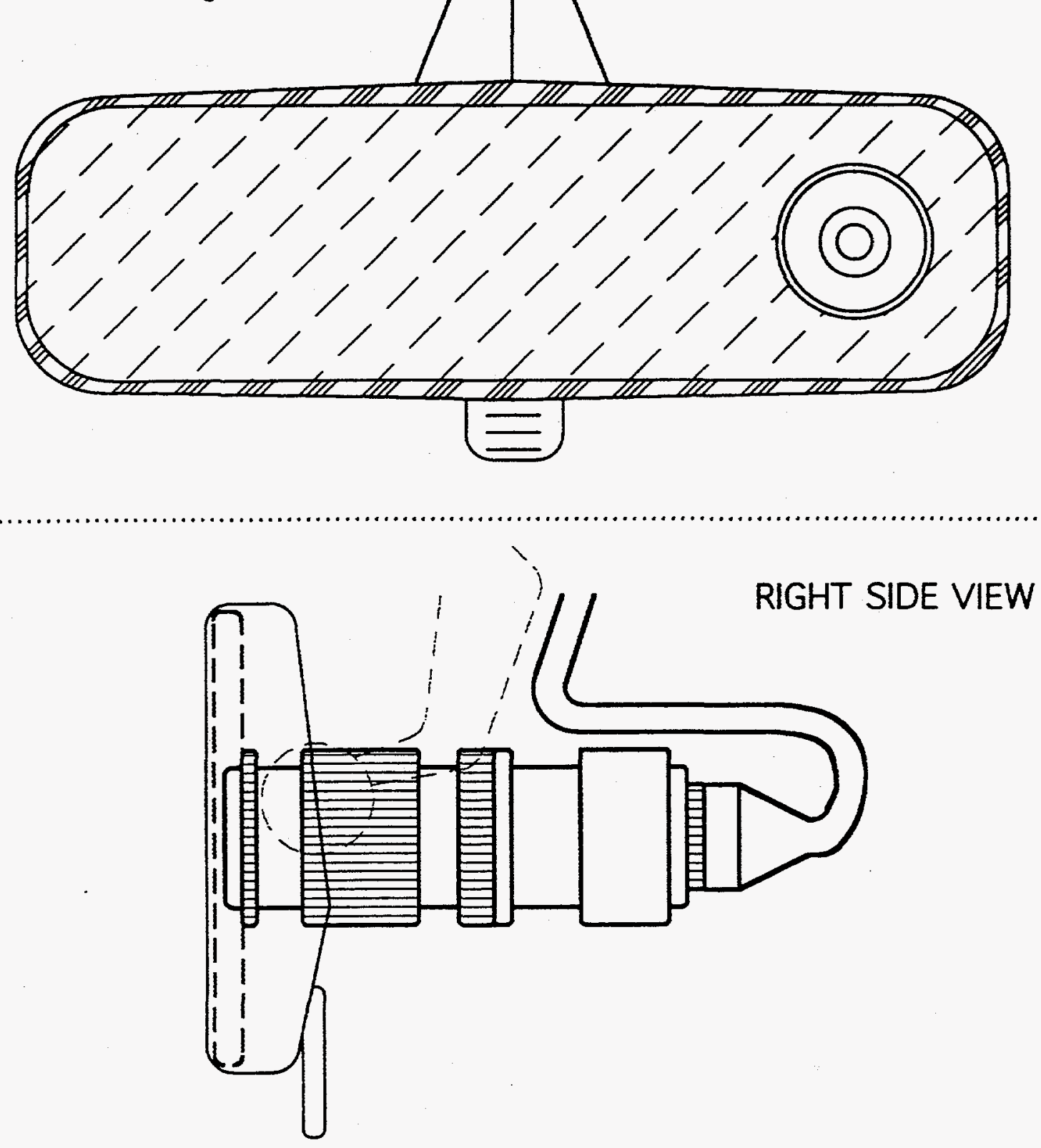

FRONT VIEW 


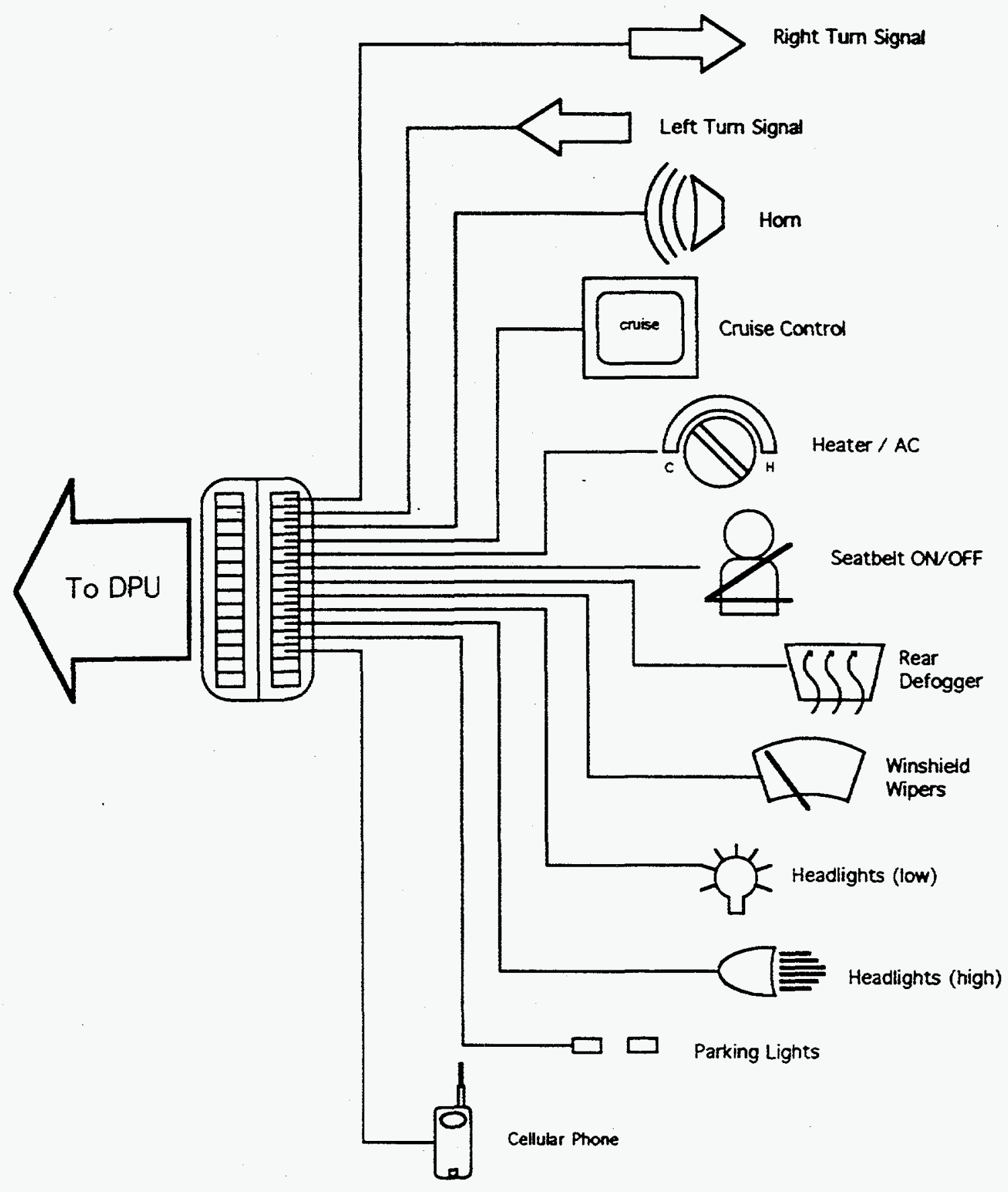

Figure 11. A diagram of the ESB. 
the integrity of the vehicle's electrical system. The second method will simply utilize the voltage signal generated by use of the device. Wires will be tapped to obtain a signal indicating the status of the equipment. The third procedure, when possible, will take advantage of the onboard diagnostics (OBD-II) bus. Although OBD-II is not a universal standard, manufacturers are increasingly incorporating this standard into their new vehicle designs. ORNL will evaluate these three methods and incorporate the most unobtrusive and cost-effective one into the initial prototype. The design of the ESB will also incorporate the ability to interface with a universally standardized data bus for use with future vehicles. This will add to the flexibility of DASCAR. In the future when a universally standardized data bus is available, a simple wiring harness can be fabricated which will allow interconnection between the vehicle's bus and the already existing ESB connection.

\subsection{Acquisition of Hardware and Software for the Prototype DASCAR}

Procurement of hardware for the prototype DASCAR will be done in stages. This will allow ORNL to test and evaluate each individual component of hardware against the manufacturer's specifications and our own standard of expected performance. The required paperwork for each piece of equipment will be prepared and subsequently submitted to ORNL's procurement department. They will then purchase the request items.

Once received the hardware will be installed on an individual basis, allowing ORNL to determine the most unobtrusive, inconspicuous, and cost-effective mounting location. Two vehicles have been lent to the project, one each from ORNL's Computer Science and Mathematics Division, and Robotics and Process Systems Division, for the installation of the prototype system.

For prototype development, the procurement process will be based primarily on importance and economics. The order of acquisition is exhibited in Figure 12. This diagram shows procurement in sequential order (going from top-to-bottom) as a function of increasing time. It is also subdivided into development procurement, off-the-shelf procurement, and CRADA hardware acquisitions to show concurrent actions.

\subsubsection{Hardware - Stage 1}

\subsubsection{1 $\quad \underline{\text { Range Sensors }}$}

As can be seen in the figure, the range sensor produced by Silicon Heights, Limited, called a controlaser, will be the first item to be procured and is located in both the development and offthe-shelf columns. Plans currently call for the procurement of three systems. Two of the three will be developed; the off-the-shelf version will be modified to add a digital output for data collection. The third controlaser will be the conventional model, utilizing seven segment lightemitting diodes and a speaker to give a visual output display and an audible alert to the driver. All three will arrive in mid-October 1994. The controlaser will be used to measure longitudinal 


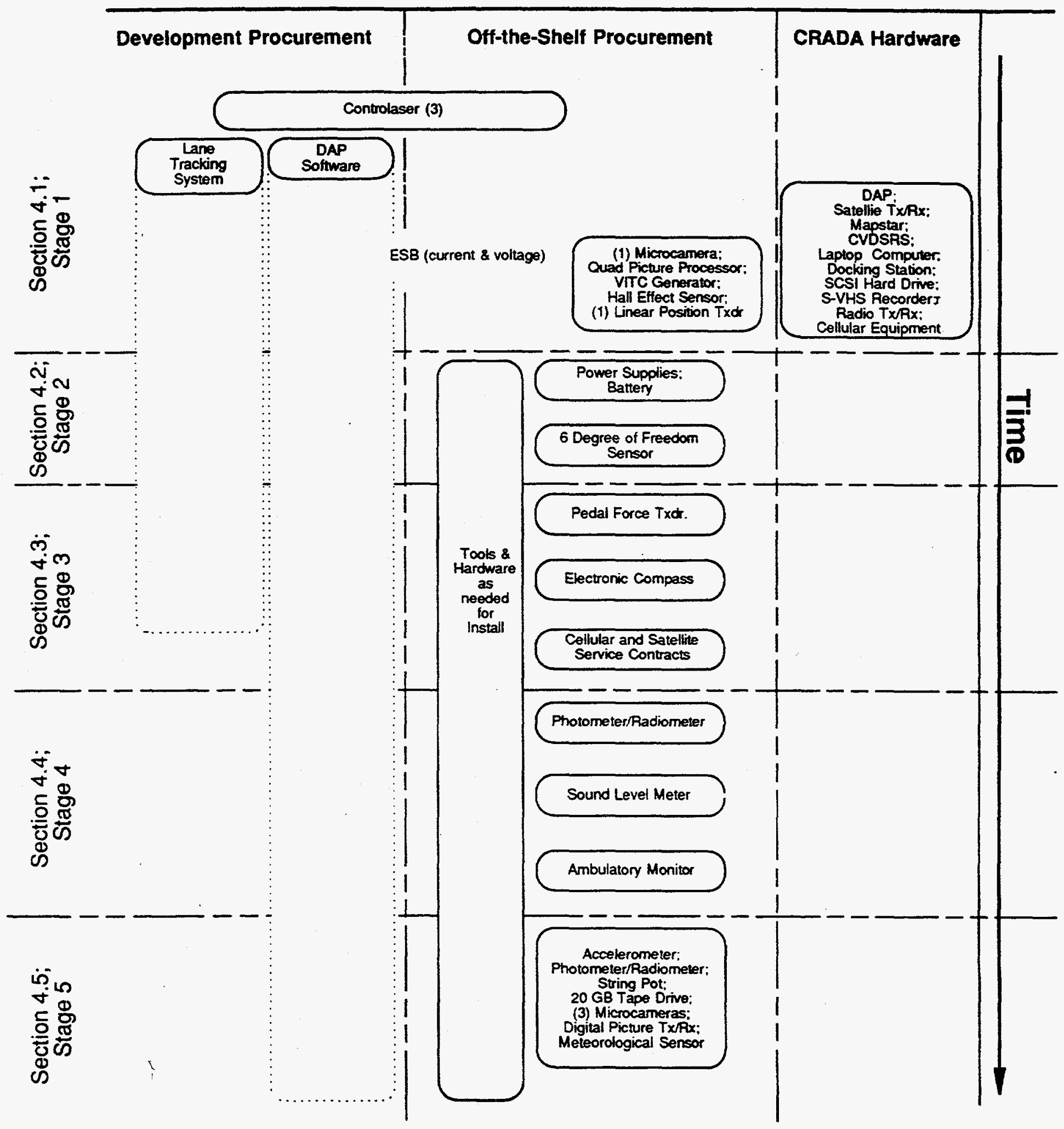

Figure 12. A procurement block diagram. 
distance (headway and tailway) between an object and the vehicle. ORNL will test and evaluate the systems, and validate their operation before incorporating them into DASCAR.

\subsubsection{Lateral Position Lane Tracking System}

A lateral-position lane tracking system is currently under development through a subcontract with Williamson Associates. This system will measure lateral positioning of the vehicle in respect to the existing painted lines on the highway. The first version of the lane tracking system is expected to be delivered in mid-December 1994. Upon receipt, ORNL will perform an evaluation and validate its working operation. Any problems or unsatisfactory system functions will be modified and revised until ORNL is satisfied with its performance. Upon acceptance of the working prototype, Williamson will assemble and deliver eight fully functional systems.

\subsubsection{CRADA Hardware}

The hardware being provided through the CRADA with Scientific Atlanta was ordered in early June 1994. The DAP, satellite transmission equipment, Mapstar system, and CVDSRS encoder are all manufactured by Scientific Atlanta. Lead time is quite long; delivery is expected in early December. Scientific Atlanta will also provide the laptop computer system, SCSI-two hard drive, cellular telephone system, radio telemetry system, and DC powered super-VHS recorder. The laptop computer will consist of a $486 \mathrm{DX}-4,14,400 \mathrm{bps}$ modem, and a docking station containing two full ISA slots. The equipment provided through the CRADA will meet all of the specifications provided in Volume three.

\subsubsection{ESB}

The ESB will be the first off-the-shelf item to be procured, developed, and installed. It will require minimal hardware procurement, wires, connectors, discrete circuitry, and little lead time. Concurrently with the ESB, procurement of one color video micro camera, a quad-picture processor, a VITC generator, the Hall-effect sensor, and a linear position transducer will take place. These items will be installed and tested against their manufacturers' specifications.

\subsubsection{Video Data System}

ORNL will select to procure either a Panasonic GP-KS152 or a Cohu 8290 micro camera, based on their performance results from testing. During this stage just one micro camera will be procured and validated in all viewing locations before acquisition of the other three. This will ensure maximum effectiveness of the video system. The Robot MV-85 quad-picture processor will be used to combine the signals from the four cameras into a single signal, NTSC and superVHS, for the purpose of recording. The Horita VG-50 VITC generator will provide an on-screen time-and-day video stamp for correlating recorded media with sensor suite data. ORNL recommends procurement of the Robot MV-85 and the Horita VG-50 from Eastern Video Systems. This hardware carries a lead time of approximately 30 days upon ordering. 
A Hall-effect sensor will be procured to obtain vehicle speed and distance traveled. It will be placed on an unpowered wheel with a fixed radius of rotation. Based on the Hall-effect principle, voltage pulses will be generated as the wheel rotates and a magnetic field passes the sensor. The pulses will then be processed by the DAP, calculating them into usable DASCAR data. ORNL recommends using Pro Sports Engineering's version because of their previous experience with similar systems on racing cars. The Hall-effect sensor has a lead time of 14 to 30 days.

\subsubsection{Linear Position Transducer}

The linear position transducer will be used for two applications; first as a sensor measuring the driver's accelerator position, and second, as a sensor measuring the radial position of the steering wheel. Initially, one string pot will be procured and installed for both measurements. Effectiveness of the sensor's installation and accuracy against the manufacturer's specifications will be evaluated before procurement of the second. The UniMeasure HX series linear position transducer will be procured. It is environmentally sealed and available in a variety of string lengths. For the prototype, a 38-centimeter string-length string pot with a voltage divider output will be procured. It is recommended that the linear position transducer be purchased through UniMeasure directly; it has approximately a 30 -day lead time upon ordering.

\subsubsection{Hardware - Stage 2}

Stage two of the hardware procurement will involve the purchasing of the DC-DC switchingpower supplies, a battery, and the six-DOF orientation sensor.

\subsubsection{Power Supplies and Battery}

The DC-DC switching-power supplies will provide for five voltages $(+5 \mathrm{~V},+12 \mathrm{~V},-12 \mathrm{~V},+15 \mathrm{~V}$, $-15 \mathrm{~V}$ ) and approximately 600 watts (W) of power. The prototype will utilize a Vicor DC Megapac, which is a self-contained single unit. The unit includes built-in fans for heat dissipation. It is recommended that the switching-power supplies be purchased through Westcor which is a division of Vicor Corporation. The DC Megapac has a lead time of approximately 60 days upon ordering.

\subsubsection{Six-DOF Orientation Sensor}

The six-DOF orientation sensor will provide data for several DASCAR parameters. It contains three "solid-state" rate gyros which will measure the degree of yaw (turning rate), pitch (longitudinal inclination rate), and roll (lateral inclination rate) of the vehicle. The sensor also contains three "solid-state" accelerometers which will measure positive and negative accelerations in each of the three axes $(x, y$, and $z)$. Vehicle accelerations and decelerations will be monitored 
up to \pm two gravities. For the DASCAR prototype, a MOTIONPAK manufactured by Systron Donner will be purchased. It has a lead time of approximately 45 days.

\subsubsection{Hardware - Stage 3}

In stage three the pedal force transducer, electronic compass, and communications service plans will be procured for the prototype.

\subsubsection{1 $\quad$ Pedal Force Transducer}

The pedal force transducer that will be used for the prototype is designed by GSE Incorporated. Upon delivery, it will be mounted on the brake pedal in several different ways to maximize its unobtrusiveness. Currently, the transducer is manufactured to rest on top of the brake pedal, raised approximately three centimeters and secured by a clamping bracket (see Figure 13). ORNL will work with GSE to modify the transducer so that it is more unobtrusive. One such method may be to eliminate the clamp base and mount the sensor under the rubber covering the pedal (see Figure 14). ORNL will evaluate these approaches and validate them against GSE specifications to measure their effectiveness. It is recommended that the transducer be purchased through GSA which is a factory distributor for GSE. The sensor has a lead time of approximately 90 days.

\subsubsection{Electronic Compass}

The electronic compass will provide information on heading and direction. For the DASCAR prototype, a C-100 compass engine with a SE-ten fluxgate sensor manufactured by $\mathrm{KVH}$ Industries will be procured. The sensor will be gimballed allowing for accurate readings through \pm 45 degrees of tilt (pitch and roll). It is recommended that the electronic compass be purchased factory direct and has a lead time of approximately 14 days.

\subsubsection{Communications Service Plans}

Cellular and satellite service contracts need to be established in order to use the communications network. Cellular coverage can be obtained in practically any city and generally requires a oneyear agreement. Prices quoted in section 9.9.1 were, as stated, for the Knoxville, TN area. A decision will be made, based on economical operating costs, where the contract will be purchased. This will become crucial during daily operation of the system. Satellite service contracts will be set up through Comsat to provide data communications for GPS. Comsat offers several different contracts which ORNL will review and subsequently determine the most appropriate one needed for DASCAR.

\subsubsection{Hardware - Stage 4}

During stage four one radiometer/photometer, a sound level meter, and the ADRS will be procured. 


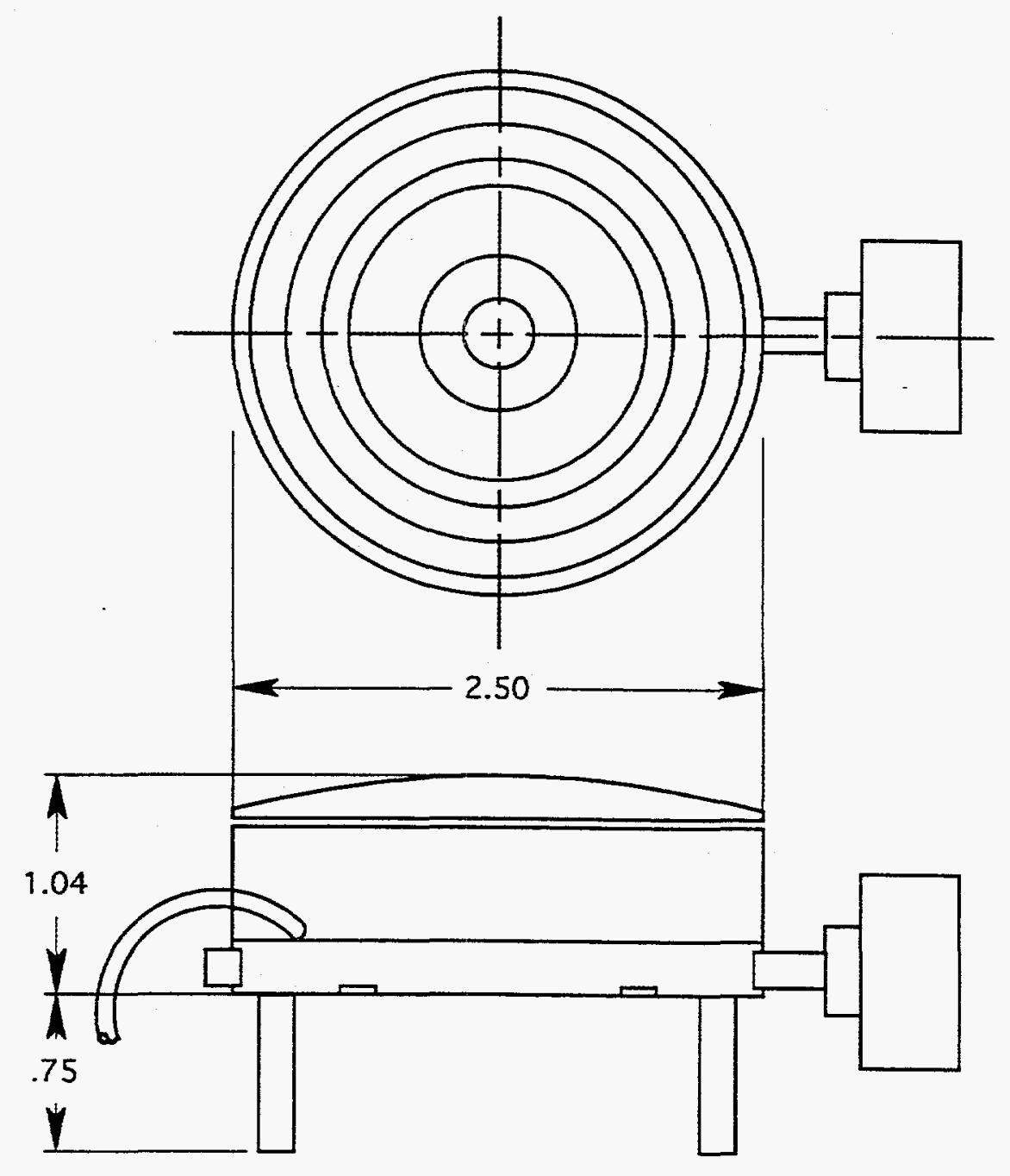

Figure 13. The pedal force transducer mounted on top of the brake pedal and secured by a clamping bracket. 


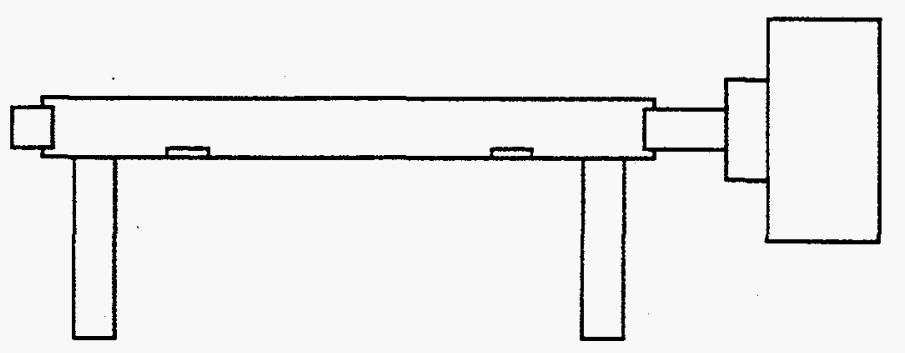

$\star \star \star N O T E:$ Clamp base removed

Brake Pedal Force Transducer mounted to brake pedal covered with rubber pad

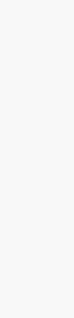




\subsubsection{1 $\quad$ Radiometer/Photometer}

The radiometer/photometer will be used for the measurement of lumination and illumination. Lumination is the amount of light intensity a surface radiates in a given direction. Illumination is the radiant flux of light per unit area on an intercepting surface at any given point. Although two radiometers/photometers will be needed, ORNL has decided to acquire just one for the purpose of testing and evaluation. The radiometer/photometer will be checked against the manufacturer's specifications and against DASCAR's system integrity. An International Light IL-1400A smart radiometer/photometer and an SEL033/Y/L30 illuminance probe will be procured for the prototype. ORNL recommends that the equipment be purchased factory direct. Delivery lead time is approximately 14 days.

\subsubsection{Sound Level Meter}

The sound level meter will measure the sound-pressure level that the vehicle operator is experiencing. It will be logged in the units of A-weighted decibels. For the prototype, a Quest 2700 sound level meter and a ten-foot microphone extension cable will be procured. It is recommended that they be purchased through Dawson Associates, Incorporated; the sound level meter and microphone extension cable have a lead time of approximately 30 days.

\subsubsection{3 $\underline{\text { ADRS }}$}

The ADRS will be used to record various physiological variables from the driver. A model 3992 Digital BioLog system will be purchased. The system is complete with all of the needed hardware and software to allow for a simple interface to the DAP and for downloading data in ASCII file format. ORNL recommends that the ADRS be purchased through its manufacturer, UFI. The BioLog has a lead time of approximately 45 - 60 days upon ordering.

\subsubsection{Hardware - Stage 5}

Stage five will consist of purchasing an accelerometer, a digital picture transmission system, a meteorological sensor, and the remaining duplicative sensors (i.e., a linear position transducer, radiometer/photometer with luminance probe, and three micro cameras).

\subsubsection{1 $\quad$ Accelerometer}

The accelerometer will be used to record gross body movement of the driver in his or her seat. A GyroChip II (model QRS1400100-103) will be procured. ORNL recommends purchasing it factory direct from Systron Donner. The accelerometer has an approximate lead time of 30 days.

\subsubsection{Digital Picture Transmission System}

The digital picture transmission system will allow DASCAR to send digital pictures from the 
video data system to the CDC/AF over ordinary cellular and land phone lines. ORNL is currently working with Robot Research, Incorporated on an agreement for acquiring a prototype color transmission system (or the off-the-shelf black-and-white version) on consignment in exchange for some validation feedback on its operation. A second option is to purchase a Robot TX-42, four camera digital picture transmission system, with the understanding that it may be upgraded at no expense, except for the difference in cost for the color ultra version when it becomes available. If the system is procured, ORNL recommends that it be purchased through Eastern Video Systems, Incorporated. Lead time for delivery of the TX-42 is approximately 30 days.

\subsubsection{Meteorological Sensor}

To record factors in the environment quantitatively, a meteorological sensor was researched. The only somewhat small device which measures wind speed and direction was found to be manufactured by Armtec Industries. It is ORNL's recommendation that this sensor not be procured at the present time due to the fact that it is economically unreasonable, and it has a delivery lead time of 38 weeks.

\subsubsection{Duplicative Sensors}

The remaining sensor procurement will consist of the purchase of: a second linear position transducer, a second radiometer/photometer with a luminance probe, and three more micro cameras. This equipment will be procured only after thorough testing is completed on the first set of these sensors and ORNL is satisfied with their operation and physical installation.

\subsubsection{Software}

For the DASCAR prototype no separate, off-the-shelf software will be procured. The DAP software will be developed as the equipment for the data system is procured. The software will integrate all output signals from the sensors to the DAP. It will also direct all system control and operation signals. Once the data are processed, the software will format them into compressed packets allowing data to be efficiently stored for later retrieval. The software is being developed through a subcontract with Scientific Atlanta. Completion of the development of the software package is expected to occur around mid-December 1994. The software will then be evaluated and modified until ORNL is satisfied with its valid operation.

\subsection{Acquisition of Hardware and Software for the CDC/AF}

A block diagram for the $\mathrm{CDC} / \mathrm{AF}$ is pictured in Figure 15. The CDC/AF will serve as the postdata collection processing station. Information will be communicated from DASCAR to it through several methods: via cellular transmissions, via satellite transmissions, via radio telemetry transmissions, and/or via physical downloading from storage media. Once the information is received at the $\mathrm{CDC} / \mathrm{AF}$, it will be processed using statistical analysis and evaluation methods for useful interpretation of the DASCAR parameters. 

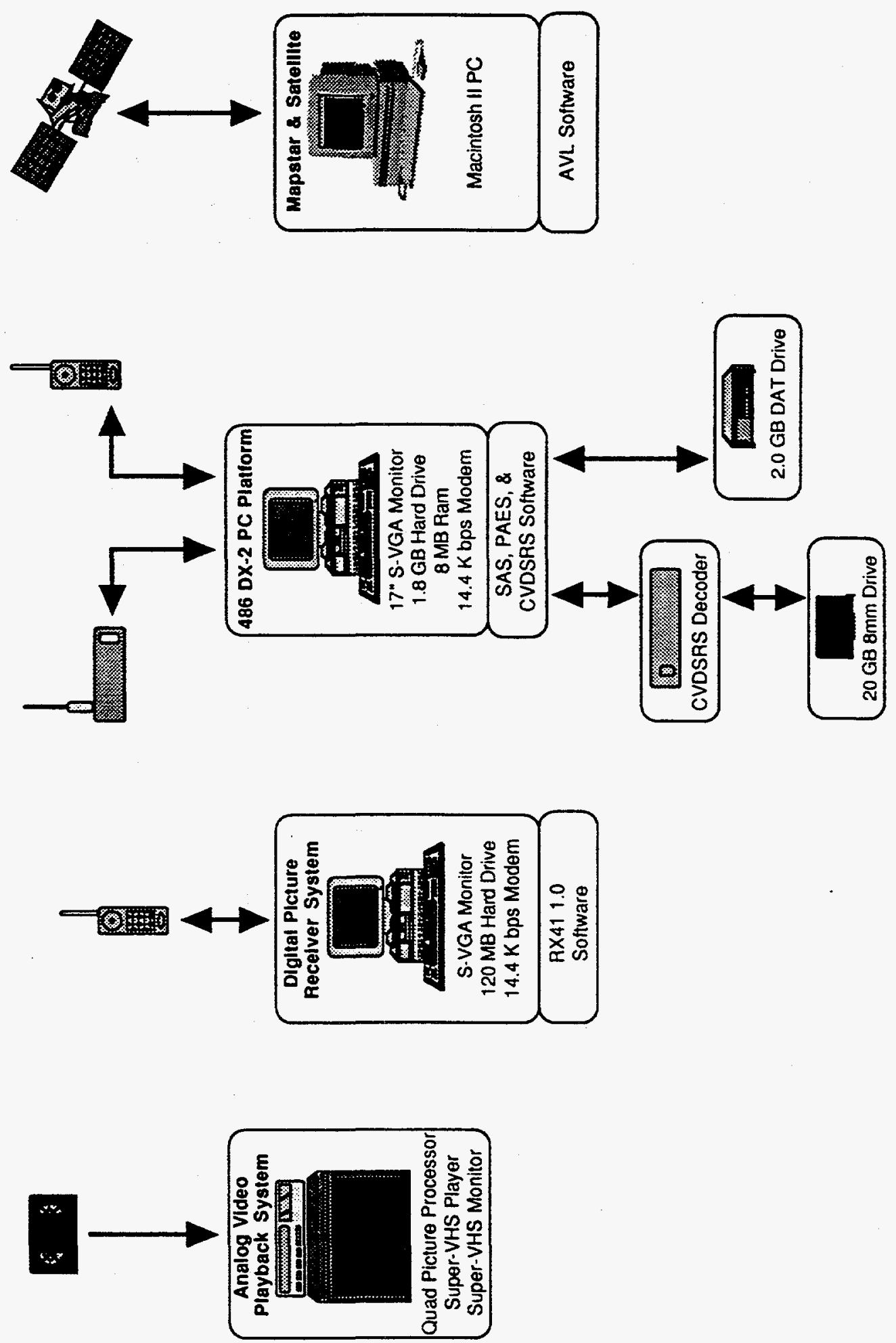

Figure 15. A block diagram of the CDC/AF. 


\subsubsection{Hardware}

\subsubsection{CRADA Hardware}

Some CDC/AF hardware will be supplied through the CRADA with Scientific Atlanta. This includes: satellite-reception equipment, radio telemetry hardware, and a CVDSRS decoder.

\subsection{Satellite Reception Equipment}

The satellite-reception equipment will provide a GPS for DASCAR. The hardware will include a Mapstar system which consists of a TerraStar-C satellite transceiver, a GPS receiver, an Apple Macintosh computer platform, and an AVL software package.

\subsection{Radio Telemetry Equipment}

The radio telemetry equipment will be identical to that used in the DASCAR prototype. This equipment will allow the CDC/AF to establish two-way radio frequency communications with DASCAR. Due to limitations of radio frequencies, this link will however only be utilized in the test-track environment.

\subsection{CVDSRS Decoder}

The CVDSRS decoder will reside inside of the 486 DX-2 PC (see section 10.3.2.1). It will allow for the decoding and playback of the encoded MPEG 1+ compressed video data. The decoder will also provide control and storage of the recorded media through the PC.

\subsubsection{2 $\quad$ Procured Hardware}

The CDC/AF will have the following procured systems: a 486-DX-2 PC platform, a digital picture receiver system, two mass storage devices, and an analog video playback system.

\subsection{PC Platform}

The PC will be the backbone for the analysis and interpretation of the collected sensor suite data. It will include: a 486-DX-2 66-MHz microprocessor, a 43 centimeter SVGA monitor, a 1.8-Gb internal hard drive, eight $\mathrm{Mb}$ of RAM, one $\mathrm{Mb}$ of video memory, a 14,400 bps fax/modem, a 3.5inch floppy drive, a 5.25-inch floppy drive, and operating accessories. The platform will operate all statistical analysis and evaluation software. The PC will also control remote sensor suite data collection, initiating and receiving the transmission information. ORNL recommends that the platform be procured through Austin Computer Systems. The system has a delivery lead time of approximately 14 to 30 days. 


\subsection{Digital Picture Receiver System}

The digital picture receiver system will receive and display video pictures that are sent through cellular phone lines from the transmission system installed in DASCAR. The system will include and is based on a 486-SX PC platform which consists of an SVGA monitor, a $120 \mathrm{Mb}$ hard drive, a 14,400 bps modem, a 3.5-inch floppy drive, and special operating software. A Robot RX-43 SX or ultra color system (if available) will be utilized for DASCAR. It will be acquired on consignment (as mentioned in section 10.2.5.2.) from Robot Research. If necessary, a black-andwhite version, Robot RX-43 SX, may be procured with the understanding that it can be upgraded for the color system when it is available. For the procurement of future systems, it is recommended that the digital picture receiver system be purchased from Eastern Video Systems; the lead time is approximately 30 days.

\subsection{Mass Storage Devices}

The two mass storage devices will be used for archiving collected data. The first device will be used for archiving sensor suite data. It will be a two $\mathrm{Gb}$ digital audio tape drive. This storage device will be procured from Austin Computer, along with the 486 DX-2 PC. The second mass storage device, although not available until 1995, will be a "mammoth" eight-millimeter tape drive manufactured by the Exabyte Corporation. It will be used to archive digitized video data from the CVDSRS. The mammoth will allow DASCAR to record and playback approximately 20 hours of a constant video recording session. Until such time that the mammoth is available, ORNL is working with Exabyte Corporation to acquire a similar device on consignment. ORNL will also collaborate with Scientific Atlanta and Exabyte on developing the most efficient method to archive digitized video. The benefit of using these devices for archiving data is that, essentially, they allow for infinite storage capacity. New cartridges may be purchased for more archiving space as needed.

\subsection{Analog Video Playback System}

An analog video playback system will be procured for DASCAR to provide for playback of superVHS video recorded in the vehicle. The system will include: a Robot MV-85, a Panasonic superVHS player, and a Panasonic 64 centimeter super-VHS monitor. The Robot MV-85 will allow the quadrature recording to be digitally zoomed, displaying one of the four pictures full screen, upon playback. The super-VHS player and monitor will provide the hardware necessary to view the playback of the previously taped data. It is recommended that all three components be procured through Eastern Video Systems. They have a lead time of approximately 30 days.

\subsubsection{Software}

10.3.2.1 $\quad$ SAS and Test PAES 
Most of the software will not need to be procured for the CDC/AF. Software rights, licensing, and/or permission already exist for the use of the SAS and Test PAES packages.

\subsubsection{Digital Picture Receiver System}

The Robot digital picture receiver system comes with its own software package. The software decodes digital pictures sent from the transmission system allowing them to be displayed on a PC monitor and/or stored for later retrieval. The software will allow up to four separate signals to be received and decoded simultaneously, thus multiplexing 16 images on the screen.

\subsubsection{3 $\quad$ Mapstar}

The Mapstar system is supported by its own AVL software package. The software supplied with the system will allow for graphical displays of vehicle location on multi-level vector-based maps. It also can perform some calculations, such as speed, distance traveled, and estimated time of arrival, all derived from the GPS data.

\subsubsection{4 $\quad$ ORNL Developed}

The DASCAR project will require some developmental software engineering in order to perform data reduction and various statistical analyses. The software will be developed by ORNL and is expected to be completed in December 1994.

\subsection{DASCAR - The Complete System}

\subsubsection{Integration and Installation}

Once all of the hardware and software have been secured and individually tested, the complete DASCAR will be integrated and installed in the vehicles being provided by ORNL. Installation methods will be investigated for time-effectiveness and portability. The DASCAR then will be examined and evaluated as a complete unit. Sampling rates and measured parameters will be analyzed to ensure optimal performance and true validity of the acquired data. Once this information is gathered, ORNL will adjust and re-calibrate the system accordingly. DASCAR will then be completely removed and installation will be repeated a number of times to gain an accurate idea of complete installation, operation, and removal of DASCAR. (In September 1994, ORNL estimated a late December time of completion for the prototype system.)

\subsubsection{Operational Demonstration}

Upon satisfactory completion of ORNL's preliminary shakedown, an operational demonstration will be presented to NHTSA at the East Liberty, OH test track facility. (ORNL projected this to occur in the month of January or February 1995.) It will include an on-the-road demonstration of 
the DASCAR and its various system components. In addition, the demonstration will also include a briefing, containing the following:

- A description of the installation process and portability of the system.

- A description of the sensor technology used and their calibration.

- A description of the parameters measured.

- A description of the video system and its technology.

- A description of the data acquisition/transmission process.

- A description of the data reduction/analysis process.

\subsubsection{NASA}

ORNL is working on a proposal for NASA to use their ACTS for the DASCAR project. It will most likely not be available for use at the time of the East Liberty demonstration. However, when the satellite comes on-line, a demonstration will be arranged and held for NHTSA showcasing its transmission power utilizing DASCAR. This demonstration will use the satellite network to transmit sensor suite data from the prototype at lightening-fast rates. More important, it will demonstrate ACTS' ability to download digital video at real-time rates and even beyond. This is expected to occur toward the middle of the 1995 calendar year.

\section{MICRO CAMERA TESTING}

\subsection{Introduction}

The prototype DASCAR will incorporate several color video micro cameras. Micro cameras were researched and specifications were gathered on various models. On the basis of physical size and technical specifications, ORNL decided upon two micro cameras to further test in house and to formulate a decision on the proper micro camera for DASCAR. ORNL obtained, on a loan basis, a Panasonic GP-KS152 color micro camera with a 7.5 millimeter lens and a two-meter interconnecting cable, and also a Cohu 8290 remote head camera with an eight-millimeter autoiris lens. Testing was performed, not to analytically evaluate the specifications supplied through the manufacturers, but rather to obtain a realistic, objective viewpoint of each micro camera's picture quality, ease of unobtrusive installation, and micro camera performance in varying lighting conditions for the DASCAR application.

\subsection{Equipment}

The equipment employed to investigate the two micro cameras contained micro cameras and support equipment.

\subsubsection{Micro Cameras}


- Panasonic GP-KS152 color video micro camera

- Panasonic GP-LM7R5TB 7.5 millimeter lens

- Panasonic GP-CA56 two meter interconnecting cable

- Cohu 8290 remote head camera (includes interconnecting cable)

- Cosmicar eight-millimeter auto-iris lens

\subsubsection{Support Equipment}

- $\quad 12 \mathrm{~V} \mathrm{DC}$ power supply

- Panasonic AG-2200 VHS recorder/player

- Magnavox 31 centimeter color television

- Three BNC-BNC coaxial cables

- 3-M T-120 VHS cassette tape

- Extension cords

- Duct tape

- $\quad$ Flashlight (five D-cell)

\subsection{Environment}

The testing took place over two days in the outside environment and in a garage, which allowed ORNL to control the light source and vary the amount of light to which the micro cameras were subjected. The micro cameras were mounted in approximate prototype locations in a 1974 Chevrolet Corvette. Another vehicle was used to simulate oncoming headlights during nighttime operation. A large flashlight was used to simulate all other areas around the vehicle and to fabricate lights from oncoming traffic. The outside environment on both days of testing was sunny and clear, and the time of day in which the micro cameras were assessed over the two-day period was approximately the same.

\subsection{Testing}

The micro cameras were mounted in three positions to test the various views that they would be recording. Micro cameras were mounted to view the driver's face, hands, and forward field of view. The micro cameras were then subjected to bright sunlight, indoor fluorescent light, high and low beams from an oncoming stationary vehicle, spot lighting from various positions (passenger, driver, and rear sides), ambient rear light (sun), transitional lighting (bright-to-dark and dark-to-bright), and a no light condition. All of the testing was recorded onto a VHS cassette viạ a VHS recorder.

A diagram comparing the relative size of the two micro cameras is supplied as Figure 16. The Panasonic camera is much more inconspicuous and was easier to install than the Cohu. The Panasonic's interconnecting cable between the head and control unit is 0.48 centimeters in diameter. The Cohu camera requires two cables to be attached to the remote head from its 
Scale $7 " 1 "$

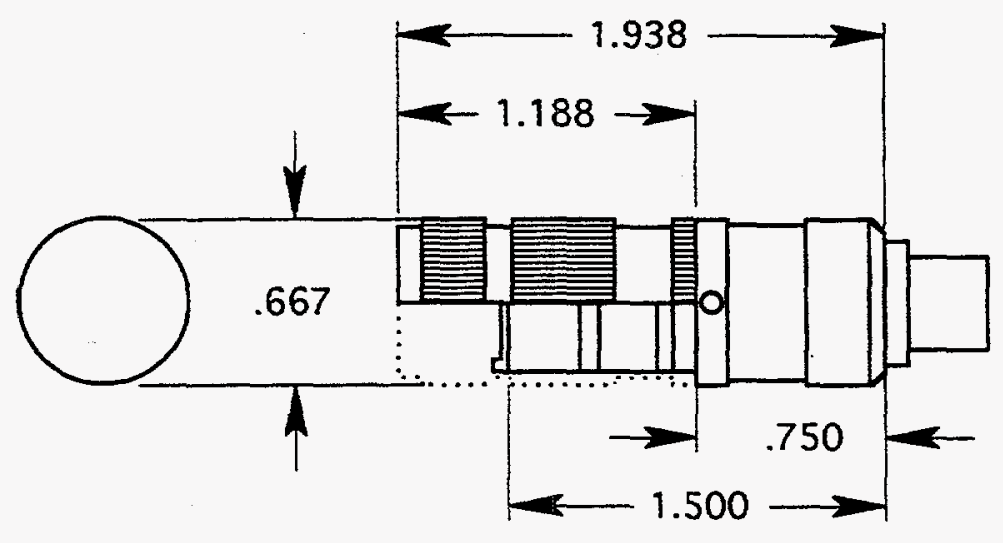

Panasonic GP-KS152 w/ lens
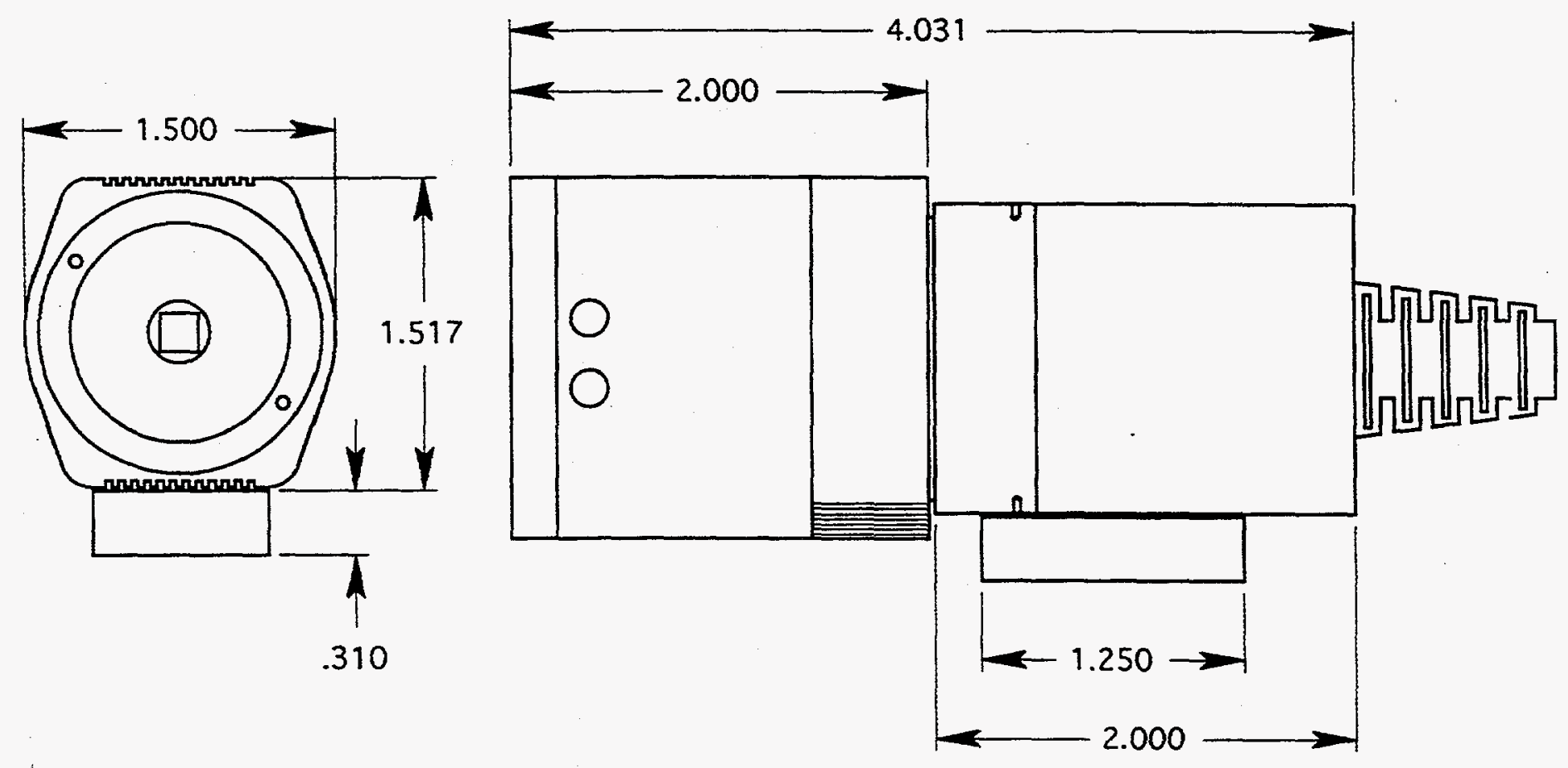

Cohu $8290 \mathrm{w} /$ lens

Figure 16. The two micro cameras shown in actual size. 
control unit, one for signal and another for the auto-iris lens. The signal cable is 0.79 centimeters in diameter and the auto-iris cable is 0.32 centimeters in diameter.

\subsection{Results}

Testing data was analyzed from and qualitative scores were provided to the data collected on the VHS cassette. Data was scored as: excellent, excellent/good, good, good/fair, fair, fair/poor, poor, and very poor. Scores on a number of variables are displayed in Table 21 . In some cases where the picture was unacceptable for the DASCAR project, a brief explanation is given. The video taped data may be obtained through ORNL.

Table 21. Results from the Micro Camera Testing

\begin{tabular}{|c|c|c|}
\hline Test Condition & Panasonic GP-KS152 & Cohu 8290 \\
\hline \multicolumn{3}{|c|}{$\begin{array}{l}\text { Micro Camera Mounted in Position to } \\
\text { View the Driver's Face }\end{array}$} \\
\hline Bright sunlight & Excellent & $\begin{array}{l}\text { Auto-iris lens causes compensation for } \\
\text { extreme ambient lighting which results } \\
\text { in the driver's face not being seen }\end{array}$ \\
\hline Fluorescent light & Excellent & Excellent \\
\hline Oncoming headlights & Excellent & Excellent \\
\hline Passenger side light & Good & Good \\
\hline Driver's side light & Good & Good \\
\hline Rear light & Fair/poor & Poor \\
\hline Ambient rear light & Excellent & Poor \\
\hline Bright light to dark light & Good & Good \\
\hline Dark light to bright light & Good/fair & $\begin{array}{l}\text { Auto-iris causes compensation for } \\
\text { extreme ambient lighting which results } \\
\text { in the driver's face not being seen }\end{array}$ \\
\hline No light & Very poor & Very poor \\
\hline \multicolumn{3}{|c|}{$\begin{array}{l}\text { Camera Mounted in Position to View } \\
\text { the Driver's Hands }\end{array}$} \\
\hline Fluorescent light & Excellent & Good \\
\hline \multicolumn{3}{|c|}{$\begin{array}{l}\text { Camera Mounted in Position to View } \\
\text { the Front Scene }\end{array}$} \\
\hline Bright sunlight & Excellent & $\begin{array}{l}\text { With automatic gain and iris control on, } \\
\text { the picture is saturated with light; the } \\
\text { picture quality can be increased by } \\
\text { manual adjustments }\end{array}$ \\
\hline Fluorescent light & Excellent & Good \\
\hline
\end{tabular}


As can be observed from the testing scores, the Panasonic GP-KS152 performed much better than the Cohu 8290 . When the micro cameras were mounted in any of the three positions tested, the Cohu did not produce a usable picture in bright background lighting conditions. The Panasonic camera was capable of producing a usable picture in most bright conditions although with rear spotlighting, the picture was barely usable when viewing the driver's face. Neither micro camera was capable of producing a picture in complete darkness.

\subsection{Conclusions}

Both micro cameras were capable of providing a quality color picture in normal ambient lighting. The differences between the two cameras became obvious as the lighting conditions varied. The Cohu 8290 uses an auto-iris lens assembly. This allows the camera's aperture to adjust accordingly to the lighting conditions present in the scene. This type of system is generally very effective when recording background scenery at any depth of field. The iris adjustment is automatically configured in respect to the entire scene illumination, not in respect to centered objects in the scene. When there is an object placed in front of bright background, the auto-iris is not smart enough to concentrate and adjust to the luminance of the object. This results in the aperture being adjusted for the entire scene and the object, which is the center of attention, to be a shadow. Figure 17 illustrates this point. In the (A) drawing, one can see both the background and the person in front of the object, just as our human eye would perceive the images. In the (B) drawing, due to the auto-iris compensation for the light intensity of the scene, the object appears as a shadow.

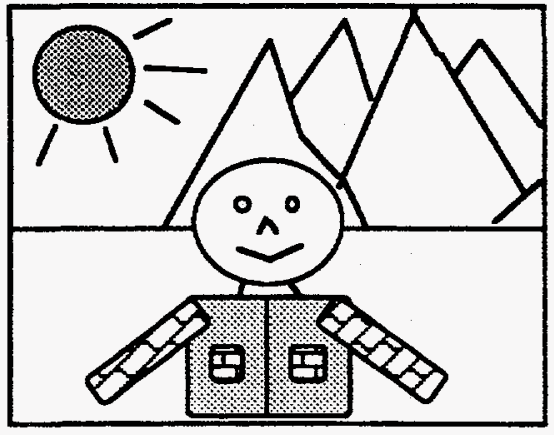

(A)

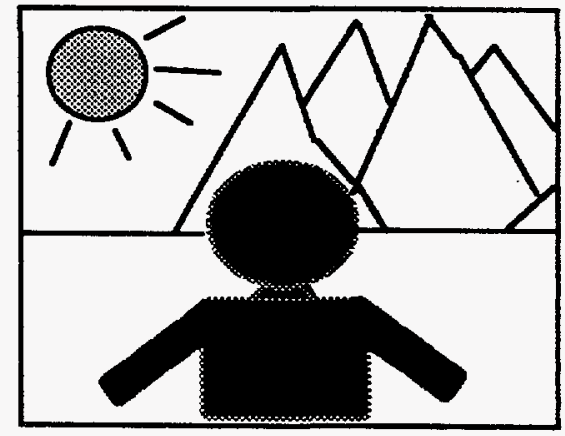

(B)

Figure 17. Pictures from the two micro cameras.

This is an inherent problem with the Cohu 8290 micro camera and for any other auto-iris video camera. In the case of the DASCAR project, ORNL concludes that this will be a downfall in monitoring the driver's face and hands with this type of camera. During bright sunshine, either through the windshield or rear window, the view of the driver will be lost, thus downgrading the 
quality of the video data system. The Cohu micro camera also needed manual iris and gain adjustments when changing from a dark environment to a predominantly bright environment in order to achieve a usable picture.

The Panasonic GP-KS152 color micro camera takes a different approach in light control. The camera uses digital signal processing to mask elements in the picture. Testing revealed that when the camera was subject to bright background lighting, the object of attention (the driver) was still clear and able to be seen as in the figure (A). This is because the camera uses digital circuitry to mask out parts of the scene which are not being monitored. For testing purposes, ORNL had used the factory preset mask, although a user programmable mask can be programmed. This feature works in conjunction with the micro camera's automatic electronic light control to provide for a quality picture over a very wide range of lighting conditions.

ORNL concludes that the Panasonic GP-KS152 micro camera will be the best camera for the DASCAR project.

\section{HEAT LOAD CALCULATIONS FOR THE INSTRUMENTATION PACKAGE IN AUTOMOBILE TRUNKS}

Some of the DASCAR instruments will be placed in the trunk of automobiles. This equipment will have maximum operating temperatures. ORNL performed heat-load calculations on the instrumentation package in a number of automobile trunks to see what temperatures would be expected.

\subsection{Problems that Were Considered}

There are two different heating problems that were considered. The first is calculating the temperatures with the equipment turned off, but with the automobile sitting in a parking lot in the bright sun. This is customarily referred to as a "hot soak." The second problem is calculating the temperatures when the equipment is running. There are two different parts of this second problem. The first is calculating the temperatures with no cooled air being supplied to the trunk. The second is calculating the air flow needed to keep the equipment cool enough to operate successfully. There is a third, but minor, problem to consider which is how fast the equipment heats up when it is turned on. In other words, after the automobile has sat in a parking lot for several hours, will the equipment heat up too rapidly when it is first turned on before any significant amount of cooled air can be supplied to it.

\subsection{Methods Used}

\subsubsection{Temperatures at Hot Soak Conditions}

ORNL has a simplified trunk heat load calculation that runs on a PC using LOTUS 123. The 
model does heat balances on the surfaces of the trunk. For each surface, the temperature is such that the heat load from solar energy is balanced by heat rejected by convection to the air and reradiation to the sky. In addition, ORNL does radiant transfer across the trunk from one surface to another. This provides a modest redistribution of the heat among the surfaces.

The highest temperatures would be expected on a sunny day with very little wind. ORNL developed a baseline calculation for an automobile with an empty trunk. The results approximately match measurements made by ORNL on a reasonably new Nissan Sentra on a warm (approximately 29 degrees Celsius $\left({ }^{\circ} \mathrm{C}\right)$ ), sunny day in May in Oak Ridge, TN. We used a solar heat load which is appropriate to solar noon, which happened about 2:00 p.m. Eastern daylight time. ORNL compared the results from the model to the temperatures measured at that time. Our model matches the temperatures of the lid of the trunk $\left(-52^{\circ} \mathrm{C}\right)$ and inside the trunk $\left(\sim 41-42^{\circ} \mathrm{C}\right)$ fairly well. The back and one side of the trunk are assumed to be directly illuminated by the sun. The estimated temperatures for these two surfaces are somewhat lower than ORNL's measurements $\left(\sim 44^{\circ} \mathrm{C}\right.$ calculated compared to $\sim 49^{\circ} \mathrm{C}$ measured). The other side is assumed to be in the shade. The calculated temperature is about five ${ }^{\circ} \mathrm{C}$ below $\mathrm{ORNL}$ 's measured value $\left(\sim 35^{\circ} \mathrm{C}\right.$ calculated compared to $\sim 40^{\circ} \mathrm{C}$ measured).

There are a couple of different ways to estimate the temperature in the interior of the trunk. The first assumes that the air in the trunk is very well stirred so that the temperature drop across the boundary layers is less than a degree. In that case, the temperature of the air in the trunk would be about the area weighted average of the surfaces of the trunk. For the hot soak case, this is about $42^{\circ} \mathrm{C}$. Another approximation is to assume that the equipment package is at an even temperature, but the transfer from the package to the trunk surfaces is by free convection plus radiant transfer. The value of the trunk temperature estimated by this latter method will depend on one's model for the free convection, particularly from the package to the lid of the trunk and to the floor of the trunk. With ORNL's best guesses about these factors, we get a hot soak average of about $42^{\circ} \mathrm{C}$.

\subsubsection{Temperatures with Equipment Running}

The model for trunk temperatures with the equipment running is almost the same as that used for the hot soak problem. There are two principal differences. The first is that the radiant transfer among the surfaces of the trunk is reduced by an order of magnitude to simulate having the equipment package blocking the radiant transfer paths. The second is that a total heat load of an additional $400 \mathrm{~W}$ is applied to the outer surfaces of the trunk. The temperature of the lid went up $\sim 17^{\circ} \mathrm{C}$ (to $\sim 69^{\circ} \mathrm{C}$ ). This was the largest increase in surface temperature

The trunk temperature estimated from an average of the surfaces rose $\sim \operatorname{seven}{ }^{\circ} \mathrm{C}$ (to $\sim 49^{\circ} \mathrm{C}$ ). The estimate assuming free convection plus radiant transfer to the trunk surfaces rose $\sim 21^{\circ} \mathrm{C}$ (to $\sim 63^{\circ} \mathrm{C}$ ). 


\subsubsection{Cooling Air Flow Needed to Keep Equipment Below Maximum Operating Temperature}

The calculated trunk temperatures are higher than the maximum equipment operating temperatures. Therefore, some cool air needs to be routed to the trunk. A question is how much cooling air is needed to keep the equipment temperature down to $35^{\circ} \mathrm{C}$.

Suppose the cooling air temperature is $24^{\circ} \mathrm{C}$, which represents conditioned air from inside the automobile. The specific heat $\left(C_{p}\right)$ and density of air $(\rho)$ at $27^{\circ} \mathrm{C}$ are:

$\mathrm{C}_{\mathrm{p}}=0.24$ British thermal unit (Btu)/pound mass $\left(\mathrm{lb}_{\mathrm{m}}\right)-\left({ }^{\circ} \mathrm{F}\right.$ (Fahrenheit) $\left.-32 / 1.8\right)$ and $\rho=0.0735 \mathrm{lb}_{m}$ /cubic foot.

The desired air flow to remove the $400 \mathrm{~W}$ of internal heat generated by the equipment is therefore:

Volume of air $=400 \mathrm{~W} / 0.2931 \mathrm{~W}$-hours $/ \mathrm{Btu} /\left[\left(35-24^{\circ} \mathrm{C}\right) \times 0.24 \mathrm{Btu} / \mathrm{lb}_{\mathrm{m}}-\left({ }^{\circ} \mathrm{F}-\right.\right.$ $32 / 1.8) \times 0.0735 \mathrm{lb}_{\mathrm{m}} / \mathrm{cubic}$ foot $]=3868 \mathrm{cubic}$ feet $/$ hour $/ 60 \mathrm{minutes} / \mathrm{hour}=64$ cubic feet per minute (cfm).

Note that this calculation is only for removing the heat generated by the equipment. Under hot soak conditions, which also represent the heat load on the trunk when the automobile is stopped in traffic, the temperature inside the trunk is about $41^{\circ} \mathrm{C}$. If the equipment package is reasonably well insulated, and if the cooling air is ducted to the equipment package, then the heat from the surfaces of the trunk should not affect the equipment package once cooling air starts flowing. However, if the equipment package is not insulated, or if the cooling air is ducted into the trunk and then is moved to the equipment package by fans circulating air inside the trunk, then additional heat must be removed to allow for the heat load from the surfaces of the trunk.

The LOTUS spreadsheet estimates equipment package temperature by three different methods. One is the temperature such that radiant and convective transfer from the package to the trunk surfaces leads to a heat balance. Under hot soak conditions, this value is about $42^{\circ} \mathrm{C}$. ORNL ran a set of calculations on the LOTUS spreadsheet in which we assumed a negative heat load in the equipment package. ORNL iterated until the equipment package temperature that leads to convective and radiant heat balance was $35^{\circ} \mathrm{C}$. This required a negative heat load of about -140 $\mathrm{W}$, which required about $23 \mathrm{cfm}$ of additional cooling air. Thus, the total cooling air requirement was $64+23=87 \mathrm{cfm}$.

\subsubsection{Rate of Rise of Temperature of Equipment Package}

When the automobile is first started up, there is no cool air available. It takes a few minutes for the air conditioner to get the interior of the automobile cooled down. Until cool air is available, the equipment will heat up from its own internal heat generation. As one may see from previous calculations, the equipment package will be too hot to be able to operate if the automobile is 
parked outside on a warm, sunny day here in the southeast. However, if the day is cool or cloudy, or if the automobile is parked in shade, the package will be cooler. One may envision a scenario for which the equipment package is below its maximum limit, but overheats after it is first turned on because the cooled air has not yet reached it. The objective of the calculation is to estimate how fast the equipment package would heat up if no cooling air was reaching it.

The equipment package weighs approximately 45.35 kilograms. For this simplified calculation, assume that the heat load is distributed fairly evenly within the package. Under such an assumption, the rate of heat rise is the heat generated divided by the heat capacity of the instrument package. The specific heat of iron and copper alloys is about $0.1 \mathrm{Btu} / / \mathrm{b}_{\mathrm{m}}-\left({ }^{\circ} \mathrm{F}\right.$ 32/1.8). Those of aluminum, glass, and wood are considerably higher. A reasonable lower bound on the average heat capacity of the equipment package is $0.1 \mathrm{Btu} / \mathrm{b}_{\mathrm{m}}-\left({ }^{\circ} \mathrm{F}-32 / 1.8\right)$. With an internal heat generation rate of $400 \mathrm{~W}$, the temperature rate of rise becomes as follows:

$$
\begin{aligned}
& \text { Rate of rise }=400 \mathrm{~W} / 0.2931 \mathrm{~W} \text {-hour } / \mathrm{Btu} /\left[0.1 \mathrm{Btu} / \mathrm{bb}_{\mathrm{m}}-\left({ }^{\circ} \mathrm{F}-32 / 1.8\right) \times 45.35\right. \\
& \text { kilograms }]=58^{\circ} \mathrm{C} / \mathrm{h} .
\end{aligned}
$$

In a period of five minutes, which is probably about the minimum time needed to start providing cool air, the temperature rise would be:

$$
\text { Temperature difference }=5 \text { minutes } /(60 \text { minutes } / \text { hour }) \times 58^{\circ} \mathrm{C} / \mathrm{h}=6^{\circ} \mathrm{C} \text {. }
$$

\subsection{Results and Conclusions}

The results and conclusions of the investigation are presented below. The principal heat load is due to the sun shining on the surfaces of the trunk. The calculations were done with a heat load appropriate to a warm (approximately $29^{\circ} \mathrm{C}$ ), sunny day in the eastern U.S. The results were compared with measurements made on such a day in Oak Ridge, TN. The laptop computer which controls the instrument package has a maximum operating temperature of approximately $35^{\circ} \mathrm{C}$. For the package to operate successfully, the temperature inside the trunk must be kept below this value.

\subsubsection{Hot Soak Problem}

The first results are for the hot soak problem. For an automobile standing still on a warm, sunny day, the temperature inside the trunk would be about $41-42^{\circ} \mathrm{C}$ with the equipment turned off. The top of the trunk may be as hot as $49-52^{\circ} \mathrm{C}$. The sides of the automobile and the back of the trunk may be as hot as $46-49^{\circ} \mathrm{C}$ if they are facing the sun. If they are facing away from the sun, the temperatures may range from $35-40^{\circ} \mathrm{C}$.

\subsubsection{Equipment Running}

The second results are for the automobile with the equipment turned on. The worst case will be 
with the automobile stopped at a traffic light or other traffic obstacle. With the automobile running at highway speeds, the additional cooling from the airflow would lower the temperatures many degrees. With the equipment generating $400 \mathrm{~W}$, the temperature inside the trunk rises between about eight ${ }^{\circ} \mathrm{C}$ and about $21^{\circ} \mathrm{C}$ (depending on how one estimates the trunk temperature), in other words to $49-62^{\circ} \mathrm{C}$. This is far higher than the operating limit for the equipment. The obvious conclusion is that the equipment cannot be operated under such conditions without a source of cool air to dissipate the heat.

\subsection{Solutions}

One way to provide cooling to the equipment is to run a duct into the interior of the automobile and pull conditioned air from the interior past the equipment. For a maximum equipment temperature of $35^{\circ} \mathrm{C}$ and an interior air temperature of $24^{\circ} \mathrm{C}$, the $400 \mathrm{~W}$ generated by the equipment can be dissipated by a cooling fan providing approximately $65 \mathrm{~cm}$ of air. This is well within the range of available fans.

When the equipment is first started, it will heat up for a while until the air-conditioning system is able to provide enough cool air to dissipate the $400 \mathrm{~W}$ heat load. The equipment package weighs about 45.35 kilograms. This provides enough thermal inertia so that the rate of rise for the equipment package is about $60^{\circ} \mathrm{C} / \mathrm{h}$. Thus, if it takes five minutes before cooled air begins to reach the equipment package, then the temperature in the package should rise a maximum of approximately $\operatorname{six}^{\circ} \mathrm{C}$. In other words, unless the trunk temperature is already higher than the maximum equipment operating temperature, the equipment should be able to start operating as soon as the automobile is started or a very few minutes later.

The calculations reported here were done assuming warm weather in the late spring here in the southeast. The probable worst conditions for the eastern U.S. would be those done for this work with an air temperature of about $35^{\circ} \mathrm{C}$. The worst conditions in the U.S. would be those in the desert southwest, particularly the Mojave desert regions of California. The clear air of the desert would increase the solar heat load by about $15 \%$. In addition, the climatological data published by the American Society of Heating, Refrigeration, and Air-Conditioning Engineers show a one percent chance of air temperatures reaching $44^{\circ} \mathrm{C}$ and a five percent chance of $42^{\circ} \mathrm{C}$. ORNL has studied the literature on air-conditioning loads and believe that its method can be used to calculate temperatures for the higher heat loads for both the worst conditions in the east and also those in the desert southwest.

\section{PHASE II OF THE RESEARCH}

There are three other tasks that will be conducted during phase II of the R\&D. The work to be accomplished in each of these steps is briefly described below. 


\subsection{Prepare an Evaluation Plan}

ORNL will generate a plan for evaluating the prototype data acquisition system with regard to: removal of DASCAR from an existing vehicle, and installation and calibration in other vehicles; reliability of the sensors and systems; data collection/transmission process (data integrity); impact on the driveability of the vehicle and obtrusiveness of the system to the driver; data analysis procedures; conspicuousness of the vehicle to other drivers; and DASCAR installation and removal training and documentation. In order to identify any operational problems not captured by the systems testing and evaluation, the evaluation plan will also address a short-term pilot research program to manipulate DASCAR under operational conditions using "naive" drivers. It is assumed that this effort will involve no more than four weeks and 10 drivers, and will exercise the full capabilities of the data acquisition system.

\subsubsection{Removal of the System from an Existing Vehicle, and Installation and Calibration in Other Vehicles}

ORNL will assess the time required to remove DASCAR from a vehicle and the time required to install and calibrate the system in other vehicles. Installation in at least five other vehicle types will be carried out and include: one compact or subcompact, one full size vehicle, one minivan, one multipurpose vehicle, and one heavy vehicle. All problems encountered in the installation and removal process will be documented. Since DASCAR is intended to be installed on a wide variety of vehicles with different vehicle imposed constraints, it is likely that problems with installation will be highly vehicle specific. For this reason, ORNL will sample (i.e., examine, not install) at least four vehicles in each class, representing a cross section of manufacturers, to identify, to the greatest extent possible, the problems that can be anticipated in installing the data acquisition system.

\subsubsection{Reliability of Sensors and Systems}

ORNL will determine the reliability of the sensors and systems by exercising DASCAR (installed in a vehicle) under a variety of conditions including: day/night, snow/rain (depending on the season), reduced visibility (e.g., fog), various roadway conditions (e.g., level, hilly, and rough), hot/cold weather, different drivers (driving styles), and different installers/repeated installations. This will be used to define: the conditions under which data collection can take place; the installation, and removal practices and constraints that will maximize system/sensor reliability; and the specific limitations of conditions (if any) under which an equipped vehicle can be utilized or of the parameters that can be measured. Since installation and use in different vehicles or types of vehicles may influence system reliability and constraints, reliability will be investigated for each vehicle type. For at least one vehicle type, ORNL will evaluate systems reliability over a continuous period of 30 days with particular attention paid to maintenance of calibration and data integrity. 


\subsubsection{Data Collection/Transmission Process}

Data will be collected under the variety of conditions defined above to determine the integrity of data from the sensors to the point of analysis. Where raw data are transmitted (i.e., not recorded onboard) to the CDC/AF, ORNL will compare raw data collected directly from the sensors and analyzed separately from vehicle systems, with data collected at the data collection point using vehicle systems. This process will be performed for all parameters with a sufficiently long datacollection period to be assured of data integrity.

\subsubsection{Impact on the Driveability of the Vehicle and Obtrusiveness of the System to the Driver}

ORNL will ensure that the installed DASCAR does not impact the driveability of the vehicle, and specifically does not compromise safety from the standpoint of vehicle handling and/or visibility. ORNL will further make sure that the system is as unobtrusive to the driver of the vehicle as possible. All instances where either the operation of the vehicle or performance of the driver is unavoidably compromised by DASCAR will be documented. At no time, however, will the safety of the driver be jeopardized.

\subsubsection{Data Analysis Procedures}

To ensure that the characteristics, format, and variability of the collected data are compatible with the potential analysis strategies, ORNL will exercise the recommended data-analysis procedures (as described in section 6) for each of the parameters measured.

\subsubsection{Conspicuousness of the Vehicle to Other Drivers}

Given the desire to minimize the impact of an instrumented vehicle's appearance on the behavior of other drivers, ORNL will assess the conspicuousness of an instrumented vehicle and how it might influence the behavior of other drivers.

\subsubsection{DASCAR Installation and Removal Training and Documentation}

ORNL will exercise the training procedures and documentation for installing, calibrating, operating, maintaining, and removing DASCAR to make sure that individuals not involved with the development and construction of the data acquisition system can successfully conduct the necessary activities.

\subsection{Conduct the Evaluation, Update the System, and Perform Pilot Research}

ORNL will evaluate and pilot test DASCAR using the approved evaluation plan. The plan will be implemented in full at the NHTSA East Liberty, $\mathrm{OH}$ test facility, and will be carried out as a cooperative effort with the Vehicle Research and Test Center staff. At the conclusion of the evaluation, ORNL will prepare a report detailing the methodology used, results of the evaluation 
and detailed recommendations for changes in the system design, the associated specifications, the documentation, and other relevant aspects of system implementation. All recommended changes will be justified in writing. Upon written approval of NHTSA, ORNL will implement the proposed changes.

\subsection{Demonstrate and Deliver the System, and Train NHTSA Staff}

ORNL will deliver DASCAR to NHTSA and perform a final demonstration of the system at the NHTSA facility located in East Liberty, OH. At this facility DASCAR will be installed on a government-owned vehicle and exercised on the test track. The installation and demonstration will encompass the data collection/analysis capability. ORNL will also conduct training of NHTSA staff on the installation, calibration, operation, maintenance, and removal of the data acquisition system. In addition, system documentation will be delivered at that time.

\section{DASCAR HARDWARE AND SOFTWARE DELIVERED TO NHTSA}

The DASCAR which was assembled, constructed, and delivered to NHTSA in December 1995 consists of seven major elements: a DAP, a data storage and transmission system, a power system, an ESB, a sensor suite, a video data system, and a CDC/AF.

\subsection{DAP, Data Storage and Transmission System, Power System, and ESB}

The DAP contains data acquisition boards. It was furnished by Scientific Atlanta. The data storage and transmission system is composed of several components: cellular telephone equipment, radio telemetry, laptop computer, docking station, and SCSI-two hard drive. The cellular telephone equipment was procured from Cellular One of Columbus, $\mathrm{OH}$. The radio telemetry, laptop computer and docking station, and SCSI-two hard drive were purchased from Proxim, IBM, and Seagate, respectively, via Scientific Atlanta. The power system includes three items, a battery, switching-power supplies, and dual-battery isolator. The battery and switchingpower supplies were acquired from Power Sonic and Vicor. The dual-battery isolator was obtained from Lynx Supply in Oak Ridge, TN. The ESB was designed and fabricated in-house at ORNL.

\subsection{Sensor Suite}

\subsubsection{Components}

The data acquisition system sensor suite comprises: a linear position transducer, pedal force transducers, an accelerometer, a six-DOF orientation sensor, an ADRS, Hall-effect sensors, an electronic compass, range sensors, radiometers/photometers, a sound level meter, a GPS receiver, and lateral-position lane tracking systems 
The linear position transducer was procured from UniMeasure. The pedal force transducer was developed and constructed by ORNL. Main components consist of 45 and 113 kilogram load cells purchased from Entran Devices, Incorporated in Fairfield, NJ. Material on the load cells is exhibited in Appendix BB. The accelerometer (GyroChip II) and six-DOF orientation sensor were acquired from Systron Donner. The ADRS was specially designed for DASCAR by UFI. The Hall-effect sensors were obtained from Pro Sports Engineering. The electronic compass was procured from KVH Industries; the range sensors (controlasers) were modified by Segnetron Israel, Limited and purchased from Silicon Heights. The radiometers/photometers were acquired from International Light. A Quest Electronics sound level meter was obtained from Dawson Associates, Incorporated in Lawrenceville, GA. A Magellan GPS receiver was supplied via the CRADA with Scientific Atlanta. A dual-function (GPS and cellular) antenna manufactured by Matsushita Electric Works, Limited was obtained from Spectra Systems, Incorporated in Boca Raton, FL. Information on the antenna is shown in Appendix BB. At the time DASCAR was delivered to NHTSA, ORNL was still developing two lateral position lane tracking systems. One was being designed via a subcontract with Williamson Associates; the other was being constructed by Aerometrics through a CRADA.

\subsubsection{Specifications}

\subsubsection{Driver Parameters}

Specifications for the sensors which gather driver-related parameters are shown in Tables 22 through 24. Table 22 presents specifications for the DASCAR driver control actions. It provides the range for each parameter. Table 23 lists the specifications for the sensors employed for recording equipment status. It furnishes information on how each sensor is measured. Table 24 exhibits the specifications for the data acquisition system physiological measures data collection. It supplies material on the fixed rate, $\mathrm{A} / \mathrm{D}$ resolution, and range for each parameter-sensor combination. $\mathrm{K}$ is the symbol for kelvin.

\subsubsection{Vehicle Parameters}

Specifications for the sensors which gather the vehicle-related parameters are shown in Table 25 . It provides full scale information.

\subsubsection{Environment Parameters}

Specifications for the sensors which record environment parameters are exhibited in Table 26. The table shows material on full scale.

\subsection{Video Data System}

The DASCAR video data system comprises both black-and-white and color video micro cameras, a VITC generator, a digital quad picture processor, super-VHS recorder, a CVDSRS encoder, 
Table 22. Driver Control Actions

\begin{tabular}{|l|l|l|}
\hline Parameter & Sensor & Range \\
\hline Accelerator/throttle & Linear position transducer & DC to full scale \\
\hline Brake pedal & Pedal force transducer & 0.4 to 136.0 kilograms \\
\hline Steering wheel & Linear position transducer & DC to full scale \\
\hline
\end{tabular}

Table 23. Equipment Status

\begin{tabular}{|l|l|}
\hline Parameter & How Measured \\
\hline Auxiliary device & On/off \\
\hline Brake lights & On/off \\
\hline Hazard flashers & On/off \\
\hline Headlights & On/off \\
\hline Horn & On/off \\
\hline Parking lights & On/off \\
\hline Rear window defogger & On/off \\
\hline Rear window wiper & On/off \\
\hline Seat belts & On/off \\
\hline Turn signals & On/off \\
\hline Windshield wipers & On/off \\
\hline
\end{tabular}

Table 24. Physiological Measures

\begin{tabular}{|l|l|l|l|l|}
\hline Parameter & Sensor & Fixed Rate & A/D Resolution & Range \\
\hline Core temperature & ADRS & $1 \mathrm{~Hz}$ & $12 \mathrm{bit}$ & $0-500$ degrees K \\
\hline Electrocardiogram & ADRS & $50 \mathrm{~Hz}$ & $8 \mathrm{bit}$ & $1 \mathrm{to} 25 \mathrm{~Hz}$ \\
\hline Electroencephalogram & ADRS & $50 \mathrm{~Hz}$ & $8 \mathrm{bit}$ & 1 to $25 \mathrm{~Hz}$ \\
\hline Electromyogram & ADRS & $10 \mathrm{~Hz}$ & $8 \mathrm{bit}$ & 20 to $500 \mathrm{~Hz}$ \\
\hline Electrooculogram & ADRS & $10 \mathrm{~Hz}$ & $8 \mathrm{bit}$ & 0.08 to $5.0 \mathrm{~Hz}$ \\
\hline Fidget index & Accelerometer & To be determined & 8 bit & Not applicable \\
\hline Galvanic skin response & ADRS & $10 \mathrm{~Hz}$ & 12 bit & 0 to $5 \mathrm{~V}$ \\
\hline Respiration & ADRS & $10 \mathrm{~Hz}$ & 8 bit & Not applicable \\
\hline Skin temperature & ADRS & $1 \mathrm{~Hz}$ & 12 bit & $0-500$ degrees K \\
\hline
\end{tabular}


Table 25. Vehicle Parameters

\begin{tabular}{|c|c|c|}
\hline Parameter & Sensor & Full Scale \\
\hline Heading & Electronic compass & 0 to 359.9 degrees \\
\hline Headway & Range sensor & 0 to 100 meters \\
\hline Lateral acceleration & Six-DOF orientation sensor & -2 to +2 gravity \\
\hline Lateral lane keeping & Lateral position lane tracking system & 0 to 1.8 meters \\
\hline Longitudinal acceleration & Six-DOF orientation sensor & -2 to +2 gravity \\
\hline Pitch & Six-DOF orientation sensor & $+/-100$ degrees per second \\
\hline Roll & Six-DOF orientation sensor & $+/-100$ degrees per second \\
\hline Tailway & Range sensor & 0 to 50 meters \\
\hline Time-to-collision & Range sensor & 0.1 to 4.0 seconds \\
\hline Vehicle location & GPS receiver & not applicable \\
\hline Velocity & Hall-effect sensor & 0 to 200 kilometers per hour \\
\hline Vertical acceleration & Six-DOF orientation sensor & -2 to +2 gravity \\
\hline Yaw & Six-DOF orientation sensor & $+/-200$ degrees per second \\
\hline
\end{tabular}

Table 26. Environmental Parameters

\begin{tabular}{|l|l|l|}
\hline Parameter & Sensor & Full Scale \\
\hline Illumination & Radiometer/photometer & Not applicable \\
\hline Lumination & Radiometer/photometer & Not applicable \\
\hline Noise/sound & Sound level meter & $30-140$ decibels \\
\hline
\end{tabular}

and a digital picture transmission system. The video data system is graphically depicted in Figure 18.

Two black-and-white CCD board cameras were procured from Edmund Scientific Company in Barrington, NJ. They are employed to record hand positions and eye point of regard. Literature on the board cameras is exhibited in Appendix CC. Two Panasonic color video micro cameras, the Horita VITC generator, the Robot digital quad picture processor, and JVC super-VHS recorder were purchased from Eastern Video Systems in Billerica, MA. The color video micro cameras are used to record the forward and aft outside video scenes. The CVDSRS encoder was furnished by Scientific Atlanta; the Robot digital picture transmission system was acquired from Vihon Associates in Tullahoma, TN. 


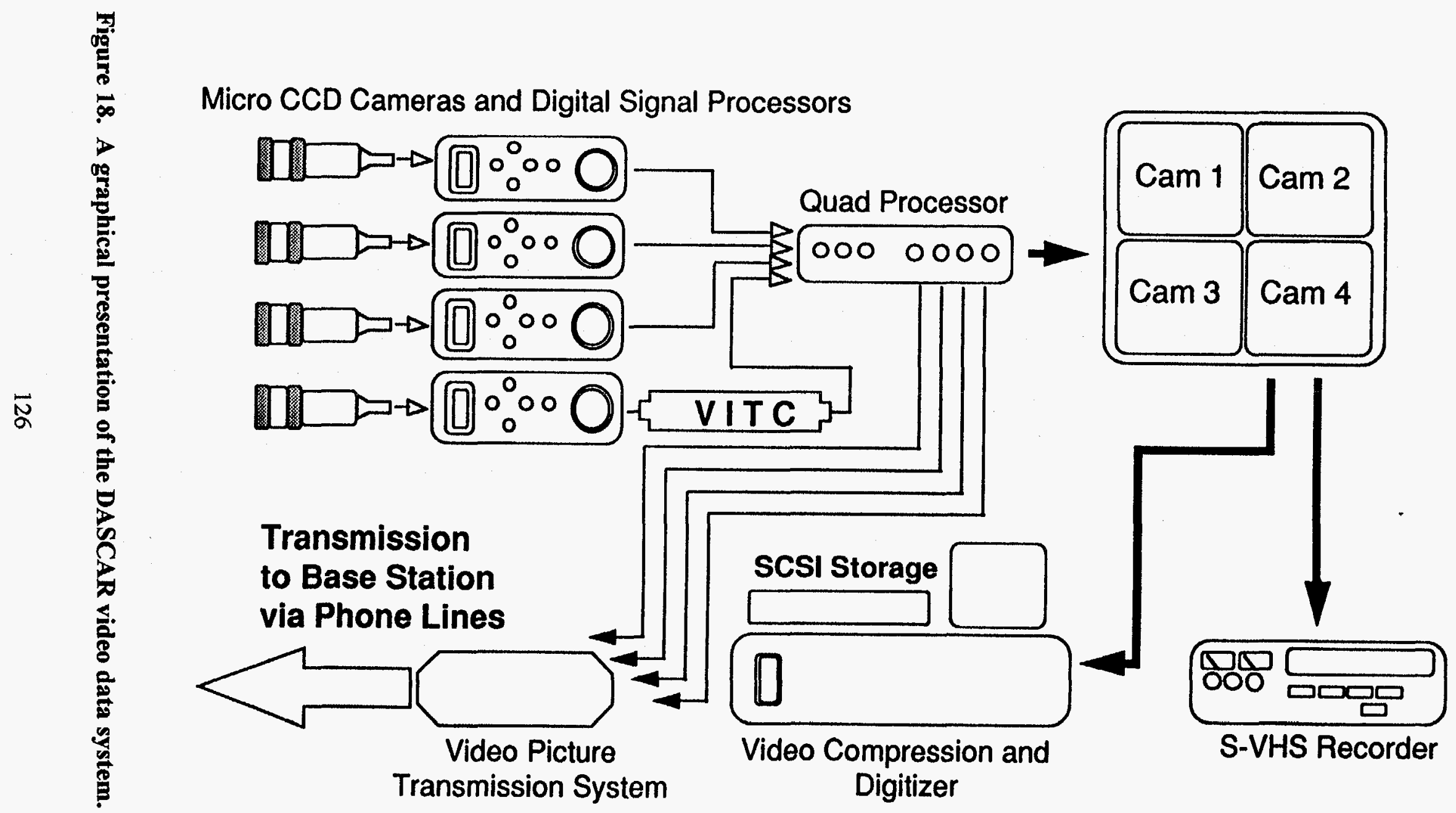




\section{$14.4 \quad \mathrm{CDC} / \mathrm{AF}$}

The CDC/AF is based around a PC platform obtained from Austin Computer. Support systems include: a digital quad picture processor, a super-VHS recorder, a super-VHS monitor, a CVDSRS decoder, radio telemetry hardware, and a digital picture receiver system. The Robot digital quad picture processor, a Panasonic super-VHS recorder, and a Panasonic super-VHS monitor were procused from Eastern Video. The CVDSRS decoder and radio telemetry hardware were supplied by Scientific Atlanta; the Robot digital picture receiver system was purchased from Vihon Associates

\subsection{Software}

The DAP-specific software was developed by Scientific Atlanta. The CDC/AF software consists of: SAS, Test PAES, and the digital picture receiver system software. SAS and Test PAES were received at no expense to the project from NHTSA and the U.S. Air Force, respectively. A small subcontract was let with Calspan Corporation (the software developer) in late 1995 to covert Test PAES from an aircraft oriented framework to one that will support analysis of ground transportation systems and have applicability to DASCAR. Figure 19 illustrates a sample of the Test PAES vehicle data display tools. The digital picture receiver system software was acquired from Vihon Associates.

\section{CRASH AVOIDANCE PROBLEMS THAT CAN BE ADDRESSED BY DASCAR}

The DASCAR will function as the cornerstone research platform for NHTSA during the next decade, and nearly all of NHTSA's crash-avoidance research will be conducted utilizing copies of the data acquisition system. The DASCAR will be employed to collect normative driverperformance data, support system-performance guideline development, evaluate both conventional and ITS technologies, support simulator validation, and fine tune simulators (e.g., scenarios, motion algorithms, and driver feedback). Normative driver-performance data include both long-term naturalistic and traffic incident/near miss data. The DASCAR will allow normative driver data to be collected within and between subjects, between various vehicle types (varying in size, weight, and vehicle design features), and under a wide variety of roadway and environmental conditions (such as visibility and roadway conditions). The data acquisition system will support system-performance guideline development for vision enhancements, the condition of the driver, and for a variety of crash scenarios (lane change, merging, backing, rear-end, intersection, and roadway departure collisions). Examples of conventional technologies to be evaluated via DASCAR include: lighting, mirrors, dashboard configuration, and control configuration. ITS technologies consist of crash-avoidance systems (e.g., intelligent cruise control), driver navigation and traveler information systems, and other advanced in-vehicle systems (e.g., active suspension and ABSs). 


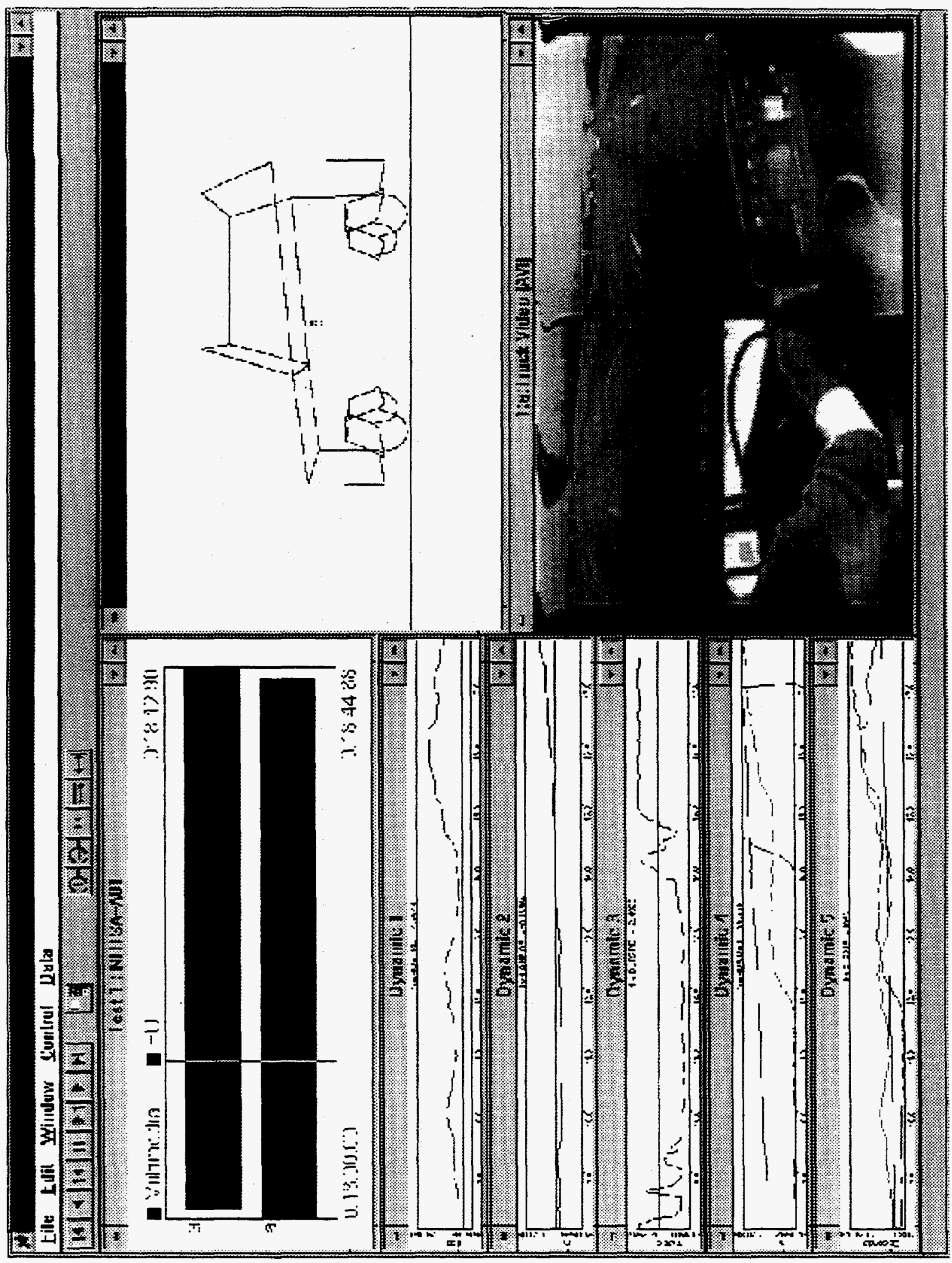

Figure 19. A sample of the Test PAES vehicle data display tools. 


\section{REFERENCES}

Burgard, M. (1992). "Making the Most Out of Your Data," UNIX WORLD, September, pp. 85-92.

Department of Defense (1968). "Specification Practices," MIL-STD-490.

Horowitz, P. and Hill, W. (1989). The Art of Electronics, Cambridge University Press.

Wayner, P. (1992). "Ample Waves of Data: Five Tools to Help You Stay Afloat," BYTE, January, pp. 259-70.

\section{ACRONYMS AND ABBREVIATIONS}

A/D analog to digital

ABS antilock brake system

ACTS Advanced Communications Technical Satellite

ADRS ambulatory data recording system

ASCII American Standard Code for Information Interchange

AVL

AWG automatic vehicle location

American wire gauge

BMDP Biomedical Data Program

bps bits per second

Btu British thermal unit

${ }^{\circ} \mathrm{C} \quad$ degrees Celsius

CCD charge coupled device

$\mathrm{CDC} / \mathrm{AF}$ central data collection/analysis facility

cfm cubic feet per minute

$\mathrm{CO}_{2} \quad$ carbon dioxide

$\mathrm{C}_{\mathrm{p}}$

CPU

specific heat

CRADA cooperative research and development agreement

CVDSRS compressed video digital storage and retrieval system

DAP data acquisition platform

DAS data acquisition station

DASCAR data acquisition system for crash avoidance research

DC direct current

DOF degrees of freedom

DPU data processing unit 
ECU engine control unit

EMI electromagnetic interference

ESB equipment status bus

F Fahrenheit

FET field effect transistor

G Gauss

GA/GPS general administrative and general plant services

$\mathrm{GHz} \quad$ gigahertz

GM General Motors

GPS global positioning system

$\mathrm{Hz} \quad$ hertz

IBM International Business Machines

IR infrared

ITS intelligent transportation systems

K kelvin

$\mathrm{Ib}_{\mathrm{m}} \quad$ pound mass

LES land earth station

$\mathrm{Mb} \quad$ megabytes

$\mathrm{MHz} \quad$ megahertz

MIL-STD military standard

modem modulator-demodulator

MPEG moving picture experts group

NASA National Aeronautics and Space Administration

NHTSA National Highway Traffic Safety Administration

OBD onboard diagnostics

OCAR Office of Crash Avoidance Research

ORNL Oak Ridge National Laboratory

$\rho \quad$ density of air

PAES Planning, Analysis, and Evaluation System

PC personal computer

PM person month

PRIP pattern recognition and image processing 
QRS

quartz rate sensor

R\&D research and development

RAM random access memory

RFI radio frequency interference

RODE electrode

SAS Statistical Analysis System

SBIR small business innovative research

SCSI

SPSS small computer system interface

STEP Statistical Package for the Social Sciences

SVGA structured test and evaluation process

UMTRI University of Michigan Transportation Research Institute U.S. United States

$\mathrm{V}, \quad$ volt

VITC vertical interval time code

W watt 

ORNL/TM-13540, Volume 1

\section{INTERNAL DISTRIBUTION}

$\begin{array}{llll}1-5 . & \text { R. J. Carter } & 21-25 . & \text { P. F. Spelt } \\ 6 . & \text { R. D. Harris } & 26 . & \text { D. R. Tufano } \\ 7-11 . & \text { J. R. Kirkpatrick } & 27 . & \text { Central Research Library } \\ 12 . & \text { H. E. Knee } & 28 . & \text { CSMD Reports Office } \\ 13 . & \text { M. A. Kuliasha } & 29 . & \text { Document Reference Section } \\ 14 . & \text { C. E. Oliver } & 30 . & \text { Laboratory Records-RC } \\ 15-19 . & \text { R. L. Schmoyer } & 32 . & \text { ORNL Patent Office } \\ 20 . & \text { J. C. Schryver } & & \end{array}$

\section{EXTERNAL DISTRIBUTION}

33 - $37 . \quad$ Frank S. Barickman, Transportation Research Center, Incorporated, P.O. Box B-37, East Liberty, OH 43319-0337

38 - 42. Michael J. Goodman, National Highway Traffic Safety Administration, 400 7th Street, SW, NRD-50, Washington, D.C. 20590

43 - $44 . \quad$ Office of Scientific and Technical Information, P. O. Box 62, Oak Ridge, TN 37831 